\title{
Morphology and karyotype in early abortion
}

Citation for published version (APA):

van Lijnschoten, G. (1993). Morphology and karyotype in early abortion. [Doctoral Thesis, Maastricht University]. Datawyse / Universitaire Pers Maastricht. https://doi.org/10.26481/dis.19931202gl

Document status and date:

Published: 01/01/1993

DOI:

10.26481/dis.19931202gl

Document Version:

Publisher's PDF, also known as Version of record

\section{Please check the document version of this publication:}

- A submitted manuscript is the version of the article upon submission and before peer-review. There can be important differences between the submitted version and the official published version of record.

People interested in the research are advised to contact the author for the final version of the publication, or visit the DOI to the publisher's website.

- The final author version and the galley proof are versions of the publication after peer review.

- The final published version features the final layout of the paper including the volume, issue and page numbers.

Link to publication

\footnotetext{
General rights rights.

- You may freely distribute the URL identifying the publication in the public portal. please follow below link for the End User Agreement:

www.umlib.nl/taverne-license

Take down policy

If you believe that this document breaches copyright please contact us at:

repository@maastrichtuniversity.nl

providing details and we will investigate your claim.
}

Copyright and moral rights for the publications made accessible in the public portal are retained by the authors and/or other copyright owners and it is a condition of accessing publications that users recognise and abide by the legal requirements associated with these

- Users may download and print one copy of any publication from the public portal for the purpose of private study or research.

- You may not further distribute the material or use it for any profit-making activity or commercial gain

If the publication is distributed under the terms of Article $25 \mathrm{fa}$ of the Dutch Copyright Act, indicated by the "Taverne" license above, 
Morphology and karyotype in early abortion 
Lay-out: Emmy \& Ineke

CIP $=$ DATA KONINKLIJKE BIBLIOTHEEK, DEN HAAG

Lijnschoten, Gesina van

Morphology and karyotype in early abortion / Gesina van

Lijnschoten. - Maastricht : Universitaire Pers Maastricht

Thesis Maastricht. - With ref.

ISBN 90-5278-113-3

Subject headings: karyotype / abortion / morphology.

The 'Abortus-project" was supported by the Praeventiefonds, project number 28-1927. 


\section{Morphology and karyotype in early abortion}

\section{PROEFSCHRIFT}

ter verkrijging van de graad van doctor

aan de Rijksuniversiteit Limburg te Maastricht, op gezag van de Rector Magnificus, Prof.dr H. Philipsen, volgens het besluit van het College van Dekanen, in het openbaar te verdedigen op

donderdag, 2 december 1993 om 12.00 uur

door

\section{Gesina van Lijnschoten}

geboren op 4 augustus 1961 te Amsterdam 
Chapter 8 The presence of cytomegalovirus antigens in karyotyped abortions.

Chapter 9 Fluorescence in situ hybridization on paraffinembedded abortion material as a means for retrospective chromosome analysis.

Chapter 10 Epilogue.

Summary

103

Samenvatting

Dank U wel

Curriculum vitae 


\section{Chapter 1}

\section{General introduction}

\subsection{Introduction}

The primary aim of this thesis is to evaluate the prediction of karyotype on the basis of histological features in spontaneous abortion. The decision making process during histological diagnosis is evaluated and the value of a morphometric method is assessed. Furthermore, the use of archival material for retrospective chromosome analysis by means of in situ hybridization is studied. Final$\| y$, attention is paid to the relation between the presence of cytomegalovirus antigens and karyotype in spontaneous abortion. The general introduction will give some background information.

\subsection{Definition of spontaneous abortion}

Spontaneous refers to involuntary, contrasting with induced or psychosocial or so-called therapeutic abortions. Missed abortion refers to retainment of the conceptus longer than 3 weeks after clinical discovery of fetal death. This term is no longer valid since ultrasonography has revealed that retention longer than three weeks after fetal death is common in spontaneous abortion.

Spontaneous abortion is used for involuntary expulsion of a child with a birth weight $<500$ gram being equivalent to birth before the end of the 20-22th week of gestation (WHO, 1977). Spontaneous abortions are often divided in first trimester and second trimester abortions or in early and late abortions. This makes sense as the causes and morphology are different for both periods. The division in early and late abortion almost equals the definitions of spontaneous abortion and immature birth as used in the Netherlands (Kloosterman, 1981). In this country, spontaneous abortion is defined as loss before the end of the 16 th week of pregnancy and immature birth means end of pregnancy between the beginning of the 17 th week and the end of the 28 th week.

In this thesis early spontaneous abortion is defined as involuntary termination of pregnancy before the 17 th week of pregnancy counted from the first day of the last menstrual period corrected for menstrual cycle length.

\subsection{The impact of spontaneous abor- tion}

Up to $60 \%$ of all conceptions will be lost, most of them not being noticed by the woman, so-called 'occult abortion' (Hertig, 1959; Roberts et al., 1975; Miller et al., 1980; Edmonds et al., 1982; Rolfe, 1982; Whittaker et al., 1983; Kline et al., 1985; Wilcox et al., 1988). It is generally known that 1 out of 6 clinically recognized pregnancies ends in spontaneous abortion (Warburton et al., 1964; Harlap et al., 1980; Miller et al., 1980).

Nearly 200,000 children a year are born in the Netherlands, as registered by the Central Bureau for Statistics (Vermunt, 1992). Therefore, about 40,000 spontaneous abortions occur in this country every year. Most of the abortions take place before 17 weeks of gestation, $75 \%$ of these between 8 and 13 weeks 
(Vlaanderen, 1983). In the Netherlands since 1983 more children are born than expected by the "Nationale Bevolkingsprognose". This is explained by the large numbers of women having postponed pregnancy to older ages corresponding with lower birth rates between 1970 and 1983. Now these women are becoming pregnant. The age at which women have their first child has moved upwards from 24.3 in 1970 to 27.4 in 1990 (Vermunt, 1992). In $1988,24 \%$ of the mothers of firstborns were over 30 years (Alkemade, 1989). In view of these changes the incidence of spontaneous abortions in the Netherlands is expected to rise. This will be explained below.

A study of the referral pattern of general practitioners revealed that $72 \%$ of the women presenting with symptoms of abortion were referred to a gynecologist (Continue Morbiditeitsregistratie, 1982, 1983). In that study, the abortion percentage of all pregnancies was estimated $12 \%$. At least it can be stated that spontaneous abortion is a common event in women planning a family. In threatened, incomplete or complete abortion, general practitioners behave rather passively (NTI, 1989), Gynecologists make use of ultrasound examination to find out whether fetal heart beat is present. If not present, the gestational age, the amount of blood loss and the patients' wishes determine whether an observational or a more aggressive treatment, i.e dilatation and curettage, is given (Edmonds et al., 1987; Aamoudse, 1990). However, if expulsion has not proceeded within two weeks, curettage is performed to avoid intrauterine infection and diffuse intravasal coagulation syndrome. Most abortions are sent to the pathologists for examination.

From several studies concerning emotional reactions to spontaneous abortions, it is clear that most of the women experience reactions of grief and guilt
(Iles, 1989; Stirtzinger et al., 1989; Neugebauer et al., 1992; van Buuren et al., 1993). About 1 out of 5 women is said to have longer lasting negative reactions (Tumer et al., 1991, Neugebauer et al,, 1992). Information about the reason for pregnancy disturbance and consequences for future pregnancies might help to ease these negative reactions (Iles, 1989).

\subsection{Causes of spontaneous abortion}

Pregnancy is a very complicated 'process' wherein the participation of mother, embryo/fetus and placenta are essential. Disturbances in one of these 'compartments" might lead to disturbances in the other 'compartments'. Frequently, the primary site of deterioration can not be discerned.

Often, one speaks about causes of spontaneous abortions but the actual mechanisms leading to abortion are virtually unknown (Clark et al., 1989; Hustin et al., 1992). For most of the causes mentioned below it would be better to speak of factors more often diagnosed after spontaneous abortion than after a pregnancy ending in the birth of a child. Subsequently, an association of the factor with the cause of the abortion might be suspected.

Without trying to give a review of the literature, which would be a repetition of the excellent reviews by Edwards (1986), Stirrat (1990b), Barnea (1992) and Simpson (1992), the most frequently mentioned factors are discussed.

In table 1 , the factors which are most certainly associated with spontaneous abortion are listed.

\section{Amost certain factors}

\section{Parental factors}

- Maternal age is related strongly to the occurrence of spontaneous abortions. 
Table 1. Non-sporadic factors associated with early spontaneous abortion

\section{Parental factors}

Increased maternal age

Overripeness of the oacyte

Luteal phase deficiency

Poor control of diabetic disease

Cervical incompetence

Carriership of a chromosome anomally

\section{Placental factors}

Implantation disturbances

\section{Embryonal/fetal factors}

Abnormal karyotype

Fecundity declines with age and the chance of abortion rises, partly due to meiotic division disturbances leading to chromosomal disorders of the conceptus (Stein et al, 1980). Other studies confirmed this relation between abnormal conceptus/abortion and maternal age (Brook et al., 1984; Pawlowitzki et al., 1986; Morton et al., 1988). The number of chromosomally normal abortions also increases with advancing maternal age (Stein et al., 1980; Stein, 1985).

- Overripeness of the oocyte due to a lengthened follicular phase or prolonged time lapse between ovulation and conception is associated with abnormal conceptions (Witschi, 1971; Guerrero et al., 1975; Jakobovits et al., 1988).

- The role of luteal phase deficiency (LPD) in spontaneous abortion is still in debate (Daya et al., 1988). However, several studies proved that an abnormality of the corpus luteum coincides with abnormal development of pregnancy (White et al, 1951; Csapo et al., 1972, Csapo et al.; 1973; Stouffer, 1988). It is still unclear how it is best diagnosed and treated (Jones, 1976; Fritz, 1988; McDonald 1989).

- Diabetes mellitus and early spontaneous abortion are associated in women with poor control of their disease reflected by high blood glucose and glycosylated haemoglobin levels during the first trimester of pregnancy (Kalter, 1987; Mills et al., 1988). There is no association in women with good control of their disease.

- Cervical incompetence is a well established but extremely rare cause of second trimester abortions (McDonald, 1987).

- Balanced translocation of chromosomes in one of the parents may give rise to unbalanced translocation in the conceptus (Jacobs, 1977; Bourrouillou et al., 1986; Castle et al., 1988). Nearly all conceptus with unbalanced translocations are aborted during the first trimester of pregnancy.

\section{Placental factors}

- Defective implantation might be a cause of pregnancy failure (Hertig, 1956; Edwards, 1985; Khong et al., 1987; Hustin et al., 1990). Arrival of the conceptus at undue time at the endometrial surface may prevent attachment as proved in in vitro studies (Kliman et al., 1990). Defective trophoblastic development which relates to defective adaptation of the maternal arteries to pregnancy and thus gives rise to arrested development of the embryo may lead to early spontaneous abortion (Hustin et al, 1990; Hustin et al., 1992).

\section{Embryonal/fetal factors}

- Abnormal karyotype is found in at least $50 \%$ of spontaneous abortions (Carr, 1971; Boué et al., 1975; Lauritsen, 1976; Hassold et al., 1980; Kajii et al, 1980; Warburton et al., 1980; Poland et al., 1981; Kline et al., 1985; Magenis, 1988; Eiben et al.; 1990). Reports of abnormal karyotype associated with spontaneous abortion date from the early sixties (Penrose et al., 1961; Kirkels, 1966). Until now it has not been elucidated how chromosomal disorders lead to abnormal development of the human conceptus and to 
rejection of pregnancy, although studies on mice date from twenty years ago (Gropp et al., 1975).

Apart from the factors which are almost certainly correlated with spontaneous abortion, some other 'causes' are frequently mentioned but not proven.

\section{Uncertain factors}

\section{Parental factors}

- Endometriosis, although frequently blamed in the past, is not associated with spontaneous abortion (Metzger et al., 1986; FitzSimmons et al., 1987; Pittaway et al., 1988a, 1988b).

- The role of immunological factors in early spontaneous abortion is still in discussion. Anti-phospholipid antibodies such as anticardiolipin antibodies and lupus anticoagulant are related to spontaneous abortion in patients with manifest systemic lupus, lupus-like disease or antiphospholipid syndrome (Out et al., 1991). However, in otherwise healthy women, the relationship between the presence of high antiphospholipid levels and spontaneous abortion is still open to questions (Infante-Rivard et al., 1991; Parke et al., 1991). The role of immune response of the mother to the 'foreign' conceptus is still unclear despite the large number of studies concerning the major histocompatibility and trophoblastic antigens.

- Congenital abnormalities of the uterus are still in discussion, also. The figures for prevalence of congenital uterus anomalies in the normal population varies from $0.025 \%-10 \%$ (Rock et al., 1986; Bennett, 1987; Simon et al., 1991). Whether these can lead to early spontaneous abortion is unclear but in a population of recurrent abortions the prevalence is $10 \%-30 \%$ (Rock et al., 1986; Bennett, 1987; Simon et al., 1991).

- Infections of the mother might directly or indirectly affect the placenta and/or embryo. Numerous infections have been described, but nowadays infection by cytomegalovirus and human parvo B19 virus (fifth disease) are in the scope. The epidemiologic significance to spontaneous abortion has still to be established. However, both viruses have been detected in early abortion specimens (van Elsacker-Niele et al., 1989; Benirschke et al., 1990).

\section{Embryonal/fetal factors}

- Most certainly absence or alteration of expression of genes coding for embryonic pattern formation, as studied in Drosophila might play a role in the chromosomally normal abortions with severe developmental disturbances such as blighted ovum (Nüsslein-Volhard, 1991; Barnea, 1992). Some of these gene defects are most probably identical to the recessive lethal genes which have been hypothesized to play a role in karyotypically normal abortions (Simpson, 1980; Diamond, 1987; Gill, 1987; Hed-rick, 1988). Future research will certainly be concentrated on this subject.

- Infections have been mentioned already above. It is possible that the embryo/fetus dies due to infection without maternal symptoms of disease.

\subsection{Recurrence risks}

Some chromosomal abnormalities are important to recognize since they can be used to counsel the parents on the basis of the known recurrence risks for consecutive pregnancies. In an unselected population of all clinically recognized pregnancies, about $12-15 \%$ will abort and at least $50 \%$ of the abortions will have an abnormal karyotype as stated before. Only a few percent of these women are thought to have a recurrent 
Table 2. Distribution of structural chromosome abnomalities against the number of spontaneous abortions (\%), adapted from De Braekeleer et al., 1990)

\begin{tabular}{|c|c|c|c|}
\hline Number of abortions & 1 & 2 & $\geq 3$ \\
\hline Number of individuals & 4,224 & 23,416 & 5,680 \\
\hline Reciprocal translocations & $21(0.5)$ & $323(1.4)$ & $86(1.5)$ \\
\hline Robertsonian translocations & $15(0.4)$ & $145(0.6)$ & $38(0.7)$ \\
\hline Inversions & $6(0.1)$ & $47(0.2)$ & $12(0.2)$ \\
\hline Total & $42(1.0)$ & $515(2.2)$ & $136(2.4)$ \\
\hline
\end{tabular}

cause of abortion (Malpas, 1938; Warburton et al., 1963). Overall studies indicate that the risk of a second abortion in a next pregnancy is about $20 \%$, rising to $30 \%$ after three or more abortions (Warburton et al., 1963; Stirrat, 1990a).

In 1-5 \% of successfully karyotyped spontaneous abortions, structural chromosome aberrations are detected (Carr, 1971; Boué et al., 1975; Lauritsen, 1976; Hassold et al., 1980; Kajii et al., 1980; Warburton et al., 1980; Poland et al., 1981; Eiben et al., 1990).

De Braekeleer et al. (1990) have collected data on 44,398 individuals $(22,199$ couples) with spontaneous abortions. The pre-valence of structural chromosome abnormalities in 'parents' of abortions are given in table 2 . This table also shows the influence of the number of abortions on the percentage of chromosome abnormalities. These results show that $2.2 \%$ of all individuals with at least two spontaneous abortion in their history, i.e. $4.4 \%$ of all couples, carry a chromosomal abnormality. This percent- age increased slightly to $4.8 \%$ after three abortions. Table 3 shows that translocations especially, are about twice as frequent in females than males. After an abortion has been proven to have a translocation, the chance that one of parents is a carrier of a translocation is about 40\% (Boué et al., 1973a). Couples whereby one partner has a translocation, have an increased risk of a live born, severely handicapped child due to an unbalanced chromosome pattern. Knowledge of this risk might give the parents the opportunity to select the most favourable alternative from the following options: acceptance of the risk, abstinence from offspring, gamete donation (especially AID), prenatal diagnosis and selective abortion, adoption and foster parenthood.

In half of the chromosomally abnormal abortions, a trisomy is found. Couples who have had a trisomic abortion are said to have an increased chance of a chromosomally abnormal child as deduced from cytogenetic studies on consecutive abortions and abortions from

Table 3. Distribution of structural chromosome abnormalities on the basis of sex of the carrier (\%), adapted from De Braekeleer et al., 1990

\begin{tabular}{lcrr}
\hline & \multicolumn{1}{c}{ females } & \multicolumn{1}{c}{ males } \\
\cline { 2 - 3 } \multicolumn{1}{c}{ Number of individuals } & $16,661(\%)$ & & $16,661(\%)$ \\
\hline Reciprocal translocations & $265(63.9)$ & & $150(36.1)$ \\
Robertsonian translocations & $133(69.6)$ & & $58(30.4)$ \\
Inversions & $35(58.3)$ & & $25(41.7)$ \\
Total & $433(65.0)$ & $233(35.0)$ \\
\hline
\end{tabular}


parents with a chromosomally abnormal child (Boué et al., 1973b; Alberman et al., 1975, 1981; Mikkelsen et al., 1979; Warburton et al., 1985, 1987; LippmanHand, 1980; Stene et al., 1984). This applies especially to trisomy 13,18 and 21 abortions, which make up $20 \%$ of all trisomic abortions and $10 \%$ of all early spontaneous abortions (Warburton et al., 1987). All other karyotypical findings permit an expectative clinical policy.

Karyotypically normal parents may benefit from being informed about the karyotype and particularly about a numerical aberration of their abortus. After a karyotypically abnormal abortion the chance of having healthy offspring is higher than after an abortion with a normal karyotype. In the latter, the chance of abortion in the next pregnancy is raised in comparison with the former, the next abortions most probably being karyotypically normal, also (Alberman et al., 1975; Boué et al., 1975; Lauritsen, 1976).

\subsection{Questions addressed in the present thesis}

It is impractical to karyotype all spontaneous abortions. Chromosome analysis requires culturing and other laboratory facilities and specially trained technicians. Furthermore, the costs would be enormous and can be estimated for 40,000 abortions to be equivalent to about 50 million Dutch guilders. Poor tissue conditions will decrease the success rate of karyotyping spontaneous abortions to about $80 \%$.

One way to solve this problem could be a histological screening of the specimens for signs indicative of chromosome abnormalities and especially trisomies. In chapter 2, the most relevant items with respect to the histological features in relation to chromosomal abnormalities are described.

The contradicting opinions of pathologists and their inability to predict an abnormal karyotype of abortions by histological assessments of placentae could be the result of observer variability. Therefore, this study was started with an examination of the intra- and interobserver variability (chapter 3). The second aim was to study which histological features could be predictive of abnormal karyotype (chapter 4). In general, histological features are not well defined. Original assessments, conform practical usage, were evaluated. Besides these qualitative assessments, some features were quantified by simple morphometrics to elucidate if and when particular values were predictive of abnormal karyotype (chapter 5). Next it was determined which of the features said to be related to karyotype, in fact could have resulted from dege-neration of the placenta due to demise of the embryo or fetus (chapter 6).

Besides microscopical assessments macroscopical analysis might reveal symptoms highly predictive of karyotype. Macroscopic analysis is largely neglected in modern pathology, but might be more informative than microscopic analysis (chapter 7).

Besides chromosomal abnormalities as cause of spontaneous abortion, there is a role for other causative agents. In this respect, cytomegalovirus infection was focussed on especially. Modern technics for cytomegalovirus antigen detection on formalin fixed material are available. The role and the manifestations of this infection in early pregnancy are largely unknown. However, in second and third trimester it is frequently shown to be present in stillborns and neonatal deaths. The presence of cytomegalovirus antigens was studied in relation to karyotype (chapter 8).

Finally, as mentioned above, it is clear 
that it is impossible to study the karyotype of all abortions. Sometimes, one would like to be informed about the presence of chromosome abnormalities, at a point in time that only fixed material is available. Fixed material is unsuit able for traditional cytogenetic analysis : Therefore, retrospective chromosomal analysis was attempted making use of fluorescence in situ hybridization (FISH) (chapter 9).

\section{References}

Aarnoudse JG. (1990) Diagnostic procedures in abortion and clinical management. In Huisjes HJ \& Lind $\mathrm{T}$ (eds.) Early pregnancy failure. Clinical Obstetrics and Gynaecology series. Churchill Livingstone, Edinburgh, London, Melbourne, New York: Churchill Livingstone, 231-239.

Alberman E, Elliott M, Creasy M. (1975) Previous reproductive history in mothers presenting with spontaneous abortions. British Journal of Obstetrics and Gynaecology, 82: 366-373.

Alberman ED. (1981) The abortus as a predictor of future trisomy 21 pregnancies. In: de la Cruz FF \& Gerald PS (eds.) Trisomy 21 (Down Syndrome): Research perspectives. Baltimore: University Park Press, 69-76.

Alkemade P. (1989) Steeds meer vrouwen in de dertig krijgen (nog) kinderen. Maandstatistiek van de bevolking (CBS) 89/9: 10-11:

Barnea ER. (1992) Epidemiology and etiology of early pregnancy disorders. In Barnea ER, Hustin I \& Jauniaux E. (eds.) The first twelve weeks of gestation. Berlin, Heidelberg: Springer-Verlag, 263-279.

Benirschke K \& Kaufmann P. (1990) Virus infections and villitides, cytomegalovirus infection. In Benirschke K (ed.) Pathology of the human placenta. 2nd edition. New York: Springer-Verlag, 585-590, 613-635.

Bennett MJ. (1987) Congenital abnormalities of the fundus. In Bennett MJ \& Edmonds DK (eds.) Spontaneous and recurrent abortion. Oxford: Blackwell Scientific Publications, 109-129.

Boué J \& Boué A. (1973a) Anomalies chromosomiques dans les avortements spontanes. In Boué A \& Thibault C (eds.) Les accidents chromosomiques de la reproduction. Paris: INSERM, 29-55.

Boué J \& Boué A. (1973b) Chromosomal analysis of two consecutive abortuses in each of 43 women. Humangenetik, 19: 275-280.

Boué J, Boué A \& Lazar P. (1975) Retrospective and prospective epidemiological studies of 1500 karyotyped spontaneous human abortions. Teratology, 12: 11-26.

Boué A, Boué J, Gropp A. (1985) Cytogenetics of pregnancy wastage. Advances in Human Genetics, 14: $1-57$.

Bourrouillou G, Colombies P \& Dastugue N. (1986) Chromosome studies in 2136 couples with spontaneous abortions. Human Genetics, 74: 399-401.

de Braekeleer M \& Dao T-N. (1990) Cytogenetic studies in couples experiencing repeated pregnancy losses. Human Reproduction, 5: 519-528.

Brook JD, Gosden RG \& Chandley AC. (1984) Maternal ageing and aneuploid embryos- Evidence from the mouse that biological and not chronological age is the important influence. Human Genetics, 66: 41-45.

van Buuren M, Braam W (1993) Als je zwangerschap misloopt. Kampen: La Rivière \& Voorhoeve.

Cart DH. (1971) Chromosomes and abortion. In Haines H \& Hirschhorn $\mathrm{K}$ (eds.) Advances in human genetics, 2. New York, London: Plenum Press, 201-257.

Castle D \& Bernstein R. (1988) Cytogenetic analysis of 688 couples experiencing multiple spontaneous abortions. American Journal of Medical Genetics, 29: 549-556.

Clark DA \& Chaouat G. (1989) What do we know about spontaneous abortion mechanisms? American Journal of Reproductive Immunology, 19: 28-37.

Continue morbiditeitsregistratie: Peilstations Nederland 1982. Utrecht, Nederlands Huisartseninstituut.

Continue morbiditeitsregistratie: Peilstations Nederland 1983. Utrecht, Nederlands Huisartseninstituut.

Csapo AI, Pulkkinen MO, Ruttner B, Sauvage \& Wiest WG. (1972) The significance of the human corpus luteum in pregnancy maintenance. I. Preliminary studies. American Journal of Obstetrics and Gynecology, 112: 1061-1067. 
parents with a chromosomally abnormal child (Boué et al., 1973b; Alberman et al., 1975, 1981; Mikkelsen et al,, 1979; Warburton et al., 1985, 1987; LippmanHand, 1980; Stene et al., 1984). This applies especially to trisomy 13,18 and 21 abortions, which make up $20 \%$ of all trisomic abortions and $10 \%$ of all early spontaneous abortions (Warburton et al., 1987). All other karyotypical findings permit an expectative clinical policy.

Karyotypically normal parents may benefit from being informed about the karyotype and particularly about a numerical aberration of their abortus. After a karyotypically abnormal abortion the chance of having healthy offspring is higher than after an abortion with a normal karyotype. In the latter, the chance of abortion in the next pregnancy is raised in comparison with the former, the next abortions most probably being karyotypically normal, also (Alberman et al., 1975; Boué et al., 1975; Lauritsen, 1976).

\subsection{Questionis addressed in the present thesis}

It is impractical to karyotype all spontaneous abortions. Chromosome analysis requires culturing and other laboratory facilities and specially trained technicians. Furthermore, the costs would be enormous and can be estimated for 40,000 abortions to be equivalent to about 50 million Dutch guilders. Poor tissue conditions will decrease the success rate of karyotyping spontaneous abortions to about $80 \%$.

One way to solve this problem could be a histological screening of the specimens for signs indicative of chromosome abnormalities and especially trisomies. In chapter 2 , the most relevant items with respect to the histological features in relation to chromosomal abnormalities are described.

The contradicting opinions of pathologists and their inability to predict an abnormal karyotype of abortions by histological assessments of placentae could be the result of observer variability. Therefore, this study was started with an examination of the intra- and interobserver variability (chapter 3). The second aim was to study which histological features could be predictive of abnormal karyotype (chapter 4). In general, histological features are not well defined. Original assessments, conform practical usage, were evaluated. Besides these qualitative assessments, some features were quantified by simple morphometrics to elucidate if and when particular values were predictive of abnormal karyotype (chapter 5). Next it was determined which of the features said to be related to karyotype, in fact could have resulted from dege-neration of the placenta due to demise of the embryo or fetus (chapter 6).

Besides microscopical assessments macroscopical analysis might reveal symptoms highly predictive of karyotype. Macroscopic analysis is largely neglected in modern pathology, but might be more informative than microscopic analysis (chapter 7).

Besides chromosomal abnormalities as cause of spontaneous abortion, there is a role for other causative agents. In this respect, cytomegalovirus infection was focussed on especially. Modern technics for cytomegalovirus antigen detection on formalin fixed material are available. The role and the manifestations of this infection in early pregnancy are largely unknown. However, in second and third trimester it is frequently shown to be present in stillborns and neonatal deaths. The presence of cytomegalovirus antigens was studied in relation to karyotype (chapter 8).

Finally, as mentioned above, it is clear 
that it is impossible to study the karyotype of all abortions. Sometimes, one would like to be informed about the presence of chromosome abnormalities, at a point in time that only fixed material is available. Fixed material is unsuit able for traditional cytogenetic analysis . Therefore, retrospective chromosomal analysis was attempted making use of fluorescence in situ hybridization (FISH) (chapter 9).

\section{References}

Aarnoudse JG. (1990) Diagnostic procedures in abortion and clinical management. In Huisjes HJ \& Lind $\mathrm{T}$ (eds.) Early pregnancy failure. Clinical Obstetrics and Gynaecology series. Churchill Livingstone, Edinburgh, London, Melbourne, New York: Churchill Livingstone, 231-239.

Alberman E, Elliott M, Creasy M. (1975) Previous reproductive history in mothers presenting with spontaneous abortions. British Journal of Obstetrics and Gynaecology, 82: 366-373.

Alberman ED. (1981) The abortus as a predictor of future trisomy 21 pregnancies. In: de la Cruz FF \& Gerald PS (eds.) Trisomy 21 (Down Syndrome): Research perspectives. Baltimore: University Park Press, 69-76.

Alkemade P. (1989) Steeds meer vrouwen in de dertig krijgen (nog) kinderen. Maandstatistiek van de bevolking (CBS) 89/9: 10-11.

Barnea ER. (1992) Epidemiology and etiology of early pregnancy disorders. In Barnea ER, Hustin J \& Jauniaux E. (eds.) The first twelve weeks of gestation. Berlin, Heidelberg: Springer-Verlag, 263-279.

Benirschke K \& Kaufmann P. (1990) Virus infections and villitides, cytomegalovirus infection. In Benirschke K (ed.) Pathology of the human placenta. 2nd edition. New York: Springer-Verlag, 585-590, 613-635.

Bennett MJ. (1987) Congenital abnormalities of the fundus. In Bennett MJ \& Edmonds DK (eds.) Spontaneous and recurrent abortion. Oxford: Blackwell Scientific Publications, 109-129.

Boué J \& Boué A. (1973a) Anomalies chromosomiques dans les avortements spontanes. In Boué A \& Thibault C (eds.) Les accidents chromosomiques de la reproduction. Paris: INSERM, 29-55.

Boué J \& Boué A. (1973b) Chromosomal analysis of two consecutive abortuses in each of 43 women. Humangenetik, 19: 275-280.

Boué J, Boué A \& Lazar P. (1975) Retrospective and prospective epidemiological studies of 1500 karyotyped spontaneous human abortions. Teratology, 12: 11-26.

Boué A, Boué J, Gropp A. (1985) Cytogenetics of pregnancy wastage. Advances in Human Genetics, 14: $1-57$.

Bourrouillou G, Colombies P \& Dastugue N. (1986) Chromosome studies in 2136 couples with spontaneous abortions. Human Genetics, 74: 399-401.

de Braekeleer M \& Dao T-N. (1990) Cytogenetic studies in couples experiencing repeated pregnancy losses. Human Reproduction, 5: 519-528.

Brook JD, Gosden RG \& Chandley AC. (1984) Maternal ageing and aneuploid embryos- Evidence from the mouse that biological and not chronological age is the important influence. Human Genetics, 66: 41-45.

van Buuren M, Braam W (1993) Als je zwangerschap misloopt. Kampen: La Rivière \& Voorhoeve.

Carr DH. (1971) Chromosomes and abortion. In Haines H \& Hirschhorn K (eds.) Advances in human genetics, 2. New York, London: Plenum Press, 201-257.

Castle D \& Bernstein R. (1988) Cytogenetic analysis of 688 couples experiencing multiple spontaneous abortions. American Journal of Medical Genetics, 29: $549-556$.

Clark DA \& Chaouat G. (1989) What do we know about spontaneous abortion mechanisms? American Journal of Reproductive Immunology, 19: 28-37.

Continue morbiditeitsregistratie: Peilstations Nederland 1982. Utrecht, Nederlands Huisartseninstituut.

Continue morbiditeitsregistratie: Peilstations Nederland 1983. Utrecht, Nederlands Huisartseninstituut.

Csapo AI, Pulkkinen MO, Ruttner B, Sauvage \& Wiest WG. (1972) The significance of the human corpus luteum in pregnancy maintenance. I. Preliminary studies. American Journal of Obstetrics and Gynecology, 112: 1061-1067. 
Csapo AI, Pulkkinen MO \& Wiest WG. (1973) Effect of luteectomy and progesterone replacement therapy in early pregnant patients. American Joumal of Obstetrics and Gynecology, 115:759-765.

Daya $\mathrm{S}$, Ward $\mathrm{S} \&$ Burrows E. (1988) Progesterone profiles in luteal phase defect cycles and outcome of progesterone treatment in patients with recurrent spontaneous abortion. American Journal of Obstericis and Gywecology, 158: $225-232$.

Diamond JM. (1987) Causes of death before birth. Noture, 329: 487-488.

Edmonds DK, Lindsay KS, Miller JF, Williamson E \& Wood PJ (1982) Early enbryonic mortality in women. Fertility and Sterility, 38: 447-453.

Edrnonds DK \& Bennett MJ. (1987) Principles of management of spontaneous and recurrent abortion. In Bennett MJ \& Edmonds DK (eds.) Spontaneous and recurrent abortion. Oxford: Blackwell Scientific Publications, 236-239.

Edwards RG. (1985) Normal and abnormal implantation in the human uterus. In Edwards RG, Purdy JM \& Steptoe PC (eds.) Implantation of the human embryo. London: Academic Press, 303-333.

Edwards RG. (1986) Causes of early embryonic loss in human pregnancy. Huwan Reproduction, 1: $185-198$.

Eiben B, Bartels $I$, Bahr-Porsch $S$, Borgmann $S$, Gatz $G$, Gellert $G$, Goebel $R$, Hammans $W$, Hentemann M, Osmers R, Rauskolb R \& Hansmann I. (1990) Cytogenetic analysis of 750 spontaneous abortions with the direct-preparation method of chorionic villi and its implications for studying genetic causes of pregnancy wastage. American Joumal of Human Genetics, 47: 656-663.

van Eisacker-Niele AMW, Salimans MMM, Weiland. HT, Vermey-Keers Chr, Anderson MJ \& Versteeg J. (1989) Fetal pathology in human parwovirus B19 infection. British Joumal of Obstetrics and Gyncecology, 96: 768-775.

FitzSimmons 1, Stah॥ R, Gocial B \& Shapiro SS. (1987) Spontaneous abortion and endometriosis. Fertility and Sterility, 47:696-698.

Fritz MA. (1988) Inadequate لluteal function and recurrent abortion: diagnosis and treatment of luteal phase deficiency. Seminars in Reproductive Endocrinology; 6: 129-143.

Gill IIJ (1987) Genetic factors in fetal losses. American Joumal of Reproductive Immunology and Microbiology, 15: 133-137.

Gropp A, Kolbus $V$ \& Giers D. (1975) Systematic approach to the study of trisomy in the mouse. II. Cylogenetics and Cell Genetics, 14: 42-62.

Guerrero R \& Rojas OI. (1975) Spontaneous abortion and ageing of human ova and spermatozoa. The New England Journal of Medicine, 293: 573-575.

Harlap S, Shionio PH \& Ramcharan S. (1980) A life table of spontaneous abortions and the effects of age, parity, and other variables. In Porter IH, Hook EB (eds.) Human embryonic and fetal death. New York: Academic Press, 145-159.

Hassold T, Chen N, Funkhouser J, Jooss $T$, Manuel B, Matsuura J, Matsuyama A, Wilson C, Yamane JA \& Jacobs PA. (1980) A cytogenetic studly of 1000 spontaneous abortions. Annals of Human Genterics, 44:15:-178.

Hedrick PW. (1988) HLA-Sharing, recurrent spontaneous abortion, and the genetic hypothesis. Genetics, 119: 119-204.

Hertig AT, Rock I \& Adams EC. (1956) A description of 34 human ova within the first 17 days of development. The American Journal of Anatomy, 98: 435-493.

Hertig AT, Rock J, Adams EC \& Menkin MC. (1959) Thirty-four fertilized human ova, good, bad and indifferent, recovered from 210 women of known fertility: A study of biologic wastage in early human pregnancy. Pediatrics, $23: 202-211$.

Hustin J, Jauniaux E \& Schaaps JP. (1990) Histological study of the matemo-embryonic interface in spontaneous abortion. Placenta, 11: 477-486.

Hustin I \& Jauniaux E. (1992) Morphology and mechanisms of abortion. In Barnea ER, Hustin J \& Jauniaux E (eds.) The first thelve weeks of gestation. Berlin, Heidelberg: Springer-Verlag, 280-296.

lles S. (1989) The loss of early pregnancy. Baillière's Clinical Obsietrics and Gynaecology; 3: 769 790.

Infante-Rivard $C$, David M, Gauthier $\mathbb{R}$ \& Rivard G-E. (1991) Lupus anticoagulants, anticardiolipin antibodies, and fetal loss. A case-control study. The New England Journal of Medicine, 325: 10631066.

Jacobs PA. (1977) Epidemiology of chromosome abnormalities in man. American Journal of Epidemiology, 105: 180-191. 
Jakobovits AA, Iffy L. (1988) Disorders of follicular ripening and ovulation in human. Acta Medica Hungarica, 45: 179-190.

Jones GS. (1976) The luteal phase defect: Fertility and Sterility. $27: 351-356$.

Kalter H. (1987) Diabetes and spontaneous abortion: A historical review. American Joumal of Obsretrics and Gynecology, 156: 1243-1253.

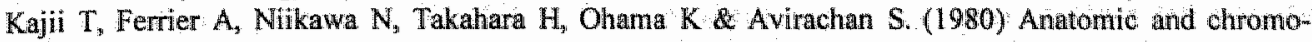
somal anomalies in 639 spontaneous abortuses. Human Genetics, 55: $87-98$.

Khong. TY, Liddel HS \& Robertson WB. (1987) Defective haemochorial placentation as a cause of miscarriage: a preliminary study. British Joumal of Obstetrics and Gynaecology, 94: 649-655.

Kirkels VGHI. (1966) Abortws en aanlegstoomissen. Een onderzoek omirent chromosomale factoren, mogoloide idionie en vruchtbare periode. Proefschrift. Nijmegen, Utrecht: Dekker \& van de Vegt N.W...

Kliman HJ, Feinberg RF \& Haimowitz JE. (1990) Human trophoblast-endometrial interactions in an in vitro suspension culture system. Placenta, 11: 349-367.

Kline J \& Stein Z (1985) Very early pregnancy. In Dixon RL (ed.) Reproductive Toxicology. New York: Raven Press; 251-265.

Kloosterman GJ (1981) De voortplanting van de mens. Leerboek woor obstertie en gynctecologie. Vijfde geheel herziene en bijgewerkte druk. Haarlem: Uitgeversmaatschappij Centen.

Lauritsen JG (1976) Aetiology of spontaneous abortion. A cytogenetic study of 288 abortuses and their parents. Acta Obstetrica Gynecologia Scandinavia $a_{n}$ [suppl] 52: 1-29.

Lippman-Hand A. (1980) Genetic counseling and human reproductive loss. Im Porter IH \& Hook EB (eds.) Embryonic and fetal death. New York: Academic Press, 299-314.

Magenis RE. (1988) On the origin of chromosome anomaly. American Joumal of Human Genetics, 42: $529-533$.

Malpas $\mathrm{P}$ (1938) A study of abortion sequences. Journal of Obstetrics and Gynaecology of the British Empire, 45: 932-949.

McDonald IA. (1987) Cervical incompetence as a cause of spontaneous abortion. In Bennett MJ \& Edmonds DK (eds.) Spontaneous and recurrent abortion. Oxford: Blackwell Scientific Publications, 168-192.

McDonald RR. (1989) Does treatment with progesterone prevent miscarriage? British Journal of Obstetrics and Gynaeccology, 96: 257-264.

Metzger DA, Olive DL, Stohs GF \& Franklin RR. (1986) Association of endometriosis and spontaneous abortion: effect of control group selection. Fertility and Sterility, 45: $18-22$.

Mikkelsen M \& Stene J. (1979) Previous child with Down-syndrome and other chromosome aberration. In Murken JD, Stengel-Rutkowski \& Schwinger E (eds.) Prenatal diagnosis: proceedings of the 3rd European Conference on Prenatal Diagnosis of Genetic Disorders. Stuttgart: Enke, 22-29.

Miller JF, Williamson E, Glue J, Gordon YB, Grudzinkas JG \& Sykes A. (1980) Fetall loss after implantation: A prospective study. The Lancet, il: 554-556.

Mills $J_{L}$, Simpson $J$, Driscoll $S G$, Jovanic-Peterson $L$, van Allen $M_{*}$, Aarons JH, Metzger $B_{n}$ Bieber FR, Knopp RH, Holmes LB, Peterson CM, Withiam-Wilson $M$, Brown $Z$, Ober $C$. Harley $\mathbb{E}$, Macpherson TA, Duckles A, Mueller-Heubach E \& the National Institute of Child Health and Human Development-Diabetes in Early Pregnancy Study. (1988) Incidence of spontaneous abortion among normal women and insulin-dependent diabetic women whose pregnanctes were identified within 21 days of conception. The New England Jounal of Medicine, 319: 1617-1623.

Morton NE, Jacobs PA, Hassold T \& Wu D. (1988) Matemal age in trisony. Annals of Human Genetics, 52: 227-235.

Neugebauer R, Kline J, O'Connor P, Shrout P, Johnson J, Skodol A, Wicks J \& Susser M. (1992) Depressive symptoms in women in the six months after miscarriage. American Journal of Obstetrics and Gynaecology, 166: part I: 104-109.

NHI. (1989) (Dreigende) Miskraam. Standaard M03. Huisarts en Wetenschap, 32: 138=143.

Nüsslein-Volhard C. (1991) The 1991 Albert Lasker Public Service Award. From agg to organism: studies on embryonic pattern formation. JAMA, 266: 1848-1849

Out HJ, Bruinse HW \& Derksen RHWM. (1991) Antiphospholipid antibodies and pregnancy loss. Human Reproduction, 6: 889-897.

Parke AL, Wilson D \& Maier D. (1991) The prevalence of antiphospholipid antibodies in women with recurrent spontaneous abortion, women with successful pregnancies, and women who have never 
been pregnant, Arthitis and Rheumatsm, 34: 1231-1235.

Pawlowitzki U-H, Urbaniok F, Miny P, Beller FK \& Holagreve W. (1986) Early fetal losses related to maternal age in year to year intervals. Hwoman Reproduction, $1: 345$.

Perirase LS \& Dellianty JDA. (1961) Triploid cell cultures from a macerated foetus. The lancet, i: 1261-1262.

Pittaway DE, Ellington CP \& Klimek M. (1988a) Preclinical abortions and endometriosis. Fertility and Sterility, 49:221-223.

Pittawfy DE, Venon C \& Fayez JA. (1988b) Spontaneous abortions in women with endometriosis. Fertility and Sterility, 50: 711-715.

Poland B.I., Miller J.R, Jones D.C, Trimble B.K. (1977) Reproductive counseling in patients who have had a spontaneous abortion. American Journal of Obstertics and Gyncecology, 127: 685-691.

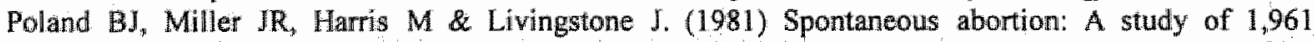
women and their conceptuses. Acta Obstetrica er Gynecologica Scandinavica, [suppl 102], 1-32.

Roberts CJ Lowe CR. (1975) Where have all the conceptions gone? The Lancet, i: 498-499.

Rock JA \& Murphy AA (1986) Anatomic anomaliesi. Clinical Obstetrics and Gynecology, 29: 886911.

Rolfe BE. (1982) Detection of fetal wastage. Fertility and Sterility 37:655-660.

Simon C, Tortajada M, Martinez $L_{\text {, }}$ Pellicer A \& Pardo F. (1991) Mullerian defects in women with normal teproductive outcome. Fertility and Sterility, 56: 1192-1193.

Simpson LL. (1980) Genes, chromosomes, and reproductive failure. Fertility and Sterility, 33: 107-1]6.

Simpson JL. (1992) Aetiology of pregnancy failure. In Stabile 1 , Grudzinskas $G$ \& Chard T (eds.) Spontaneous abortion: diagnosis and treatment. London: Springer-Verlag, 21-47.

Stein Z, Kline J, Susser E, Shrout P, Warburton D \& Susser M. (1980) Maternal age and spontaneous abortion. In Porter IH \& Hook EB (eds.) Embryonic and fetal death. New York: Academic Press, 107-127.

Stein ZA. (1985) A woman"s age: childbearing and child rearing. American Joumal of Epidemiology, $121 ; 327-342$.

Stene J, Stene E \& Mikkelsen M. (1984) Risk for chromosome abnormality at amniocentesis following a child with a non-inherited chromosome aberration. A European collaborative study on prenatal diagnosis 1981. Prenatal Diagnosis, 4: 81-95.

Stirrat GM. (1990a) Recurrent miscarriage I: definition and epidemiology. The Lancet, 336: 673-675.

Stirrat GM. (1990b) Recurrent miscarriage $\mathbb{I}_{\text {: }}$ clinical associations, causes, and management. The Lancet, 336: 728-733.

Stirtzinger R \& Robinson GE. (1989) The psychologic effects of spontaneous abortion. Canadian Medical Association Journal, 140: 799-805.

Stouffer RL. (1988) Perspectives on the corpus futeum of the menstrual cycle and early pregnancy. Seminars in Reproductive Endocrinology, 6: 103-113.

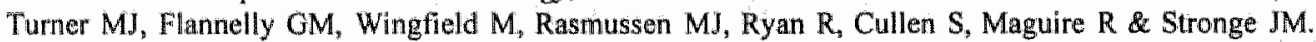
(1991) The miscarriage clinic: an audit of the first year. British Journal of Obsterrics and Gynaecology: $98: 306-308$.

Vermunt JK. (1992) Geboorte: ontwikkelingen in het verleden en toekomstverwachitingen. Madndstatistiek van de Bevolking (CBS), 92: 18-28.

Vlaanderen W. (1983) De spontane abortus. Academisch proefschrift. Amsterdam, Rodopi.

Warburton D \& Fraser FC. (1964) Spontaneous abortion risks in man." data from reproductive histories collected in a medical genetics unit. Human Genetics, 16: 1-25.

Warburton D, Stein Z, KJine J \& Susser M. (1980) Chromosome abnormalities in spontaneous abortion: Data from the New York city study. In Porter IH \& Hook EB (eds.) Embryanic and fetal death. New York: Academic Press, $261-287$.

Warburton D. (1985) Genetic factors influencing aneuploidy frequency. In: Dellarco VL, Voyter PE \& Hollaender A (eds.) Ameuploidy: etiology and mechanisms. New York and London: Plenum Press, $133-148$.

Warburton D, Kline J, Stein Z, Hutzler M, Chin A \& Hassold T. (1987) Does the karyotype of a spontaneous abortion predict the karyotype of a subsequent abortion?- Evidence from 273 women with two karyotyped spontaneous abortions. American Joumal of Human Genetics, 41: 465-483.

White RF, Hertig AT, Rock J \& Adams E. (1951) Histological and histochemical observations on the corpus luteum of human pregnancy with special reference to corpora lutea associated with early 
normal and abnormal ova. Contributions to Embryology, no 224, 34: 55-74.

Whittaker PG, Taylor A \& Lind T. (1983) Unsuspected pregnancy loss in healthy women. The Lanced, i: $1126-1127$.

WHO (1977) Recommended definitions, terminology and format for statistical tables related to the perinatal period and use of a new certificate for cause of perinatal deaths. Acta Obstetrica Gynaecologia Scandinawia, 56: 247-253.

Wilcox A, Weinberg CR, O'Connor JF, Baird DD, Schlatterer $\mathbb{P}$, Canfield RE, Armstrong EG \& Nisula BC. (1988) Incidence of early loss of pregnancy. The New England Journal of Medicine. 319: $189-194$.

Witschi E. (1971) Teratogenic effect from overripeness of the egg. In Fraser FC \& Mckusick VA (edis.) Congenital Malformations- Proceedings of the 3 th interwational conference. Amsterdan: Excerpta Medica, 157-169. 
$\because \quad \therefore \quad \therefore \quad=$

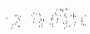




\section{Morphology of the placenta}

\subsection{Normal development of the pla- centa in early pregnancy}

The development of the human placenta is described in many textbooks (for example Boyd et al., 1970; Kaufmann, 1981; Ramsey, 1982; O'Rahilly et al., 1987) and is schematically given in figure 1. Six days after fertilization, i.e. seven days after ovulation, the human embryo has developed to the blastocyst stage (50-100 cells). By then, it has reached the uterine cavity and implantation starts by apposition and adhesion of the embryonic pole to the epithelial lining of the endometrium (Lindenberg, 1990; Johannisson, 1991). This orientation is essential for placental development, but the responsible mechanisms are not known. At day eight three cell layers are present: the inner cell mass from which the embryo and the amniotic membrane will develop, the trophoblastic outer layer and the extra embryonal mesoderm, which both will form the placenta and the chorionic membrane. The trophoblastic cells proliferate and migrate into the endometrium and contact the maternal vessels and glands. At this moment human chorionic gonadotrophin produced by the trophoblastic cells is released in the maternal blood.

Between the 7th and 12th day after ovulation the blastocyst becomes completely embedded by the endometrium. Trabeculae are formed out of the trophoblastic layer due to fusion of trophoblastic cells. The fused cells are called syncytiotrophoblast. The spaces between the trabeculae will become the intervillous space. Simultaneously with the appearance of trabeculae, the trophoblastic cells, which do not show fusion, grow into the syncytiotrophoblastic layer. About 13 days after fertilization the cytotrophoblast is invaded by stromal cells, which have their origin at the extraembryonal mesoderm. At the same time angioneogenesis in the stroma is seen, the angiogenic cells being derived from the extraembryonal mesoderm. From the 13th day on syncytial sprouts or extensions of the trophoblastic layer, consisting of trophoblastic cells emerge, followed by ingrowth of stromal tissue, forming villi. By proliferation and branching of the villous tree, new placenta tissue is formed. During the first trimester, mesenchymal and immature intermediate chorionic villi dominate, the former being the precursors of the latter. The immature intermediate villi develop into stem villi by transformation of reticular into fibrous stroma. The mature intermediate villi and their branches, i.e. the terminal villi, also develop from the mesenchymal villi. They are only seen after the end of the second trimester (Kaufmann et al., 1979; Kaufmann, 1981; Kaufmann et al., 1987; Castelluci et al., 1990). The mesenchymal villi show stroma with few capillaries and a well developed cytoand syncytiotrophoblastic layer. The latter has a number of extensions, which are termed syncytial sprouts. The immature intermediate villi have larger vessels, arterioles and venules, a well-developed trophoblastic layer with at light microscopical examination a few syncytial sprouts only. The stem villi are characterized by a large number of col- 
A

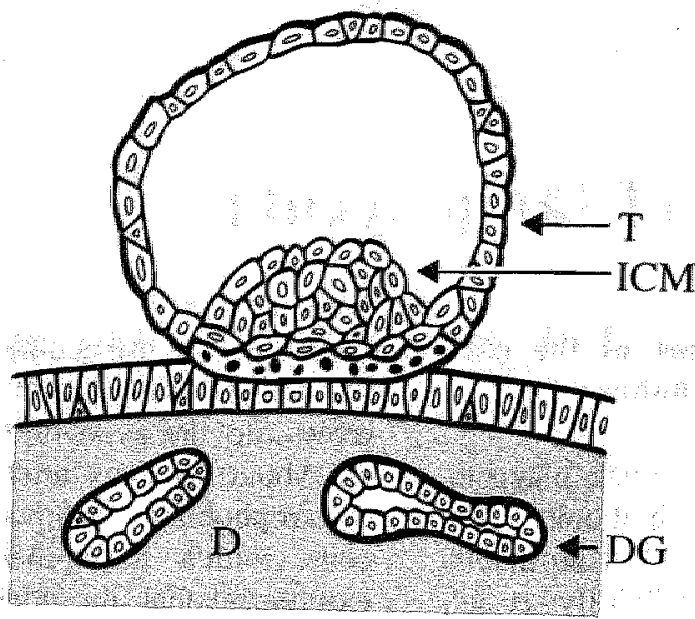

B

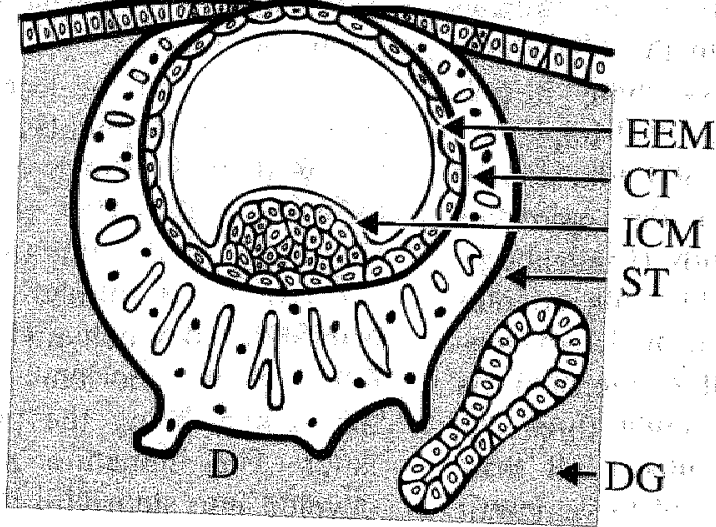

Figure 1. The deve opment of the huma placenta is schemat ically given. A) repre sents the developmen at 6-7 days after fertil ization, B) 8-9 day: after fertilization, $C$. $3-13$ weeks after fertil. ization.

BV, blood vessel, CT, cytotrophoblastic lay. er; EEM, extra embry. onal mesoderm; $D$, decidua; $D G_{3}$ decidual gland; ICM, inner cell mass; $\mathrm{MV}$, maternal vessel, ST, syncytiotrophoblastic layer; $\mathrm{T}$, trophoblastic layer (adapted from Kaufmann, 1981).

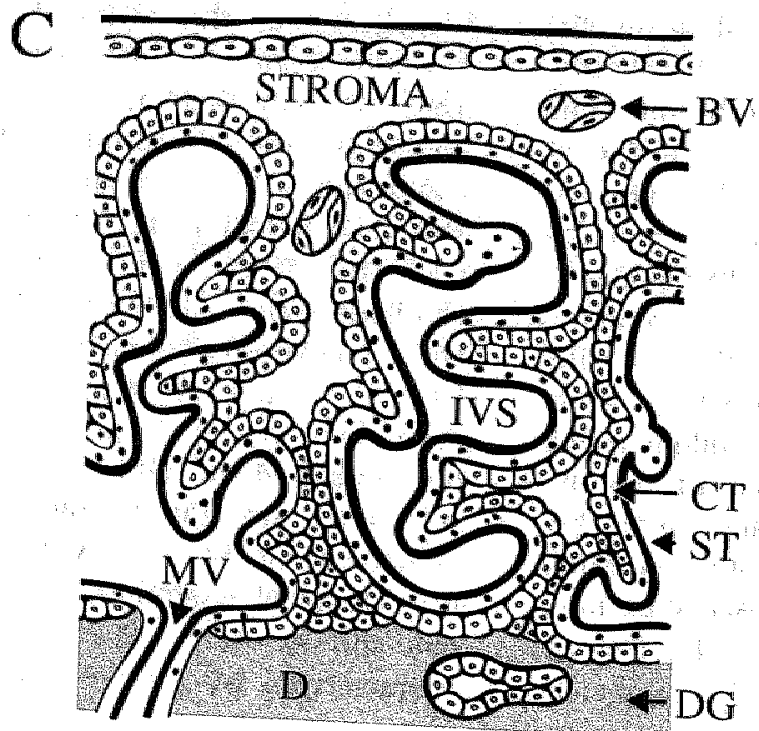


lagen fibres in the stroma and the presence of arteries containing a tunica media, arterioles, veins and venules. The villous vessels follow the stromal architecture and join at the chorionic plate to form the umbilical vessells. Between the sixth and 16th week of gestation, the trophoblastic layer consists of a monolayer of cytotrophoblast and a monolayer of syncytiotrophoblast. The cytotrophoblast, from which the syncytiotrophoblast is derived, is separated from the stromal tissue by a basement membrane (Gerbie, 1968). After the 16th week the cytotrophoblastic layer largely disappears, syncytiotrophoblast flattens and villous vessels line the basement membrane to facilitate transport between the intervillous maternal component and the intravillous fetal component:

Originally, the villi are evenly distributed around the chorionic membrane. From the eighth week onwards the chorionic villi of the abembryonic pole degenerate. At twelve weeks of normal gestation this polarization of villi is completed and a chorion frondosum and laeve can be distinguished. Three months after fertilization placental septa extending from the decidual plate are present dividing the placenta in units: the maternal cotyledons. It is not clear how these septa are formed. At the end of the fourth month of pregnancy the definitive architecture has been attained.

\subsection{Morphology of the placenta in abnormal karyotype.}

The first report of an abnormal chromosomal constitution in a malformed fetus was published in 1961 (Penrose et al, 1961). The relation between abnormal chromosomal constitution and abnormal development of the fetus was described in a now classic paper by Carr (1967). A Dutch thesis on chromosomal abnor- malities in spontaneous abortions in relation to their phenotype by Kirkels did not attract much attention (1966). Larger series of eytogenetic studies in spontaneous abortions were performed thereafter (Carr, 1971; Boué et al., 1975; Lauritsen, 1976; Hassold et al., 1980; Kajii et al, 1980, Warburton et al, 1980, Poland et al, 1981, Eiben et al., 1990). Honore et al. (1976) investigated a large number of placentae with known karyotype. These authors concluded that also the placenta participates in the dysmorphogenesis brought about by numerical chromosomal abnormalities. Furthermore, it was claimed that placenta morphology indicated the type of chromosomal abnormality.

In the following section, the characteristics investigated in the 'observer-variability'-, 'prediction of karyotype'-, 'morphometric'- and 'regression'-study of this thesis are described (chapter 3-6). It is especially focused on the relationship between morphology and karyotype.

Generally, normal karyotypes are marked by a structural uniformity of the villi despite zonal differences, abundant growth activity and coordination of the different cell types (Honoré et al. 1976). Abnormal karyotype of the conceptus is associated with depressed growth activity and dysmorpho genesis of the ehorionic villi. Regression processes during the retention time are claimed to result in an uniform pattern of dysmorphogenesis (Honoré et al. 1976).

\section{Chorionic villous size}

In normal pregnancies chorionic villous size as present in histological sections declines with duration of pregnancy. Comparison of normal, trisomic, triploid, monosomic $X$ and tetraploid 
karyotype reveals that mean chorionic villus size decreases from triploid/-tetra-

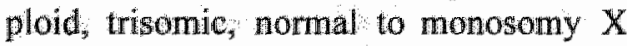
karyotype (Philippe, 1973, Röckelein et a., 1989): Triploidy consists of a group with a maternally derived extra chromosome set $(20 \%)$ which is morphologically similar to the group with a normal karyotype and a group with a paternally derived chromosome set most frequently caused by dispermy $(80 \%)$ which morphologically resembles partial hydatidiform mole (Szulman et al., 1981; Jacobs et al., 1982). In the literature, the only deseribed effect of retention of the placenta in utero after embryonic/fetal death on villus size is that the villi enlarge due to stromal hydrops during the second week of retention (Philippe, 1986).

\section{Chorionic villous contour}

Villous contour can be round to scalloped. Scalloping gives rise to pseudoinclusions in tangential cutting (Boué et al., 1976). Normally, the contour is slightly irregular. In monosomy $\mathrm{X}$ and tetraploidy the contours are rounded, whereas in trisomy in more than half of cases an irregular contour is seen (Honoré et al., 1976; Göcke et al., 1985). Scalloping is extremely clear in triploidy of paternal origin (Szulman et al., 1981). Regression would give rise to a more irregular out line (Rushton, 1981).

\section{Number of blood vessels}

The relationship between the number of blood vessels and karyotype is not known. It has been hypothesized that for an optimal development of blood vessels in chorionic villi an embryonic circulation is essential (Philippe et al.; 1969 and 1986). At the fifth week of normal embryonic development a functional heart is present. In trisomy, triploidy, monosomy $\mathrm{X}$ and tetraploidy the villi are said to be hypo- or avascular (Philippe, 1973, Honoré et al., 1976; Göcke et al., 1985). Degeneration of the placenta coincides with degeneration of blood wessels. The longer the period of decay the less blood wessels are expected in the chorionic villi (Rushton, 1981; Philippe, 1986).

Basophylic staining under the basement membrane

Basophylic staining reflecting the presence of fragmented basement membrane material is said to be more often present in monosomy $\mathrm{X}$ karyotype and trisomy than in all other karyotypes (Rushton, 1987). In addition, these fragmented basement membranes impregnated with ferro granules are attributed to retention of more than two weeks (Rushton, 1981; Philippe, 1986).

\section{Pseudo-inclusions}

Pseudo-inclusions as already indicated above are not true inclusion bodies of trophoblast: They represent tangential cuttings of a scalloped surface. In $70 \%$ of triploid abortions these pseudo-inclusions are easily found, whereas they are rare in normal karyotype, tetraploidy, and monosomy X (Honoré et al., 1976; Szulman et al, 1981; Göcke et al., 1985). In trisomy pseudo-inclusions are said to be frequently present (Honoré et al., 1976; Göcke et al., 1985).

\section{Stromal hydrops}

Stromal hydrops is thought to be a sign of abnormal pregnancy: (Naeye et al., 1983; Shen-Schwarz et al., 1989). In trisomy villous edema is present but not as pronounced as in triploidy from paternal origin. The hydrops in triploidy even leads to lacunae; acellular accumulations of fluid (Szulman et all, 1981). Hydrops is less frequently present in monosomy $\mathrm{X}$ and tetraploidy, although some tetraploid pregnancies might im- 
pose as hydatidiform moles (Honoré et al, 1976; Lage et al., 1989). In normal karyotype hydrops is seen in degenerating villi of the chorion laeve (Honore, 1976). After one week of retention the chorionic villi are said to show slight stromal edema due to ischaemia. The hydrops is said to be increased with length of retention being maximal at two weeks but declining afterwards (Philippe, 1986).

\section{Stromal fibro-hyalinization}

During normal development fibrosis of the villous stroma increases with gestational age (Castelluci et al., 1990). Fibrosis of the chorionic villous stroma is not a feature in triploid abortions but may be present in abortions with other karyotypes (Honore et al., 1976; Szulman et al., 1981). A month after fetal death the villi show abundant fibrosis of their stroma (Rushton, 1981; Philippe, 1986).

\section{Status of the trophoblastic layer}

After one month of retention chorionic villi are said, to have lost their trophoblastic layer (Philippe, 1986).

\section{Trophoblastic hyperplasia}

Although the real nature of this hyperplasia is still unknown triploidy is said to have normal villi and villi with a hypertrophy of the syncytial layer (Szulman et al., 1981). In trisomy especially the cytotrophoblastic layer is hypertrophied (Honoré et al., 1976). In contrast monosomy $\mathrm{X}$ and tetraploidy are characterized by a hypoplastic trophoblastic layer (Honoré et al., 1976). In the first week of retention cytotrophoblastic cells increase their growth activity, resulting in a thickening of the trophoblastic layer. After four weeks of retention the trophoblastic layer is replaced by fibrin deposits (Phillippe, 1986).

\section{Trophoblastic lacunae}

In normal pregnancy lacunae or vaeuoles in the trophoblastic layer are present till 7 weeks of gestation (Szulman et al., 1981). Only in triploid karyotypes these lacunae persist. It is not known whether retention of the chorionic villi has any effect on the presence of lacunae.

\section{Syncytial knots}

The accumulation of nuclei in the trophoblastic layer, i.e. syncytial knots, is physiologically seen only at the end of normal gestation and considered to be a feature of ageing or regressive change of the placenta (Fox, 1965, Alvarez et al, 1967). Fox hypothesized that the appearance of these knots is initiated by reduced embryonic/foetal blood flow, which not necessarily corresponds to ischaemia as the trophoblastic layer is surrounded by maternal blood, a view supported by Rushton (Fox, 1965; Rushton, 1981). About $20-30 \%$ of spontaneous abortions have an increased number of syncytial knots (Fox, 1978).

\section{Intervillous fibrin deposits}

The presence of fibrin deposits in the intervillous space in spontaneous abortion is believed to increase with the duration of retention after cessation of embryonic/foetal circulation, finally resulting in 'materrial floor infarction' (Fox, 1978; Rushton, 1981; Philippe, 1986). It is thought to be a physiological way of complete expulsion of the demised embryo/foetus by decrease of intervillous space and tightening of the chorio-decidual junction with reduction of maternal blood loss (Fox, 1978).

\section{Intervillous trophoblastic buds}

In early pregnancy intervillous trophoblastic buds or free floating trophoblastic buds are of syncytiotrophoblastic nature (Boyd et al., 1970). The exten- 
sions of the trophoblastic llayer mentioned previously (8 2.1 ) may loose their connection with this layer and thus become free floating. These buds are frequently found in the matemal circulation during normal pregnancy. The meaning of these free floating buds in early pregnancy is unclear. Also, it is not known, whether their number changes after prolonged embryonic/fetal death.

\subsection{Morphology of the placenta in cytomegalovirus infection.}

In second and third trimester pregnancies, sequelae in placentae after infection with cytomegalovirus (CMV) are well described, but highly variable (Monif et al, 1972; Blanc, 1978; Benirschke et al., 1974; Garcia et al, 1989). Macroscopically the placenta might be of normall weight for the duration of pregnancy. Abnormally heavy or abnormally small placentae, however, have also been reported. The aspect of the chorionic villi may be pale or normal. Which of these macroscopic features of the placenta is most frequently seen in CMV-infection is not known. Histological abnormalities are not all ways present in proven fetal infections, but antigens may be proved to be present (Garcia et al., 1989; Mühlemann et al. 1992). In typical cases, besides normal featuring villi, there are pathologically altered villi with edematous stroma infiltrated with plasma cells and lymphocytes. These latter villi show depositions of hemosiderin pigment localized around blood vessels mostly and in Hofbauer cells, which may be present in high numbers and sometimes have eosinophilic granules in their cytoplasm Monif et al., 1972: Benirschke et al., 1990). The presence of multinucleated giant cells in stroma and trophoblast is described in gestations aged $21-27$ weeks (Garcia et al., 1989). Also, necrotic and fibrotic villi are found. Vas cullitis, thrombi and intra- and extravascular calcifications are frequently reported. Pathognomonic cytoplasmic and nuclear cytomegalovinus inclusion bodies are described in stromal and endothelial cells Monif et al., 1972 ; Blanc, 1974; Garcia et al., 1989 ; Benirschke et al, 1990), In placentae these cytomegalic inclusion bodies frequently can only be found after meticulous search. Increased amounts of intervillous fibrin deposits may be observed (Monif et al., 1972; Benirschke et al. 1990). In the decidua the presence of a mononuclear infiltrate is considered physiological rather than pathological (Schneider, 1970; fox, 1978) In second and third trimester pregnancies, cytomegalovirus inclusion bodies have not been found in the decidua (Garcia et al. 1989).

Intensive literature search using Science Citation Index, Medline and references in articles on CMV infection and pregnancy on regarding spontaneous abortions of less than 17 weeks of gestation associated with CMV revealed 8 case reports (Goranov et al., 1963; Altshuler, 1973, 1974; Benirschke, 1974; Dehner et al., 1975; Blanc, 1978; Benirschke et al., 1990; Schwartz et al., 1992). None of these abortions has been karyotyped. CMV infection has only been recognized by the presence of CMV inclusion bodies in the decidual glands (gestational ages 6-10 weeks $(n=2)$ ) or in the chorionic villi (gestational ages 2 months-16 weeks $(n=6)$ ). Plasma cells, which are frequently reported in second and third trimester pregnancies, were described in only 2 out of 8 cases and even in these they were rare. Other signs of infection were absent in 5 out of 8 cases. The relation of this infection with the abortions is unclear. It is unknown whether first 
trimester embryos or foetuses are able to resist infections. Presumably histologic alterations cannot be seen in early preg- nancies despite cytomegalovirus infection (Benirschke et al., 1990).

\section{References}

Altshuler G. (1973) Implications of two cases of human placental plasma cells. American Joumal of Pathology, 70: 18a.

Altshuler G. (1974) Immunologic competence of the immature human fetus. Morphologic evidence from intrauterine cytomegalovirus infection. Obstetrics and Gynaecology, 43: 811-816.

Alvarez $H_{3}$ Benedetti WL \& Kreel de Leonis V. (1967) Syncytial proliferation in normal and toxemic pregnancies. Obstetrics and Gyncrecology, 29:637-643.

Benirschke K, Mendoza GR \& Bazeley PLi (1974) Placental and fetal manifestations of cytomegalovirus infection. Virchows Archivs B Cell Pathology, 16: 121-139.

Benirschke K \& Kaufmann P. (eds.) (1990) Virus infections and villitides: cytomegalovirus infection. In Pathology of the human placenta. 2ed Heidelberg: Springer-Verlag, 585-590, 613-635.

Blanc WA. (1978) Pathology of the placenta and cord in some viral infections. In Hanshaw IB \& Dudgeon JA (eds.) Viral diseases of the fetus and newborn. Philadelphia: W.B. Saunders Company, 237-258.

Boué J, Boué A \& Lazar P. (1975) Retrospective and prospective epidemiological studies of 1500 karyotyped spontaneous human abortions. Teratology, 12: 11-26.

Boué J, Philippe E, Giroud A \& Boué A. (1976) Phenotypic expression of lethal chromosome anomalies in human abortuses. Teratology, 14: 3-20.

Boyd JD \& Hamilton WJ. (1970) The human placenta. London: Heffer W \& Sons.

Cantle Sf, Kaufmann P \& Schweikhardt G. (1979) Classification of human placental villi. I. histology. Cell Tissue Research, 200: 409-423.

Carr DH. (1967) Chromosome anomalies as a cause of spontaneous abortion. American Journal of Obstetrics and Gynaecology, 97: 283-293.

Carr DH. (1971) Chromosomes and abortion. In Haines $\mathrm{H} \&$ Hirschhom K (eds.) Advances in hwman genetics, 2. New York, London: Plenum Press:

Castelluci M, Scheper M, Scheffen I, Celona AS \& Kaufmann P. (1990) The development of the human placental villous tree Anatomy and Embryology, 181: 117-128.

Dehner LP \& Askin FB. (1975) Cytomegalovirus endometritis. Report of a case associated with spontaneous abortion. Obstetrics and Gynecology, 45: 211-214.

Eiben $B$, Bartels 4 , Bähr-Porsch $S$, Borgmann $S$, Gatz $G$, Gellert $G$, Goebel $R$, Hammans $W$, Hentemann M, Osmers R, Rauskolb R \& Hansmann 1. (1990) Cytogenetic analysis of 750 spontaneous abortions with the direct preparation method of chorionic villi and its implications or studying genetic causes of pregnancy wastag. American Journal of Human Genetics, 47: 656663.

Fox H. (1965) The significance of syncytial knots in the human placenta. Journal of Obsterrics and Gynaecology, 72:347-355.

Fox H. (1978) Pathology of the placenta. Volume VI Major problems in pathology. London: Saunders WB. Company Ltd. ISBN 0-7216-3831-7.

Garcia AGP, Fonseca EF, Souza Marques de RL \& Lobato YY. (1989) Placental morphology in cytomegalovirus infection. Placenta, 10: 1-18.

Gerbie $A B$, Hathaway $\mathrm{HH}$ \& Brewer J1. (1968) Autoradiograhic analysis of normal trophoblastic proliferation. American Joumat of Obstetrics and Gynoceology, 100: 640-648.

Göcke H, Schwanitz G, Muradow I \& Zerres K. (1985) Pathomorphologie und Genetik in der Frühschwangerschaft. Pathologe, 6; 249-259.

Goranov I \& Gančev S. (1963) Fehlgeburt bei Zytomegalie. Zentralblatt fiur Gynaekologite, 85: 1037* 1040 .

Hassold $T$, Chen $N_{*}$ Funkhouser $J$, Jooss $T$, Manuel $B$, Matsuura $J$, Matsuyama $A$, Wilson $C$, Yanane JA \& Jacabs PA.(1980) A cytogenetic study of 1000 spontaneous abortions. Ammals of Human Genefics, 44: 151-178. 
Honore LH, DIII FI, Poland BJ (1976) Placental morphology in spontaneous abortuses with normal and abnomal karyotypesi. Teratology, 14: 151-166.

Jacobs $\mathrm{PA}$, Szuman $\mathrm{AE}$, Funkhouser J, Matsuura JS, Wison CC. (1982) Human triploidy: relationship between parental origin of the additional haploid complement and development of partial hydatidiform mole. Amales de Human Genetics, 46: 223-231.

Johaninisson E. (1991) Morphological and histochemical factirs related to implantation. Bawlière s Cinical Obstetrics and Gmaecology, $5: 191-209$.

Kajii T, Ferrier A, Nikawa $N$, TakaharaH, Ohama K \& Avirachan $\mathrm{S}$. (1980) Anatomic and chromosomal anomahes in 639 spontaneous abortuses. Human Genetics; $55,87.98$.

Kaufmann P, Sen DK \& Schweihart G. (1979) Classification of human placental villi. Cell and Tissue Research, 200: 409-423.

Kaufmann P. (1981) Entwicklang der Plazenta. In Becker V, Schiebler TH \& Kubli F (eds). Die Plazenta des Mensehen. Stuttgart-New York: Georg Thieme Verlag, 13-50.

Kaufmann $P$, Luckhardt $M$, Schweikhardt G \& Cantle SJ (1987) Cross-sectional features and three- dimensional structure of human placental villi: Placenta, 8: 235-247.

Kirkels VGHJ. (1966) Abortus en adnlegstoanissen. En onderzoek omirent chromosomale factoren, mongoloide Idiotie en uruchbare periode. Nijmegen, Utrecht: Dekker \& van de Vegt N.V..

Lage JM, Weinberg DS, Yavner DL, Bieber FR. (1989) The biology of tetraploid hydatidiform males: Histopatholgy, cytogenetics and flowcytometry. Human Pathology $20: 419 \times 425$.

Lauritsen JO. (1976) Aetiology of spontaneous abortion. A cytogenetic study of 288 abortuses and their parents. Acta Obstetrica et Gynecologica Scandinavica [suppl] 52: 1-29.

Lindenberg $\mathrm{S}$, Kimber $\mathrm{S}$, Hamberger $\mathrm{L}$. (1990) Embryo-endometrium interaction. In Evers $\mathrm{JLH} \&$ Heineman MJ (eds.) From ovulation to implantation. Elsevier Science Publishers B.V. (Biomedical Division), $285-295$.

Monif GRG \& Dische RM. (1972) Viral placentitis in congenital cytomegalovins infection. American jousnal of Clinical Pathology, 58: 445-449.

Mühlemann K, Miller RK, Metlay L \& Menegus MA. (1992) Cytomegalovirus infection of the human placenta: an immunocytochemical study. Human Pathology, 23: 1234-1237.

Naeye RL, Maisels MJ, Lorenz RP \& Botti JJ. (1983) The clinical significance of placental willous edema. Pediatrics, 4: 588-594.

O'Rahilly R \& Müller F: (1987) Dewelopmental srages in human embryos. Including a revision of Sireeter"s "horizons" and a survey of the Carnegie Collection. Carnegie Institution of Washington, publication 637.

Penrose LS \& Dellhanty JDA. (1961) Triploid cell cultures from a macerated foetus. Lancet i: 1261 1262.

Philippe $\mathbb{E} \&$ Boué JG. (1969) Le placenta des aberrations chromosomiques lethales-memoines originaux. Annales' d'Anotomile Parhologique Paris, 14: 249-266.

Plïlippe E. (1973) Consequences des anomalies chromosomiques sur le developpement. In Boue A \& Thibault (eds.) Les accidents chomosomiques de la reproduction. Paris: INSERM, 119-126.

Philippe E. (1986) Pathologie foeto-placentaire. 2nd edition. Paris: Masson.

Ramsey EM. (1982) The placenta: human and animal. New York, U.S.A.: Praeger Publishers.

Röckelein $\mathrm{G}$, Ulmer R Schröder 1. (1989) Korrelation von Karyotype und Plazentamorphology beim Fruthabort. Pothologe, 10: 306-314.

Rushton DI. (1981) Examination of products of conception from previable human pregnancies. Journal of Clinical Pathology, 34:819-835.

Rushton DI. (1987) Pathology of abortion. In Fox H (ed:) Hlaines and Taylor: Obstetrical and Gynecofogical Pathology. 3rd edition. Edinburgh: Churchill Livingstone, 1131-1136.

Schwartz D.A., Khan R., Stoll Bu, (1992) Characterization of the fetal inflammatory response to cytomegalovirus placentitis. Archives of Pathology and Laboratory Medicine, 116: 21-27.

Schneider L. (1970) Uber Vorkommen und Bedeutung leuköcytarer Infiltrate im Ablösungsvereich der spontan geborenen Placenta. Archiv für Gynäkologie, 208: 247-254.

Shen-Schwartz S, Ruchelli E \& Brown D. (1989) Villous oedema of the placenta: a clinicopathological study. Placenta, 10: 297-307.

Szulman AE, Philippe E; Boué JG \& Boué A. (1981) Human triploidy: association with partial hydatidiform moles and nonmolar conceptuses. Human Pathology, 12: 1016-1021. 
Warburton D, Stein Z, Kline J, Susser M. (1980) Chromosome abnormalities in spontaenous abortion: Data from the New York city study. In Porter IH \& Hook EB (eds.) Embryonic and Fend Death. New York Academic Press, 261-287. 



\title{
Intra- and inter-observer variation in the interpretation of histological features suggesting chromosomal abnormality in early abortion specimens
}

\author{
G van Lijnschoten, JW Arends, AA de la Fuente, HJA Schouten, JPM Geraedts. \\ (1993) Histopathology 22, 25-29.
}

Early spontaneous abortion is a common phenomenon, with more than $50 \%$ of early cases showing chromosomal abnormalities. We have undertaken a study to evaluate intra- and inter-observer reproducibility of histological diagnosis of features associated with chromosomal abnormalities, such as chorionic villus size, shape, vascularity, trophoblastic proliferation and trophoblastic pseudo-inclusions. The intra-observer variation for most histological features was small. However, the agreement beyond chance between two or more observers in judging histomorphological features of early abortion placentae only reached clinicalIy relevant values for size and shape of the chorionic villi and for the number of trophoblastic pseudo-inclusions.

\section{Introduction}

Early spontaneous abortion is a common phenomenon, occurring in about $20 \%$ of all pregnancies 1,2 . In more than $50 \%$ of these cases chromosomal abnormalities are present ${ }^{3}$. Since some of the structural chromosomal abnormalities are hereditary, it may be important to investigate the karyotypic status of abortions in view of potentially serious consequences for a future pregnancy. In addition, couples with a numeric chromosomally abnormal abortion have a better prognosis for a live born child in a future pregnancy than couples with karyotypically normal abortions ${ }^{4,5}$. For financial and logistic reasons, however, it is impossible to karyotype all abortion products. Therefore, the pathologist is often faced with the question whether chromosomal abnormalities might be present.
Attempts in the past to predict the karyotypic status on the basis of histopathological features have yielded conflicting data.

Placental morphology in early pregnancy is influenced by several factors. First, there is an influence of gestational age, in that the size and structure of chorionic villi alter in the course of gestation $^{6}$. Secondly, regressive changes following uterine retention of the deceased gestational product have a profound impact on morphological characteristics, such as stromal oedema, syncytial knotting, fibro-hyalinization and fragmentation of the trophoblastic basement membrane, with subsequent impregnation with haemosiderin granules seen as basophilic staining ${ }^{7}$. Several of the above mentioned features, however, have also been claimed to be associated with abnormal karyotypes ${ }^{8,9,10,11}$. 
Certain criteria, such as size, shape and vascularity of the chorionic villi and the presence of trophoblastic inclusions are still believed to be of relevance in the assessment of the karyotypic status $^{12,13,14,15}$. In the context of a larger study exploring the relation between karyotype and histopathological features in abortions, we first investigated the reliability of the assessment of features claimed to be associated with abnormal karyotypes, since a literature study revealed no data on observer variation with regard to histomorphological features in young placentae.

\section{Materials and methods}

The early abortion specimens were collected over a 2-year period. All 95 specimens, each containing at least 50 chorionic villi, were included in this part of the study. Gestational ages at first vaginal bleeding and at final pregnancy loss ranged from 28 to 120 days and from 46 to 126 days, respectively. Each speci- men was stored in Hank's medium a room temperature and examined macro. scopically. Cell cultures for chromosome analysis were made of the tissues expec. ted to be of non-maternal origin, i.e chorionic villi, chorion, amnion, embryo or fetus. The outcome of the analysis revealed the presence of 33 nomal and 61 abnomnal karyotypes in the series. In one case chromosome analysis failed. The remaining material was fixed in $4 \%$ formalin and embedded in paraffin. Sections, $4 \mu \mathrm{m}$ thick, of the chorionic villi were made and stained with haematoxylin and eosin. One to four sections per specimen were prepared for independent observer examination.

The first author and two independent experienced pathologists screened the slides (unaware of the chromosomal constitution) according to the items listed in table 1. Only one answer per item was allowed. In doubtful cases, the dominant characteristic was to be chosen. All tabulated items have been claimed to be associated with karyotypic and secondary degenerative changes due

Table 1. Scoring list for histopathological features of chorionic villi of early abortion specimens

\begin{tabular}{l} 
Characteristics \\
\hline General \\
Size \\
Shape \\
Stromal characteristics \\
Blood vessels/erythrocytes \\
Basophilic staining present \\
Pseudo-inolusions \\
Hydrops \\
Fibro-hyallinization
\end{tabular}

Trophoblastic characteristics

Largely intact

Trophoblastic hyperplasia

Lacunae quantity

Many syncytial knots

Intervillous space

Fibrin deposits

Many trophoblastic buds

Scoring list

small / intermediate / large - very large

regular / irregular - very irregular

few / moderate / abundant

yes / no

none - few / moderate - abundant

none / moderate $/$ abundant / lacunae

none - moderate / intermediate / abundant

yes / no

yes / no

none - little / moderate - abundant

yes / no

yes / no

few / moderate / abundant

yes / no 
to death of the embryo Without prior knowledge on the part of the investigators, 25 specimens were scored more than once by each observer, in order to estimate the intra-observer variation.

\section{Statistics}

Intra- and inter-observer variation was assessed by computing Cohen kappas for all three observers, for each of the three possible combinations of observers, and for all observers combined, for all items included in the score ${ }^{16}$. Kappa. values above 0.60 were considered to reflect good agreement, scores between 0.40 and 0.60 reasonable agreement, and scores below 0.40 poor agreement, in accordance with the criteria generally accepted in the literature ${ }^{17}$.

\section{Results}

\section{Intra-observer variation}

Table 2 shows the observed and expected intra-observer agreement, based on 60 assessments of 25 specimens, and the computed kappa statistics. Intra-observer agreements ranged from 0.59 to 1.00 , with medians of $0.83,0.84$ and 0.79 for each observer. The lowest and highest results for expected agreement were 0.34 and 1.00 respectively, with medians of $0.66,0.59$ and 0.63 for each observer. Observer 1 gave identical scores on the integrity of the trophoblastic layer and the presence of trophoblastic lacunae on each of the 25 specimens assessed more than once, resulting in identical observed and expected results, and thus in an undefined kappa value.

Two observers showed kappa statistics $\geq 0.60$ for size and shape of the chorionic villi, number of blood vessels, presence of basophilic staining under the basement membrane and number of trophoblastic pseudo-inclusions. Intraobserver kappa values between 0.40 and 0.60 were found for hydrops of villous stroma and trophoblastic buds in at least two observers. Two observers showed kappa statistics which were variable but $\geq 0.40$ for the presence and extent of trophoblastic hyperplasia and the num-

Table 2. The intra-observer variation: observed agreement, expected agreement and the kappa values

\begin{tabular}{|c|c|c|c|c|c|c|c|c|c|}
\hline \multirow[t]{2}{*}{$\ldots$} & \multicolumn{3}{|c|}{ Observer 1} & \multicolumn{3}{|c|}{ Observer 2} & \multicolumn{3}{|c|}{ Obserwer 3} \\
\hline & Observed & Expected & Kappa & Observed & Expected & Kappa & Observed & Expected & Kappa \\
\hline \multicolumn{10}{|l|}{ General } \\
\hline Size & 0.72 & 0.49 & 0.45 & 0.84 & 0.59 & 0.61 & 0.89 & 0.71 & 0.63 \\
\hline Shape & 0.83 & 0.69 & 0.44 & 0.93 & 0.67 & 0.80 & 0.91 & 0.70 & 0,68 \\
\hline \multicolumn{10}{|l|}{ Stromal characteristics } \\
\hline Blood vessels/erythrocytes & 0.71 & 0.48 & 0.45 & 0.78 & 0.38 & 0.65 & 0.79 & 0.44 & 0.62 \\
\hline Basophilic staining & 0.87 & 0.66 & 0.60 & 0.81 & 0.70 & 0.39 & 0.93 & 0.55 & 0.85 \\
\hline Pseudoinclusions & 0.87 & 0.68 & 0.60 & 0.93 & 0.72 & 0.76 & 0.91 & 0.84 & 0.41 \\
\hline Hydrops & 0.77 & 0.56 & 0.48 & 0.70 & 0.34 & 0.55 & 0.69 & 0.47 & 0.42 \\
\hline Fibro-hyalinization & 0.74 & 0.57 & 0.39 & 0.67 & 0.48 & 0.35 & 0.92 & 0.82 & 0.56 \\
\hline \multicolumn{10}{|l|}{ Trophoblastic characteristies } \\
\hline Largely intact & 1.00 & 1.00 & undefined & 0.96 & 0,96 & -0.02 & 0.91 & 0.78 & 0.58 \\
\hline Trophoblastic hyperplasia & 0.75 & 0.50 & 0.49 & 0.93 & 0.74 & 0.74 & 0.71 & 0.53 & 0.37 \\
\hline quantity & 0.75 & 0.73 & 0.10 & 0.73 & 0.51 & 0.46 & 0.90 & 0.61 & 0.75 \\
\hline Lacunae & 1.00 & 1.00 & windefined & 0.91 & 0.82 & 0.48 & 0.76 & 0.72 & 0.14 \\
\hline Many syncytial knots & 0.74 & 0.53 & 0.44 & 0.85 & 0.63 & 0.61 & 0.63 & 0.55 & 0.17 \\
\hline \multicolumn{10}{|l|}{ Intervillous Space } \\
\hline Fibrin deposits & 0.93 & 0.94 & -0.03 & 0.59 & 0.34 & 0.37 & 0.75 & 0.43 & 0.55 \\
\hline Many trophoblastic buds & 0.92 & 0.92 & -0.04 & 0.80 & 0.51 & 0.59 & 0.75 & 0.52 & 0,49 \\
\hline
\end{tabular}


Table 3. The inter-observer variations: observed agreement, expected agreemient and kappa values

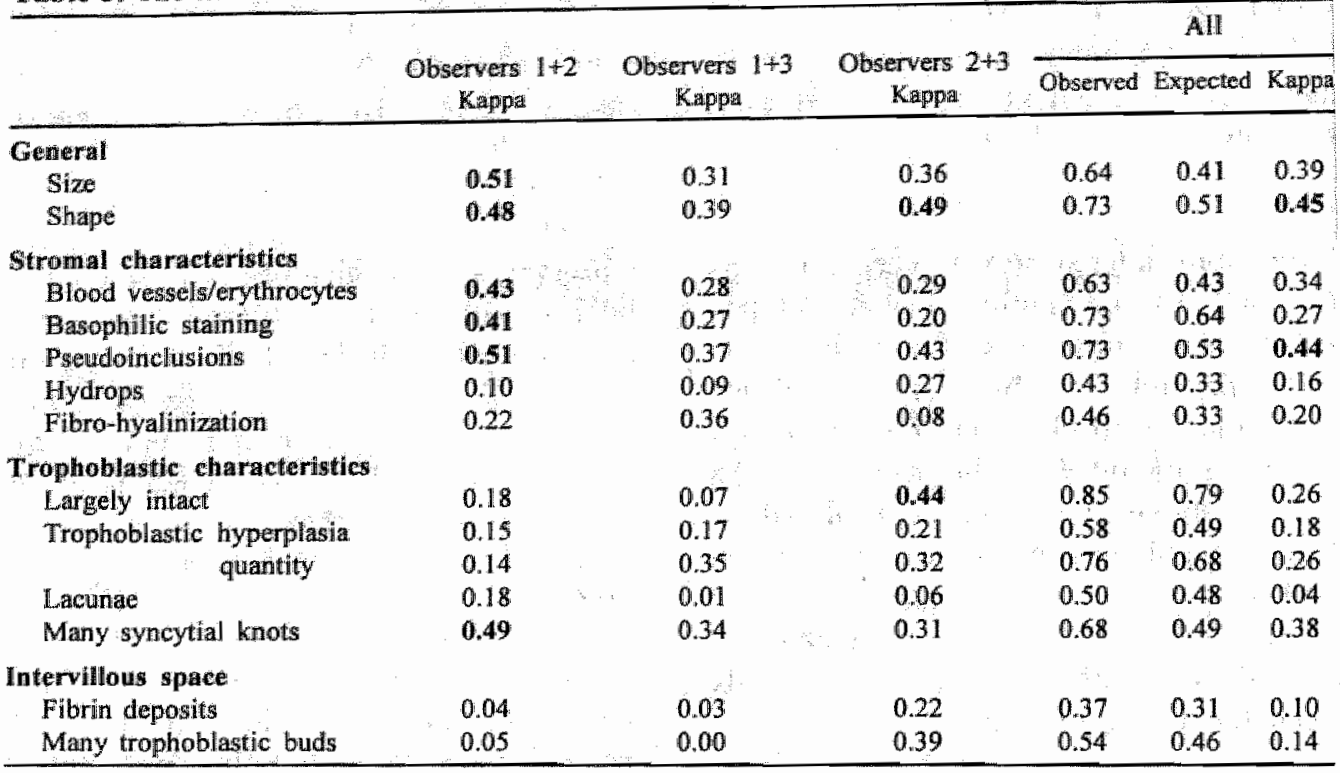

ber of syncytial knots. Kappa values $<0.40$ were found for two of the three observers for all other items.

\section{Inter-observer variation}

Table 3 lists the observed and expected agreements and kappa statistics for all observers combined. For each specimen only the first observation was used to estimate inter-observer variability. The first three columns present the kappa statistics for all possible combinations. The last three columns show the observed and expected agreements and the kappa statistics for all three observers compared. The agreements for pairs of observers are not shown as they offered no additional information. The interobserver agreements, in general, were found to be lower than the intra-observer agreements. For the combination of observers $1+2$, kappa values $>0.40$ were obtained for size and shape of the chorionic villi, number of blood vessels, basophilic staining under the basement membrane, number of pseudo-inclusions and syncytial knots. The remaining valu- es for this combination were $<0.40$. The combination of observers $2+3$ showed values $>0.40$ for shape of the chorionic villi, number of pseudo-inclusions and integrity of the trophoblastic layer only. For the combination of observers $1+3$ all kappa statistics were $<0.40$.

Combining all observer pairs resulted in values $>0.40$ for shape of the chorionic villi and the number of pseudo-inclusions. The kappa values for size of the chorionic villi and for number of syncytial knots were nearly 0.40 . The agreement beyond chance between all observers was particularly low for stromal hydrops and fibro-hyalinization, presence of trophoblastic hyperplasia and lacunae, amount of intervillous fibrin deposits and trophoblastic buds.

\section{Discussion}

PJacental morphology in early pregnancy is influenced by gestational age, karyotype and regressive changes following uterine retention of the deceased gestati- 
onal product. Part of the uncertainty about the exact relationship between early placental morphological features and karyotype may be explained by the partial overlap of changes caused by other factors. It is conceivable, however, that the lack of consistency in the recognition of the features mentioned could add to the confusion. No data about intra- and inter-observer variation in the study of early placental morphology are available in the literature.

All of the above features relating to gestational age, karyotype and regression were screened for in this study, as is shown in Table 1. Kappa values were used instead of observed agreements to estimate intra- and inter-observer variability, because this statistic corrects for the agreement by chance. If only the observed agreements, ranging from 0.59 to 1.00 and from 0.31 to 0.79 , respectively, had been calculated, good scores for almost all items would have been found. After correction for agreement by chance, good values were obtained only for intra-observer reproducibility of size and shape of the chorionic villi, for number of blood vessels, for the presence of basophilic staining under the basement membrane and for number of pseudo-inclusions. As regards the reproducibility beyond chance between observers, good results were obtained for size and shape of the chorionic villi and for the number of pseudo-inclusions and syncytial knots. Observed intra-individual agreements were generally high for most of the histological features scored. The kappa statistics computed for each ob. server were reasonable, especially those for size and shape of the chorionic villi, number of stromal blood vessels, the presence of basophilic staining under the basement membrane and number of trophoblastic pseudo-inclusions. The observed agreement between observers was much lower than the corresponding intra-observer kappa values. Best interobserver values were obtained for shape and size of the chorionic villi and number of pseudo-inclusions and syncytial knots. Considerably lower agreement beyond chance between the three observers was found for all other items.

Thus, intra-individual variability in the detection of most histological features associated with karyotypically abnormal abortions was small. The inter-observer variation beyond chance was considerably larger. Therefore, the reliability and, especially, the general applicability of the results of many studies reporting associations between possibly specific karyotypic abnormalities and histological features might be questioned. The predictive value of these parameters is the subject of current investigation.

\section{References}

1. Kline J, Stein Z. Very early pregnancy. In: Dixon RL ed. Reproductive Toxicology. New York, Raven Press, 1985;251-265.

2. Wilcox AJ, Weinberg $\mathrm{CR}, \mathrm{O}^{\prime}$ Connor JF et al. Incidence of early loss of pregnancy. New Engl.J.Med. 1988;319;189-194.

3. Edwards RG. Causes of early embryonic loss in human pregnancy. Human Reprod $1986 ; 1 ; 185-198$.

4. Boué J, Boué A, Lazar P. Retrospective and prospective epidemiological studies of 1500 karyotyped spontaneous human abortions. Teratology 1975;12;11-26.

5. Lauritsen JG. Aetiology of spontaneous abortion: A cytogenetic and epidemiological study of 288 abortuses and their parents. Acta Obstet.Gynecol.Scand. 1976;5uppl.52;1-29. 
6. Philippe E, Boue JG. Le placenta des aberrations chromosomiques lethales- memoires originaux. Ann.Anat Pathol.Paris $1969 ; 14 ; 249-266$.

7. Fox H ed. Pathology of the Placenta. Volume VII Major problems in Pathology, London:Saunders, $1978,244-248$.

8. Honore LH, Dill FJ, Poland BJ. Placental morphology in spontaneous human abortuses with normal and abnormal karyotypes. Teratology 1976;14;151-166.

9. Philippe E ed. Pathologie Foeto-Placentaire. 2nd ed. Paris: Masson, 1986;108-123.

10. Szulman AE, Philippe $E$, Boué JG, Boué A. Human triploidy: association with partial hydatidiform moles and nonmolar conceptuses. Hum.Pathol, 1981;12;1016-1:021.

11. Rushton DI. Pathollogy of Abortion. In. Fox H ed. Haines and Taylor: Obstetrical and Gynecological Pathology. 3rd ed. Edinburgh; Churchill Livingstone, 1987;1131-1136.

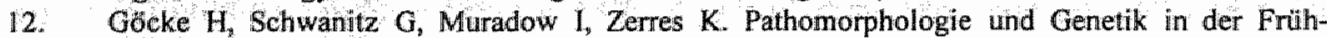
schwangerschaft. Pathologe 1985;6,249-259.

13. Novak R, Agamanolis D, Dasu $\mathrm{S}$ et al.. Histologic analysis of placental tissue in first trimester abortions. Pediatr.Pathol. 1988;8;477-482.

14. Röckelein $\mathrm{G}$, Ulmer $\mathrm{R}$, Schrö der J. Korrelation von Karyotyp und Plazentamorphologie beim Frithabort. Pathologe $1989 ; 10 ; 306-314$.

15. Rehder $H$, Coerdt $W$, Eggers $R$, Klink F, Schwinger $E$. Is there a correllation between morphological and cytogenetic findings in placental tissue from early missed abortions? Hum.Genet. $1989 ; 82 ; 377-385$.

16. Schouten HJA. Nominal scale agreement among observers. Psychometrika 1986;51;453-466.

17. Landis JR, Koch GG. The measurement of observer agreement for categorical data. Biometrics $1977 ; 33 ; 159-174$. 


\title{
The value of histomorphological features of chorionic villi in early spontaneous abortion for the prediction of karyotype
}

\author{
$G$ van Lijnschoten, JW Arends, P Leffers, AA de la Fuente, HJAM van der Looij, \\ JPM Geraedts. (1993) Histopathology 22, 557-563.
}

This study was conducted to evaluate the value of histomorphological features of chorionic villi, such as size, shape, vascularity, trophoblast proliferation and trophoblastic pseudoinclusions, for the prediction of chromosomal abnormality. Slides of 83 early spontaneous abortions were assessed by three observers. Assessments and karyotype were compared and likelihood ratios computed. Likelihood ratios of $\leq 0,40$ or $\geq 2.50$ were not obtained by all three observers for any of the features. One or two observers obtained likelihood ratios. of $\geq 2.50$ for lacunar stromal hydrops, presence of trophablastic hyperplasia, moderate to abundant trophoblastic hyperplasia, presence of trophoblastic lacunae, few intervillous fibrin deposits and few intervillous traphoblastic buds. Likelihood ratios of $\leq 0.40$ were found for small chorionic villi and presence of basophilic staining. Lacunar stromal hydrops and trophoblastic lacunae were predictive of triploid karyotype, but not specific for any other type of chromosomal abnormality. After application of data previously obtained on Cohen kappas, lacunar stromal hydrops, moderate to abundant trophablastic hyperplasia and presence of trophoblastic lacunae remained as possibly useful features, again mainly for triploidy. Most of the items claimed to be rellated to abnormal karyotype, however, were not predictive at all.

\section{Introduction}

The numerous studies that have been devoted to the relation between karyotype and histology of early abortion specimens have not always yielded unequivocal results $1,2,3,4,5,6,7,8,9,10,11$. Nevertheless, abnormal karyotypes such as triploidy have been claimed to be associated with features like increased villous size, irregularity of the surface and increased trophoblastic proliferation. To a lesser extent a typical pattern has been described for tetraploidy and monosomy $\mathrm{X}$.

The design of most studies generally starts from a known abnormal karyotype and subsequently analyses the histologi- cal features associated with the abnormal karyotype identified ${ }^{1-7}$. However, there are remarkably few studies that attempt to deduce the karyotype from the histological findings ${ }^{8-11}$. This is surprising, given the pressure put on the pathologist by clinicians to indicate the presence of relevant abnormal karyotypes in genetic counselling. This is especially true for abnormalities of chromosomes 13,18 and 21 , which are basically compatible with life but result in serious handicaps. If these karyotypes are found in abortion products, the risk of a subsequent pregnancy with a lifecompatible trisomy is probably increased and therefore genetic counselling is worthwhile ${ }^{12,13,14,15,16,17,18,19}$. 
Furthermore, some of the structural chromosomal abnormalities are hereditary.

Even if unable to indicate specific karyotypic anomalies a pathologist could at least, through observation of certain histological features, raise the level of suspicion to such a degree that cases might be selected for further analysis involving more extensive and expensive procedures such as karyotyping or application of molecular techniques to establish a definite diagnosis. In an extensive study of the relationship between cytogenetics and histology of early abortions we reported the intra- and inter-observer variability in the assessment of features claimed to be associated with abnormal karyotypes $^{20}$. Here we describe their value in the identification of abortions with abnormal karyotype.

\section{Material and methods}

Over a 2-year period (1989-1991), 98 consecutive early spontaneous abortion specimens were collected at the University Hospital Maastricht, the Netherlands. Gestational age at vaginal bleeding as a first symptom, as well as at final pregnancy loss, maternal age and previous obstetrical history were recorded. Fifteen specimens were excluded because there was insufficient material for study (12 cases had less than 50 chorionic villi) or unsuccessful chromosomal analysis (three cases), leaving 83 cases for final examination. Specimens were stored in Hank's medium at room temperature and scrutinized macroscopically. From the material taken to be of non-maternal origin (chorionic villi, chorion, amnion, embryo or fetus), cell cultures, chromosome analysis and $\mathrm{G}$-banding were carried out according to standard procedures. The remaining material was fixed in $4 \%$ formalin and embedded in paraffin wax. Sections, $4 \mu \mathrm{m}$ thick, were made and stained with haematoxylin and eosin.

One author (G.v.L.) and two experienced pathologists assessed the slides for the features listed in table 1. Only one answer per item was allowed. In doubtful cases, the dominant characteristic had to be chosen. The observers were unaware of the results of karyotyping.

Chromosome analysis was successful in 95/98 (97\%) spontaneous abortions. In $60 \%$ of the spontaneous abortions an abnormal karyotype was found (table 2). A relatively large number of chromosomally normal karyotypes: $7 / 38(18 \%)$, compared with $4 / 56(7 \%)$ of abnormal karyotypes, had too few chorionic villi to be assessed. Maternal contamination of the cell cultures seems unlikely as an explanation, as the female/male ratios before and after selection were 22:16 and 17:14 respectively. The normal karyotype and the abnormal karyotype group were comparable in gestational age, corrected for normal menstrual cycle length, with mean values of 84.7 days (range 51-126) and 81.7 days (range 45-119) respectively.

\section{Analysis}

Likelihood ratios were computed for each histological feature for all three observers in relation to the presence of abnormal karyotypes, using the standard formula:

$$
L R_{\text {feamure }}=\frac{\% \text { of abnormal karyotype group }}{\% \text { of normal karyotype group }}
$$

Likelihood ratios center on 1 and range from 0 to $\infty^{21}$. Values close to 1 mean that the feature is as frequent in abnormal as in normal karyotypes. Values less than 1 indicate that the feature is less frequent in abnormal than in normal karyotype. Values greater than 1 indicate that the features are more frequent in abnormal than in normal karyotype. 
Table 1. Scoring list for histological features of chorionic will in early spontaneous abortion specimens. The likelihood ratios for the analysis of chromosomal abnormality for each observer are listed in right hand part of the table. The number of specimens is given in parentheses. Ratios of $\leq 0.40$ and $\geq 2.50$ are in bold (selected ranges, see text)

\begin{tabular}{|c|c|c|c|c|}
\hline \multirow{2}{*}{ Features } & & \multicolumn{3}{|c|}{ Likelihood ratios } \\
\hline & & Observer I & Observer 2 & Observer 3 \\
\hline \multicolumn{5}{|l|}{ General } \\
\hline \multirow[t]{3}{*}{ Size } & small : & $0.70(13)$ & $0.20(4)$ & $1.04(11)$ \\
\hline & intermediate & $1.33(42)$ & $1.08(45)$ & $1.04(22)$ \\
\hline & large - very large & $0.79(28)$ & $1.09(3.4)$ & $0.97(50)$ \\
\hline \multirow[t]{2}{*}{ Shape } & regular & $1.16(47)$ & $0.64(31)$ & $1.04(33)$ \\
\hline & irregular - very irregular & $0.83(36)$ & $1.34(52)$ & $0.97(50)$ \\
\hline \multicolumn{5}{|l|}{ Stromal characteristics } \\
\hline \multirow[t]{3}{*}{ Blood wessels } & few & $0.89(45)$ & $0.85(51)$ & $0.99(64)$ \\
\hline & moderate & $1.38(32)$ & $1.29(19)$ & $1.19(18)$ \\
\hline & abundant & $1.19(6)$ & $1.34(13)$ & $0(1)$ \\
\hline \multirow[t]{2}{*}{ Basophilic staining present } & yes & $0.40(5)$ & $0.99(8)$ & $0.77(32)$ \\
\hline & no & $1.06(78)$ & $1.00(74)$ & $1.19(51)$ \\
\hline \multirow[t]{2}{*}{ Pseudoinclusions } & none - few & $0.77(41)$ & $0.66(40)$ & $0.66(21)$ \\
\hline & moderate - abundant & $1.33(42)$ & $1.54(43)$ & $1.16(62)$ \\
\hline \multirow[t]{2}{*}{ Hydrops } & none: & $0.91(38)$ & $0.64(29)$ & $1.19(12)$ \\
\hline & moderate & $1.03(41)$ & $1.19(36)$ & $0.91(38)$ \\
\hline : & abundant & $1.79(4)$ & $0.95(13)$ & $0.70(24)$ \\
\hline : ... & lacunae & $-(0)$ & $\infty(5)$ & $4.77(9)$ \\
\hline \multirow{2}{*}{ Fibro-hyalinization } & none - moderate & $0.99(48)$ & $1.04(11)$ & $1.19(57)$ \\
\hline & intermediate & $1.56(19)$ & $0.93(4 l)$ & $0.70(13)$ \\
\hline$\because \vdots$ & abundant & $0.77(16)$ & $1.08(31)$ & $0.70(13)$ \\
\hline \multicolumn{2}{|l|}{ Trophoblastic characteristics } & & & \\
\hline \multirow[t]{2}{*}{ Largely intact } & yes & $0.98(82)$ & $0.95(75)$ & $1.08(62)$ \\
\hline & no & $\infty$ (1) & $1.79(8)$ & $0.79(21)$ \\
\hline \multirow[t]{2}{*}{ Trophoblastic hyperplasia } & yes & $1.25(34)$ & $1.31(49)$ & $2.68(22)$ \\
\hline & no & $0.86(49)$ & $0.76(34)$ & $0.75(61)$ \\
\hline \multirow[t]{2}{*}{ quantity } & none - little & $0.99(72)$ & $0.89(65)$ & $0.90(78)$ \\
\hline & moderate - abundant & $1.04(11)$ & $1.55(18)$ & $\infty(5)$ \\
\hline \multirow[t]{2}{*}{ Lacunae } & yes & $-(0)$ & $3.58(7)$ & $1.17(65)$ \\
\hline & no & $1(83)$ & $0.91(76)$ & $0.60(18)$ \\
\hline \multirow[t]{2}{*}{ Many syncytial knots } & yes & $1.19(42)$ & $1.02(46)$ & $1.09(65)$ \\
\hline & no & $0.84(41)$ & $0.98(37)$ & $0.75(18)$ \\
\hline \multicolumn{5}{|l|}{ Intervillous space } \\
\hline \multirow[t]{3}{*}{ Fibrin deposits } & few & $\infty(4)$ & $1.19(9)$ & $1.03(30)$ \\
\hline & moderate & $0.92(79)$ & $0.50(24)$ & $1.08(31)$ \\
\hline & abundant & $-(0)$ & $1.39(50)$ & $0.86(22)$ \\
\hline \multirow[t]{2}{*}{ Many trophoblastic buds } & yes & $0.94(80)$ & $0.92(33)$ & $0.82(45)$ \\
\hline & no & $\infty$ (3) & $1.06(50)$ & $1.29(38)$ \\
\hline
\end{tabular}


Table 2. Karyotype of all spontaneous abortion specimens (I) and of spontaneous abortions fit for qualitative anallysis of chorionic villi (II)

\begin{tabular}{lcc}
\hline Karyotype & I & II \\
\hline Triploid & 13 & 13 \\
Tetraploid & 3 & 2 \\
45, XO & 6 & 5 \\
Trisomy & 24 & 24 \\
Unbalanced translocation & 10 & 8 \\
Faillure & 3 & \\
Others. & 1 & \\
Normal 9 & 22 & 17 \\
& 16 & 14 \\
Total of & 98 & 83 \\
\hline
\end{tabular}

Values 0 and $\infty$ represent perfect tests.

The pre-test odds for abnormal karyotype was calculated by dividing the number of abnormal karyotypes by the number of normal karyotypes in the population under study, i.e. 52:31= $1.68^{21}$. Likelihood ratios multiplied by the pre-test odds for abnormal karyotype yielded the post-test odds for abnormal karyotype $^{21}$. The post-test probability of abnormal karyotype was then calculated by the formula" ${ }^{21}$ :

Post-test probability abmarmal karyoutype $=\frac{\text { post-test odds }}{\text { post }- \text { test odds }+1}$

Likelihood ratios $\leq 0.40$ and $\geq 2.50$ were selected for further study in order to test the relation of those features with type of chromosomal abnormality. Confidence intervals for the likelihood ratios were read from tables for confidence intervals for fractions ${ }^{22}$.

\section{Results}

Histological features in relation to abnormal karyotype.

Likelihood ratios of all observers for all histological features have been compiled in Table 1. From this table it can be seen that no feature reached ratios of $\leq 0.40$ or $\geq 2.50$ by all of the three ob- servers. Two observers found ratios $\geq 2.50$ for lacunar stromal hydrops. $O$ observer showed ratios of $\geq 2.50$ for lo of integrity of the trophoblastic layer, presence of trophoblastic hyperplasi moderate to abundant trophoblastic $h$ perplasia, presence of trophoblastic lac nae, few intervillous fibrin deposits ai not many trophoblastic buds. For or observer, ratios of $\leq 0.40$ were compute for small chorionic villi and the pre ence of basophilic staining. None of th other features showed likelihood ratic in the selected ranges.

Histological features in relation to th various abnormal karyotypes

Table 3 shows the relative frequencie of abnormal karyotypes in specimens fc several features. Data are only given $\mathrm{fc}$ those features for which at least on observer had a likelihood ratio of $\leq 0.4$ or $\geq 2.50$. For each feature selected, th distribution of karyotypes is given fo all observers. In two observers higl likelihood ratios for lacunar hydrop were found to be markedly associatec with triploidy. Of the chromosomally abnormal cases $63-100 \%$ were triploid whereas the prevalence of triploidy it the abnormal karyotype group was $25 \%$ Furthermore, the presence of trophoblas. tic lacunae seemed specific for triploic karyotype $(100 \%$ v. $25 \%)$. No other features were found to be correlated with any of the other abnormal karyotypes. The numbers are too small to permit formal statistical analysis.

Table 4 lists the post-test odds, posttest probabilities for abnormal karyotype and their 95\% confidence intervals corresponding with likelihood ratios of $\leq 0.40$ and $\geq 2.50$. The pre-test probability of abnormal karyotype was $63 \%$. Ratios of $\leq 0.40$ correspond with posttest probabilities of $\leq 40 \%$, whereas ratios of $\geq 2.68$ correspond with post-test probabilities of $\geq 80 \%$, thereby raising 
Table 3. Relative frequency (percentage) of abnomal karyotypes in specimens for several features. Data are only given for those features with likelihood ratios of $\leq 0.40$ or $\geq 2.50$ for at least one observer. The percentages and absolute numbers corresponding to these ratios are in bold. All other numbers correspond to ratios between 0.40 and 2.50 .

\begin{tabular}{|c|c|c|c|c|c|c|c|}
\hline & triploidy & tetraploidy & $45, \times 0$ & trisomy & unbtrt. & Albinotin: & Mominal \\
\hline Fieatume & observer $13(25 \%)$ & $2(4 \%)$ & $5(10 \%)$ & $24(46 \%)$ & $8(15 \%)$ & $52(100 \%)$ & \\
\hline
\end{tabular}

\section{Size}

smiall

$\begin{array}{lll}1 & 2 & 0 \\ 2 & 1(100 \%) & 0 \\ 3 & 0 & 0\end{array}$

Basophilic staining present yes

$\begin{array}{lll}1 & 1(50 \%) & 0 \\ 2 & 0 & 0 \\ 3 & 4 & 0\end{array}$

Hydrops

lacunae

$\begin{array}{lll}1^{*} & 2 & 0 \\ 2 & 5(100 \%) & 0 \\ 3 & 5(63 \%) & 0\end{array}$

Trophoblastic layer largely not intact

$$
\begin{array}{ll}
1 & 0 \\
2 & 0 \\
3 & 1
\end{array}
$$

2
0
4

$\begin{array}{ll}7 & 6 \\ 1 & 3 \\ 7 & 4\end{array}$

0

0
0
3

$\begin{array}{ll}1(50 \%) & 0 \\ 5 & 0 \\ 9 & 2\end{array}$

$\begin{array}{cc}2 & 3 \\ 5 & 3 \\ 18 & 14\end{array}$

Trophoblastic hyperplasia yes

$\begin{array}{llllllll}1 & 8 & 1 & 2 & 10 & 2 & 23 & 11 \\ 2 & 8 & 1 & 3 & 17 & 4 & 43 & 16 \\ 3 & 7(39 \%) & 0 & 2(11 \%) & 9(50 \%) & 0 & 18 & 4\end{array}$

Hyperplasia quantity moderate-abundant

$\begin{array}{llllllll}1 & 1 & 0 & 3 & 1 & 1 & 7 & 4 \\ 2 & 4 & 0 & 1 & 6 & 2 & 13 & 5 \\ 3 & 4(80 \%) & 0 & 0 & 1(20 \%) & 0 & 5 & 0\end{array}$

Trophoblastic lacunae

$\begin{array}{lllllllll}\text { yes } & 1 & 0 & 0 & 0 & 0 & 0 & 0 & 0 \\ & 2 & 6(100 \%) & 0 & 0 & 0 & 0 & 6 & 1 \\ 3 & 11 & 2 & 4 & 19 & 7 & 43 & 22\end{array}$

Fibrin deposits

few

$\begin{array}{ccclcccc}1 & 0 & 0 & 2(50 \%) & 2(50 \%) & 0 & 4 & 0 \\ 2 & 2 & 0 & 0 & 2 & 2 & 6 & 3 \\ 3 & 6 & 0 & 0 & 10 & 3 & 19 & 11\end{array}$

Many imtervillows buds no

\begin{tabular}{cccccccc}
1 & $1(33 \%)$ & 0 & $1(33 \%)$ & $1(33 \%)$ & 0 & 3 & 0 \\
2 & 10 & 1 & 2 & 13 & 6 & 32 & 18 \\
3 & 8 & 0 & 1 & 12 & 5 & 26 & 12 \\
\hline
\end{tabular}

\footnotetext{
* observer 1 did not use lacunar hydrops; the numbers for abundant hydrops are listed. Unb.trl, unbalanced translocation, Abnorn. = abnormal karyotype
} 
Tablle 4. Posi-test odds $(=\mathrm{LLR} \times$ pre-test odds $=\mathrm{LR} \times 1.68)$ and predictive values for abromal karyotype:

\begin{tabular}{|c|c|c|c|c|c|}
\hline Feature & Obs & LR & PT odds & $\begin{array}{c}\text { PT prob } \\
(\%)\end{array}$ & Confidence interval* \\
\hline \multicolumn{6}{|l|}{ Size } \\
\hline small & 2 & 0.20 & 0.34 & 25 & $0-60$ \\
\hline \multicolumn{6}{|c|}{ Basophilic staining present } \\
\hline yes & 1 & 0.40 & 0.67 & 40 & $5-85$ \\
\hline \multicolumn{6}{|l|}{ Trophoblastic hyperplasia } \\
\hline yes & 3 & 2.68 & 4.50 & 82 & $60-95$ \\
\hline \multicolumn{6}{|l|}{ Trophoblastic lacunae } \\
\hline yes & 2 & 3.58 & 6.01 & 86 & $42-100$ \\
\hline \multicolumn{6}{|l|}{ Hydrops } \\
\hline lacunae & 3 & 4.77 & 8.01 & 89 & $52-100$ \\
\hline lacunae & 2 & $\infty$ & $\infty$ & 100 & $48-100$ \\
\hline \multicolumn{6}{|l|}{ Trophoblastic layer intact } \\
\hline no & 1 & $\infty$ & $\infty$ & 100 & undefined \\
\hline \multicolumn{6}{|c|}{ Trophoblastic hyperplasia quantity } \\
\hline moderate-abundant & 3 & $\infty$ & $\infty$ & 100 & $48-100$ \\
\hline \multirow{2}{*}{$\begin{array}{l}\text { Fibrin deposits } \\
\text { few }\end{array}$} & & & & & \\
\hline & 1 & $\infty$ & $\infty$ & 100 & $40-100$ \\
\hline \multicolumn{6}{|l|}{ Many trophoblastic buds } \\
\hline no & 1 & $\infty$ & $\infty$ & 100 & $29-100$ \\
\hline
\end{tabular}

* 95\%-confidence interval for post-test probability.

Obs, observer; LR, Likelihood ratio; PT adds, post-test odds for abnormal karyotype; PT prob, posttest probability for abnormal karyotype.

the level of suspicion of abnormal karyotype from 63 to at least $80 \%$. The $95 \%$ confidence intervals for the likelihood ratios listed were considerable, owing to the small number of specimens with the corressponding features.

\section{Discussion}

Based on the idea that abnormal genetic make-up results in abnormal development and structure of chorionic villi, and the concept that each genetic abnormality is characterized by specific structural deviations, many studies have been undertaken to explore the relationship between karyotype and histological features in the early placentae. Classical pioneer studies performed by Philippe \& Boué and Honoré et al. yielded histological pictures which were reported to be characteristic for triploidy, tetraploi$\mathrm{dy}$, monosomy $X$ and trisomy $\mathrm{y}^{1,2}$. These observations were confirmed and extended for monosomy $X$ and triploidy respectively ${ }^{4,5}$. The histological features in $80 \%$ of triploid placentae are characterized by either diffuse or focal stromal oedema with increased villus size, stromal lacunae, hypo- or avascularity, irregular outline of villi with invaginations or pseudo-inclusions and focal trophoblastic hyperplasia ${ }^{5}$. Trophoblastic lacunae, normally seen until 7 weeks amenorrhoea, are often present after longer periods of amenorrhoeas. Tetraploidy is associated with hydropic as 
well as fibrous villi, which are moderately increased in size and of normal outline. The stroma contains few blood vessels and the trophoblast is hypoplastic $^{1-3}$. The picture of monosomy $X$ is dominated by generally small hypovascular villi with a hypoplastic trophoblast $^{1-4}$. In trisomy, a subgroup with irregularly outlined hypovascular middle sized villi with trophoblastic inclusions is observed ${ }^{1-3}$.

Morphometric studies confirmed most of these observations ${ }^{6,7}$. Philippe ${ }^{6}$ found that triploid placentae contained the largest villi and karyotypically normal placentae the smallest, whereas the size of villi in trisomic abortions was intermediate. Röckelein et al. ${ }^{7}$ semiquantitatively investigated the thickness and condition of the trophoblastic layer, the number of intervillous fibrin deposits, the amount of stromal oedema and the number of blood vessels. Size was measured using a morphometry unit. Trophoblast thickness and quality were found to increase in the following order: monosomy $\mathrm{X}$ and tetraploidy, normal karyotype, triploidy and trisomy. The number of fibrin depositions increased from monosomy $\mathrm{X}$ via trisomic and tetraploidy to triploid to chromosomally normal abortions. Stromal oedema was found to be most extreme in trisomy and tetraploidy, whereas chromosomally normal abortions and monosomy $\mathrm{X}$ were less hydropic. The authors concluded that triploidy and monosomy $\mathrm{X}$ bear a typical histological pattern, whereas chromosomally normal abortions can mimic trisomic or even triploid abortions?.

Although several studies relating histological features to a known abnormal karyotype have been performed, only a few have addressed the issue the other way round, i.e. trying to distinguish between abnormal and normal karyotype abortions on the basis of their histologi- cal features. Yet, in daily practice the pathologist tries to assess the karyotypic status from the observed histological features, which is why it is important to know their test characteristics. Minguillon et all. ${ }^{8}$ designed a histological classification for normal or abnormal karyotypes and calculated the predictive value of chorionic villi histology. The predictive value observed in their study (55.4\%) only marginally outweighed the prevalence of abnormal karyotypes $(51.8 \%)$, thus rendering this test characteristic of very little value. Eiben et al.", from the same group as Minguillon, used the same classification on a larger population and achieved similar results. Rehder et al. ${ }^{10}$ assigned placentae to five histological groups according to a sliding scale of severity of histological changes, unaware of their chromosomal constitution. Chromosomally abnormal abortions were expected to have more severe changes than chromosomally normal abortions. Only the group with the severest changes, i.e. clear villous hydrops, irregular shape, focal trophoblastic hyperplasia and pseudo-inclusions, contained a higher percentage of chromosomally abnormal cases than could be expected by chance. In this group $24 \%$ of cases were triploid.

Novak et al. " were the first to study individual histological features. Seventyfive placentae were assessed by at least three pathologists for the presence of hydropic changes, fibro-hyalinization, irregular shape with pseudo-inclusions, cytotrophoblastic cells in the stroma core and lymphocytes aggregations with signs of acute inflammation of the decidua. Of the features assessed, only irregular shape of the chorionic villi with pseudo-inclusions appeared to be of relevance for the recognition of abnormal karyotype.

The approach used in our study closely resembles that of Novak et al." , but the 
analysis of the results differs, since the likelihood ratio was used as a test characteristic for comparing the value of the features in distinguishing between abnormal and normal karyotypes. Likelihood ratios are relatively independent of the prevalence of abnormal karyotype, although the interpretation of results concerning the general population requires the sample under study to be representative in this respect. In our study the distribution of karyotypes was the same as that found in large epidemiological studies on early spontaneous abortions.

The results of all three observers were analyzed, as there was no reason to expect one to be better than the others. Small chorionic villi and basophilic staining appeared to be parameters with a likelihood ratio of $\leq 0.40$ in individual observers. Ratios of $\geq 2.50$ were seen for lacunar stromal hydrops by two observers and for loss of integrity of the trophoblastic layer, presence of trophoblastic hyperplasia, moderate to abundant trophoblastic hyperplasia, presence of trophoblastic lacunae and $a$ few fibrin deposits and syncytial buds in the intervillous space for one observer. These data indicate that the post-test probabilities for the presence of an abnormal karyotype are reduced from 63 to 25 and $40 \%$ when small villi and basophilic staining respectively are noticed and increased from 82 to $100 \%$ when histological features such as lacunar stromal hydrops and trophoblastic lacunae are seen.

Yet, there is not much reason to be optimistic about the possibility to raise the level of suspicion for abnormal karyotypes by histological examination. First, the abnormal karyotype indicated by most of the features generally turns out to be triploidy, whereas other, clinically more relevant conditions, such as trisomy, pass unnoticed. Secondly, the relevance of our findings is further reduced, by the fact that most of the features with meaningful likelihood ratios turned out to show high intra- and/or inter-observer variation in our previous study, indicating a low reproducibility 20 . This is also illustrated by the finding in this report that no single parameter emerged in the analysis with meaningful ratios in all three observers. Lacunar stromal hydrops, moderate to abundant trophoblastic hyperplasia and the presence of trophoblastic lacunae were the only features highlighted in both anallyses. These features, however, only point to triploidy: Therefore, in our opinion, histological examination is not useful as a method for screening for abnormal karyotypes of interest in genetic counselling.

\section{Aknowledgements}

We would like to thank the registrars and staff of the Department of Obstetrics and Gynaecology of the University Hospital Maastricht for their help in collecting the abortion specimens.

\section{References}

1. Philippe $\mathrm{E}_{x}$ Boue JG. Le placenta des aberrations chromosomiques lethales - memoires origimaux. Ann.Anat.Pathol.Paris $1969 ; 14 ; 249-266$.

2. Honore LH, Dill FJ, Poland BJ. Placenital motphology in spontaneous human abortuses with normal and abnormal karyotypes. Teratology 1976; 14: 151-166.

3. Phillippe E. Morphologie et morphométrie des placentas d'aberration chromosomique léthalle. Rev. Franç.Gynec: $1973 ; 68 ; 645-653$. 
4. Canki $N$, Warburton D, Byrne J. Morphological characteristics of monosomy $X$ in spontaneous abrof tions. Ann Génét. 1988; 31; 4-13.

5. Szulmam $A E$, Philippe $\mathbb{E}$, Boue $J G_{*}$ Boue $A$. Human triploidy: association with partial hydatidiform moles and nonmolar conceptuses. Hum.Pathol. 1981; 12; 1016-1021.

6. Philippe E. Consequences des anomalies chromosomiques sur le developpernent. In: Boue $A_{\text {, Thibault }}$ C (eds.), Les Accidents Chromosomiques de la Reproduction. Paris: INSERM, 1973; 119-126.

7. Röckelein G, Ulmer R, Schröder I. Korrelation von Karyotype und plazentamorphology beim Frühabort. Pathologe 1989; 10; 306-314.

8. Minguillon $C$, Eiben $B$, Băhr-Porsch, Vogel M, Hansmann 1 . The predictive value of chorionic villus histology for identifying chromosomally normal and abnormal spontaneous abortions. Hum. Genet. $1989 ; 82 ; 373-376$.

9. Eiben $B$, Vogel $M$. The predictive walue of placental histology for identifying chromosonally normal and abnormal spontaneous abortions. In: Marcek $M_{x}$ Ferguson-Snith MA, Spála M (eds.). Early fetal diagnosis: tecent progress and public health implication. Prague: Karolinum-Charles University Press, $1992 ; 323-324$.

10. Rehder H, Coerdt W, Eggers R, Klink F, Schwinger E. Is there a correlation between morphological and cytogenetic findings in placental tissue from early missed abortions? Hum.Gienet. 1989;82;377. 385 .

11. Nowak $R$, Agamanolis D, Dasu $S$ et al.. Histologic analysis of placental tissue in first trimester abortions. Pediatr.Pathol. 1988; $8 ; 477-482$.

12. Boué $\mathrm{J}$, Boué A. Chromosomal analysis of two consecutive abortuses in each of 43 women. Humangenetik $1973 ; 19 ; 275-280$.

13. Alberman $\mathbb{E}_{\text {, Elliott }} M$, Creasy $M$, Dhadial $\mathbb{R}$. Previous reproductive history in mothers presenting with spontaneous abortions. Br.J.Obstet.Gynaecol. 1975; 82; 366-373.

14. Lauritsen JG. Aetiology of spontaneous abortion: a cytogenetic and epidemiological study of 288 abortuses and their parents. Acta Obstet.Gynecol.Scand. 1976; 52(suppl.); 1-29.

15. Kajii T, Ferrier A. Cytogenetics of aborters and abortuses. Am.J.Obstet.Gynecol. $1978 ; 131 ; 33-38$.

16. Hassold TJ. A cytogenetic study of repeated spontaneous abortions. Am.J.Hum.Genet. 1980; 32; 723730 .

17. Warburton D, Stein $Z$, KLine J, Susser M. Chromosome abnormalities in spontaneous abortion: data from the New York city study. In: Porter IH, Hook EB (eds.), Human embryonic and fetal death. New York: Academic Press, 1980; 261-287.

18. Lippman-Hand A. Genetic Counseling and human reproductive loss. In: Porter 1H, Hook EB (eds), Human embryonic and fetal death. New York: Academic Press, 1980; 299-314.

19. Warburton $D$, Kline J, Stein Z, Hutzler M, Chin A, Hassold T, Does the karyotype of a spontaneous abortion predict the karyotype of a subsequent abortion? Evidence from 273 women with two karyotyped spontaneous abortions. Am.J.Hum.Genet. 1987; 41; 465-483.

20. Lijnschoten wan G, Arends JW, Fuente de la AA, Schouten HJA, Geraedis JPM. Intra- and interobserver variation in the interpretation of histological features suggesting chromosomal abnormality in early abortion specimens. Histopathology 1993; 22; $25-29$.

21. Sackett DL, Haynes RB, Tugwell P. Clinucal Epidemiology: A Basic Science for Clinical Medicine. Boston: Little, Brown and Company. 1985; 108-124.

22. Diem K. Lentner C. Wissenschaftliche Tabellen. Basel, Ciba-Geigy. 1976; 85-103. 



\section{A morphometric approach to the relation of karyotype, gestational age and histological features in early spontaneous abortions}

G van Lijnschoten, JW Arends, FBJM Thunnissen, JPM Geraedts. Placenta, in press.

Previous studies revealed that chorionic villus size and proliferation of trophoblast were of little value as predictors of chromosomal abnormality. Since these findings might be due to the known intra- and inter-observer variation in histological assessments of early placentae, objective measurement of features might be more valuable to predict abnormal karyotype. Also, gestational age might influence structural development of villi in different karyotypes in a variable way, obscuring a possible relationship between features and karyotype. Therefore, villus size composed of stromal and trophoblastic tissues in 82 placentae were quantified using the point counting method and related the results to karyotype and gestational age. At the group level there appeared to be no difference in the median mean cross-sectional villus-, stromal- and trophoblastic area, trophoblast/stroma ratio and trophoblastic thickness between chromosomally normal and abnormal placentae. Of the abnormal placentae only triploid placentae showed areas larger than normal and other abnormal placentae. In respect of gestational age villous profile area increased with age in triploid placentae, but decreased in trisomic abortions. At the individual case level parameter values outside the 'normal' range appeared to be rather insensitive, but highly specific for the prediction of karyotypic aberrations, again mainly triploidy.

\section{Introduction}

The assumption exists that about one fifth of human conceptions is miscarried within the first trimester of pregnancy (Kline and Stein, 1985; Wilcox et al., 1988). Of the aborted pregnancies more than haif have chromosomal abnormalities, some of which, such as translocations and trisomy 13,18 and 21 , are important in view of the prognosis for next pregnancies (Boué and Boué, 1973; Alberman et al., 1975; Lauritsen, 1976; Kajii and Ferrier, 1978; Hassold, 1980;
Warburton et al., 1980; Lippman-Hand, 1980; Warburton et al., 1987). Therefore, it would seem to be worthwhile to try to detect these abnormal karyotypes in abortions for the purpose of genetic counselling. To this effect complete karyotyping stands as the method of choice. The costs as well as the required skills and logistics, however, hamper the efficiency of karyotyping in practice. Hence, alternative methods would be preferable such as the histological examination of abortion products. Against this background we previouslly studied 
the predictive value of several histological features for the presence of abnormal karyotypes (van Lijnschoten et al., in press). Only lacunar stromal hydrops, moderate to abundant trophoblastic hyperplasia and the presence of trophoblastic lacunae emerged as parameters of value in the prediction of abnormal karyotype, predominantly pointing to triploidy. It is conceivable that these disappointing findings are at least partly attributable to the inconsistency and poor reproducibility of the interpretation of most other histological features (van Lijnschoten et al., 1993a), claimed to be associated with abnormal karyotypes (Honore, Dill and Poland, 1976; Szulman et al, 1981; Philippe, 1986). In addition, villus architectural features might be related to gestational age in a variable way for different karyotypes, thus obscuring a possible relationship between histological features and karyotype.

Therefore, the purpose of the present study was to quantify size of the chorionic villus and amount of trophoblast in relation to karyotype and gestational age using a simple morphometric procedure. To this end the point counting method as described by Weibel (1979, 1980), Gundersen and Østerby (1981a), Gundersen, Boysen and Reith $(1981 \mathrm{~b})$ and Mayhew (1983) was chosen. Recently, this method has been employed to assess the elaboration and maturation of placental villi (Jauniaux et al., 1991; Jackson, Mayhew and Boyd, 1992).

\section{Material and methods}

\section{Material}

During a two year period 83 early spontaneous abortions were collected. Gestational age corrected for menstrual cycle length at final pregnancy loss ranged from 45 to 126 days (mean 83 days, median 79 days). In 69 of 83 cases dilatation and curettage was performe Each specimen was stored in Hank medium at room temperature and exam ined macroscopically. Of the tissue suspected to be of non-maternal origir i.e. chorionic villi, chorion, amnion embryo or fetus, cell cultures for chro mosome analysis were made. The re maining material was fixed in $4 \%$ for malin, processed and embedded in par. affin. Of each specimen $4 \mu \mathrm{m}$ sections were cut and stained with haematoxylin and eosin for qualitative analysis, as previously described (van Lijnschoten et al., in press). To enhance the contrast of stromal and trophoblastic tissues for morphometric analysis the sections were subjected to haematoxylin only.

\section{Cytogenetic analysis}

In short the procedure was performed as follows: the selected tissues were cut in pieces of about $1 \times 1 \times 0.5 \mathrm{~mm}$ and incubated in HAM-F10 $+20 \%$ fetal calfserum $+0.3 \%$ L-glutamine $+1 \%$ penicillin/streptomycin at $37^{\circ} \mathrm{C}$ with $5 \%$ $\mathrm{CO}_{2}$. If sufficient numbers of cells were present metaphases were arrested with 4\% Colcemid during $3-4$ hours. Cell suspensions were hypotonically treated with $0.075 \mathrm{M} \mathrm{KCl}$ and fixed by 3 washes of methanol:acetic acid $3: 1$ and 3 washes with methanol:acetic acid:aquadest 3:1:4. After centrifugation cell suspensions were dropped on clean slides and G-banded. At least ten cells of different clones were analyzed.

Normal karyotype was found in 31 specimens. The chromosomal abnormalities demonstrated in the other specimens were trisomy $(\mathrm{n}=24)$, unbalanced translocations $(\mathrm{n}=8)$, triploidy $(\mathrm{n}=13)$, monosomy $X(n=5)$ and tetraploidy $(n=2)$. One of the unbalanced translocations was excluded from morphometry as described below. The nature of trisomies is listed in table 1. 
Table 1. Types of trisomy. In the first collumn the extra chromosome is given. The number of specimens concerned is on the right.

\begin{tabular}{cc}
\hline Chromosome & Number \\
\hline 16 & 9 \\
15 & 3 \\
18 & 2 \\
22 & 2 \\
2 & 1 \\
8 & 1 \\
10 & 1 \\
13 & 1 \\
14 & 1 \\
17 & 1 \\
21 & 1 \\
$15+21$ & 1 \\
Total & 24 \\
\hline
\end{tabular}

\section{Morphometry}

For quantification of the studied histological features the point counting method as described by Weibel (1979, 1980), Gundersen and Osterby (1981a), Gundersen et al. (1981b) and Mayhew (1983a) was used. The microscopic images were projected on a screen (objective $6.3 \times$; NA 0.16$)$. A 100 points Weibel grid drawn on a transparent sheet was superimposed. At final magnification the total surface area of the grid represented $0.92 \mathrm{~mm}^{2}$ (field) and each point $0.0092 \mathrm{~mm}^{2}$ at section level. According to the Delesse principe, the cross-sectional areas are representative for volumes (Weibel; 1979). In each specimen the following features were counted: number of villi and number of points on stromal and trophoblastic tissues. Chorionic villi transecting or hitting the right or lower border of the grid or its extensions were not included in the number of villi counted. However, for the point counting all points were counted inside the grid even if they were superimposed on not counted villi (Gundersen, 1977, Gundersen et al., 1988). Excluded from measurement were villi without a surrounding tropho- blastic layer. To avoid selection bias the measurements started with the chorionic vilus closest by the upper rim of the slide. In general, every other field in every other row was counted while screening the slide in a meander fashion. The progressive mean (summation average) and standard deviation were calculated in 7 slides. Statistical stability, defined as a stable progressive mean and standard deviation in plots for all parameters, was reached in all specimens after counting 50 villi or 2000 points. Thus in each specimen 25 fields were counted, containing at least 50 chorionic villi. If necessary more fields were counted to reach the number of 50 villi. If less than 25 fields were present, the specimen was considered sufficient if at least 50 chorionic villi were scored. One calse with an unbalanced translocation was discarded from further evaluation since the number of villi was insufficient.

Counting was performed in a "blind" fashion, i.e. the morphometric observer was unaware of the gestational age and the chromosomal constitution of the specimens.

\section{Parameters}

From the counted features five parameters were calculated with the formula shown in table 2: mean chorionic villous profile area consisting of stroma and trophoblast areas; trophoblast/stroma ratio and trophoblastic thickness. The trophoblastic thickness was estimated using a circular model, chorionic villi being considered as circles. The difference between the radii calculated for mean stromal surface and mean total surface (stromal and trophoblastic) (Area $=\pi r^{2}$ ), was taken to be the trophoblastic thickness in this model.

\section{Statistical analysis}

The term 'mean' was used to denote feature values at specimen level. The 
Table 2. The quantitative parameters and their formula

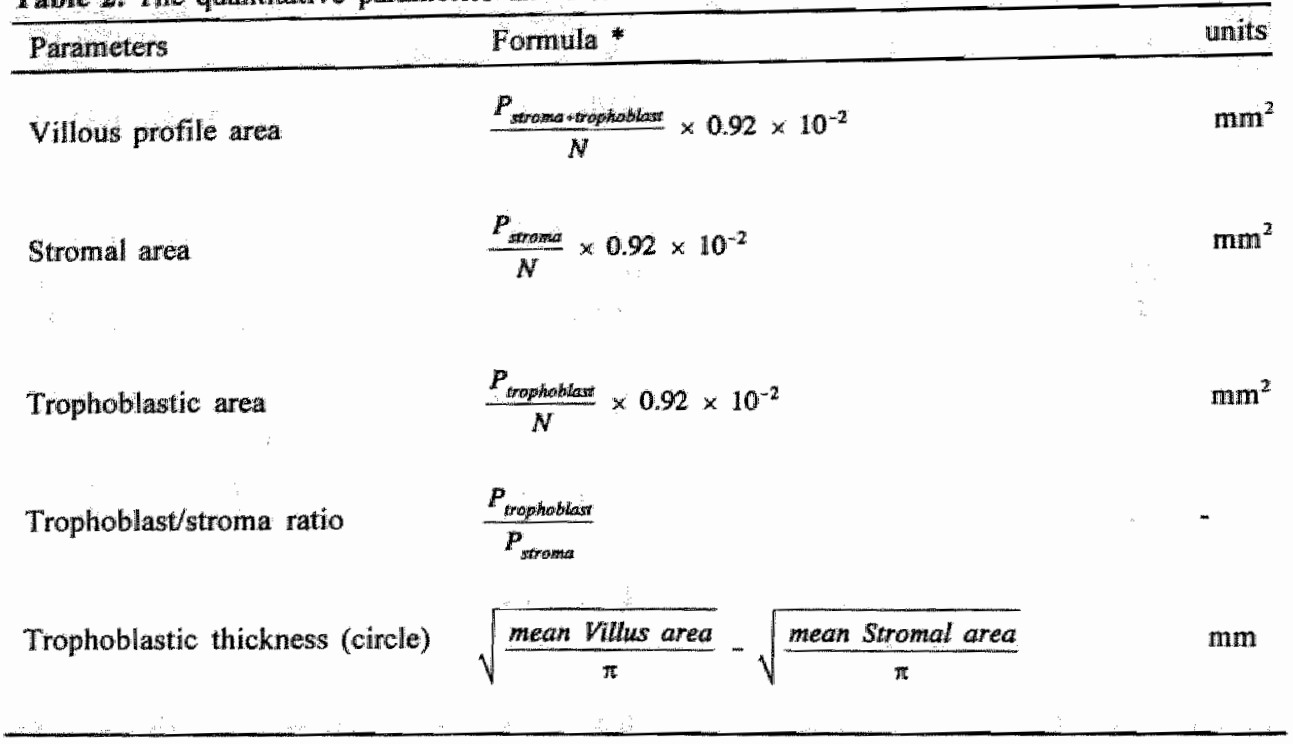

* $=$ number of points hitting tissues (stroma and/or trophoblast, given in subscript), $N=$ number villi counted.

intra-observer variation was estimated by counting one slide randomly chosen 10 times on different days and computing the coefficients of variation (CV). The $\mathrm{CV}$ was defined as square root of variance divided by the mean or standard error of the mean divided by the mean times 100\% (Weibel, 1979). These $\mathrm{CVs}$ for mean villous profile area, stromal area, trophoblast area, trophoblast fraction, trophoblast/stroma ratio and trophoblastic thickness were $3.0 \%$, $3.4 \%, 3.4 \%, 2.2 \%, 3.1 \%$ and $0.1 \%$ respectively. Therefore, the reproducibility of counting was considered to be high. Variation in sampling, expressed as difference between slides of the same or different blocks of a specimen, was investigated by repeating the sampling in 12 cases. Concerning chromosomal constitution four cases showed a normal, six a trisomy, one an unbalanced translocation and one a triploid karyotype, whereas, gestational age ranged from 58 to 102 days (median 76.5 days). Also, the relationship between variation size and karyotype or gestational age $\mathrm{w}$ examined for these 12 cases (onew analysis of variance). Of the specime used for estimating the reproducibility counting and sampling variation, $t$ examination with the lowest number the series was taken for the further it vestigations.

Firstly, the relationship between karyc type and histological feature was exan ined. The median values for each $\mathrm{p}$ rameter for the chromosomally norma and abnormal group as a whole wer computed and compared (Mann-Whitney $U$ test, SPSS/PC+). This nonparametric test was chosen as the distribution o values was skewed to the higher values There were no differences in distribution between the normal and the abnormal karyotype group.

Subsequently, the abnormal group was divided according to the type of chromosomal aberration into trisomy, unbalanced translocation, triploidy, monosomy $\mathrm{X}$ and tetraploidy and again the average values with standard deviations 
were computed. Each of these groups was compared with the normal karyotype group. The hypothesis that two groups were equal was tested with Mann-Whitney $U$ test corrected for ties. In case of $p$-values $<0.05$, indicating that the groups were not equal, the hypothesis was rejected. The Kruskal-Wallis oneway analysis of variance was used to examine the distribution of gestational age over the six chromosomal groups. There were no differences between the normal, the trisomic and other chromosomal aberrations as shown in figure 1 . Then the predictive value of the absolute values of the studied parameters for the detection of normal and chromosomally abnormal placentae was analyzed using the $95 \%$ interval around the median values for the chromosomally normal placentae as the normal range and designating values outside the $95 \%$ interval as extreme. Secondly, the correlation between each parameter and gestational age corrected for menstrual cyclle length was investigated for the types of chromosomal patterns with at least 10 cases in the series (normal, trisomy and

Figure 1. Distribution of gestational age over the different groups of chromosome pattern: normal karyotype (1), trisomy (2), unbalanced translocation (3), triploidy (4), monosomy X (5) and tetraploidy (6). The median is given by $t$. $p=0.66$

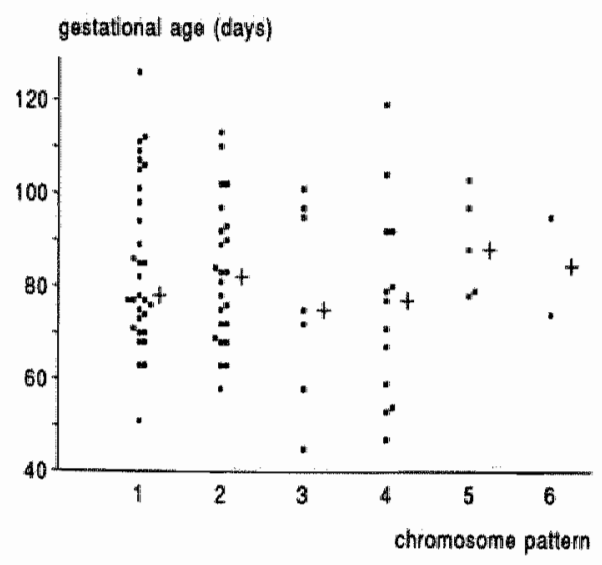

triploidy) using Pearson correlation coefficients. According to the literature villus surface areas and gestational age are logarithmically related. Therefore, the logarithmic of mean cross-sectional villous profile area, stromal area and trophoblastic area was analyzed. Statistical significance had to be $<0.01$ to conclude that the studied parameter was related with gestational age.

\section{Results}

\section{Biologic variation}

Table 3 compiles the coefficients of variation (CV) for the 12 cases, in which sampling variation was analyzed. As seen from this table CV demonstrated a wide range for all parameters measured indicating considerable heterogeneity of villus, stromal and trophoblastic area as well as trophoblastic/stroma ratio and trophoblastic thickness in the different areas of a specimen.

Quantitative parameters in normal versus abnormal karyotypes

In table 4 the median values and ranges of the quantitative parameters for placentae with normal versus abnormal karyotype as well as for the different karyotypic abnormalities are compiled. No significant differences were found between the normal placentae and the abnormal placentae taken together. In regard of the different karyotypic abnormalities only triploid abortions demonstrated significantly larger villus, stromal and trophoblastic areas than the normal placentae. No differences in the parameter values were found for the other chromosomal abnormalities. The trophoblastic/stroma ratio and trophoblastic thickness were equal for all groups.

Figure 2 shows the distribution of parameter values of all individual cases distincted according to karyotype to- 
Table 3. Coefficients of variation for the 12 specimens sampled repeatedly

\begin{tabular}{lcc}
\hline Feature & median & range \\
\hline Villous profile area & 7.9 & $1.8-14.4$ \\
Stromal area & 7.8 & $3.9-16.4$ \\
Trophoblastic area & 8.3 & $2.4-17.0$ \\
Trophoblast/stroma ratio & 7.4 & $0.7-30.3$ \\
Trophoblastic thickness & 6.2 & $0.6-231$ \\
\hline
\end{tabular}

gether with group medians. The grey area represents the $95 \%$ interval around the median of the values for the cases with a normal karyotype. If the upper border of the $95 \%$ interval of the normal karyotype abortions is taken as cut off value, 1 normal, 2 trisomic and 5 triploid abortions showed extremely high villous profile areas. Thus 7 out of 8 extreme cases were of abnormal karyotype. Stromal areas larger than the cut off value were found in 1 normal, 2 trisomic and 5 triploid abortions, implying that 7 out of 8 were of abnormal karyotype. Values for trophoblastic area above the upper limit were found in 10 cases, 1 with normal and 9 with abnormal karyotype. In 6 cases a triploid karyotype was present. The abnormal values for villus, stromal and tropho- blastic area were found in $\mathbf{1 1}$ different specimens (2 normal, 3 trisomy, 6 triploidy). In 7 cases ( 2 trisomic and 5 triploid) all three parameters were of extreme high value, thus raising the posterior chance of chromosomal abnormallity from $62 \%$ (prior chance $51 / 82$ ) to $100 \%$.

Of the triploid cases with increased trophoblastic area 5 out of 6 had a trophoblast/stroma ratio at or below the group median for triploidy, wo even below the lower cut off point, implying more stromal than trophoblastic increase in these cases. Two of these 6 triploid cases had a slightly raised and 1 had an extremely raised trophoblastic thickness. All other triploid cases had normal values for trophoblast/stroma ratio and trophoblast thickness. One of the trisomic cases had both an extreme high value for trophoblastic/stroma ratio and trophoblastic thickness.

Quantitative parameters related to geslational age

Figure 3 depicts the distribution of logarithmic trophoblastic area for normal, trisomic and triploid karyotype. As can

Table 4. The median values and ranges are shown for each group. The numbers of specimens are given in brackets. The areas have to be multiplied $10^{-2}$ to get the real size in $\mathrm{mm}^{2}$. The trophoblastic thickness has to be multiplied with $10^{\text {*a }}$ to get real size in $\mathrm{mm}$.

\begin{tabular}{lcccccccc}
\hline & & & \multicolumn{5}{c}{ A.bnomal } \\
\cline { 5 - 8 } Parameters & Normal & Abnormal & trisomy & unb.trl. & triploidy & 45, Xo & tetraploidy \\
& $(31)$ & $(51)$ & $(24)$ & $(7)$ & $(13)$ & $(5)$ & $(2)$ \\
\hline Villous profile area & 2.5 & 2.9 & 2.9 & 2.3 & $5.3^{*}$ & 2.9 & 2.4 \\
& $(1.3-6.6)$ & $(1.2-10.4)$ & $(1.3-8.1)$ & $(1.3-5.5)$ & $(1.4-10.4)$ & $(1.2-3.6)$ & $(2.3-2.4)$ \\
Stromal area & 1.8 & 2.0 & 1.9 & 1.5 & $4.4^{*}$ & 2.2 & 1.6 \\
Trophoblastic area & $(0.9-5.2)$ & $(0.7-8.8)$ & $(0.8-6.5)$ & $(0.7-1.4)$ & $(0.9-8.8)$ & $(0.8-2.7)$ & $(1.6-1.7)$ \\
Trophoblast/stromat ratio & 0.8 & 0.8 & 0.8 & 0.6 & $1.2^{*}$ & 0.7 & 0.7 \\
Trophoblastic thickness & $(0.4-1.4)$ & $(0.4-2.6)$ & $(0.4-1.6)$ & $(0.5-1.4)$ & $(0.5-2.6)$ & $(0.5-0.9)$ & $(0.6-0.9)$ \\
& $(0.2-0.8)$ & 0.4 & $0.2-0.9)$ & $(0.2-0.9)$ & $(0.3-0.8)$ & $(0.2-0.5)$ & $(0.3-0.6)$ & $(0.3-0.6)$ \\
& 1.4 & 1.5 & 1.4 & 1.5 & 1.6 & 1.3 & 1.4 \\
& $(0.9-2.2)$ & $(1.0-2.7)$ & $(1.0-2.7)$ & $(1.1-1.8)$ & $(1.1-2.5)$ & $(1.2-1.6)$ & $(1.1-1.7)$ \\
\hline
\end{tabular}

* these parameters are statistically different between normal and triploid group ( $p$-value $<0.01$ ). 
mean chotionic villous profile area (mm2)

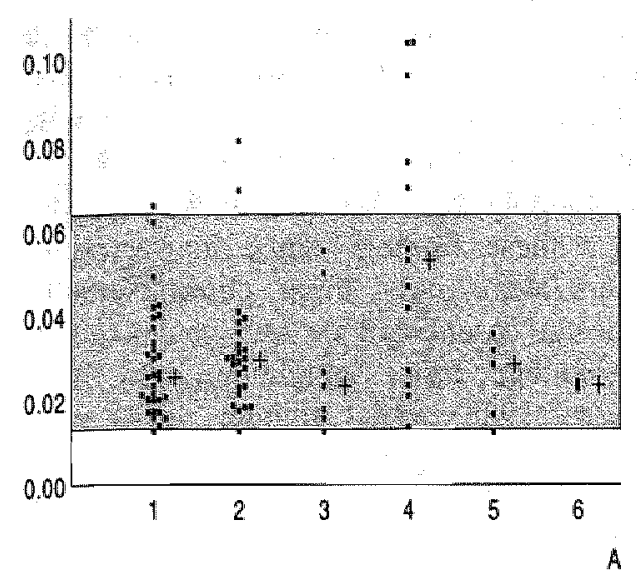

A

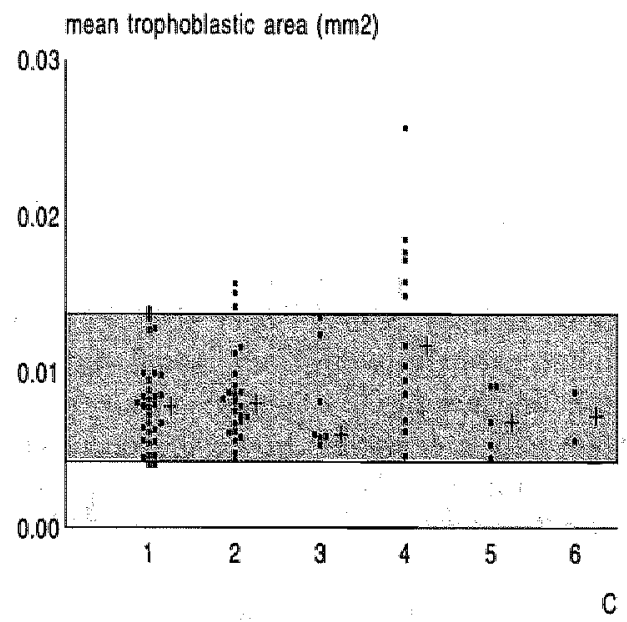

mean trophoblastic thickness (mm)

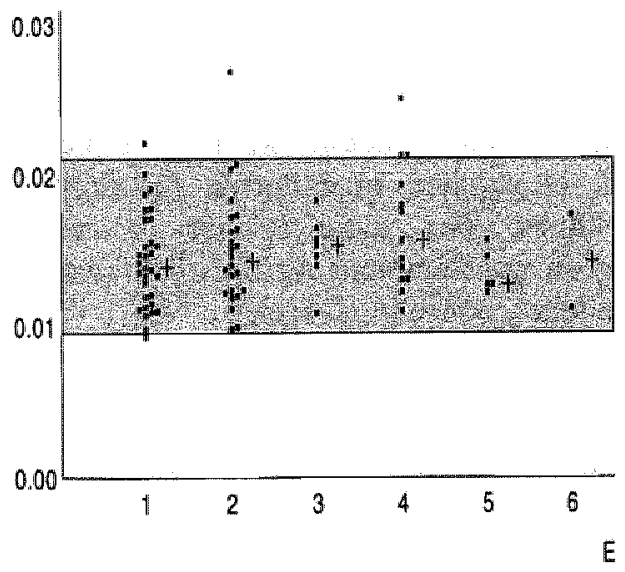

mean stromal ares (mme)
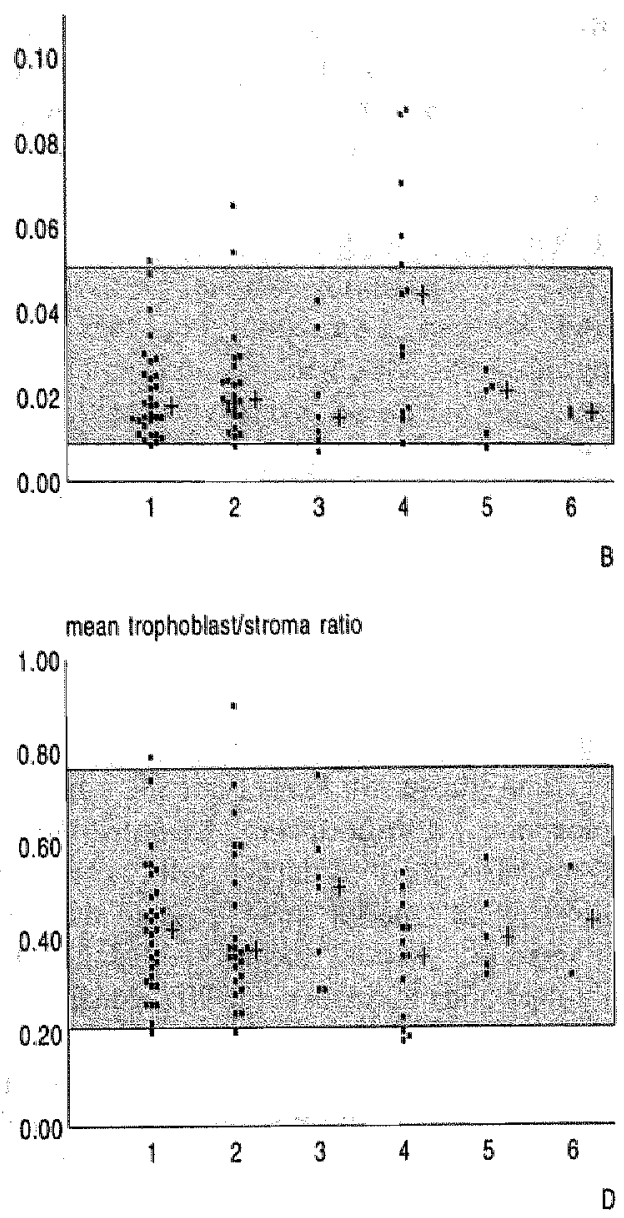

Figure 2. At the horizontal axis the specimens are grouped as follows: 1 normal karyotype, 2 trisomy, 3 unbalanced translocation, 4 triploindy, 5 monosomy $X$ and 6 tetraploidy. At the vertical axis the mean chorionic villous profile area(A), mean stromal area(B), mean trophoblastic area(C), mean trophoblast/stroma ratio(D) and mean trophoblastic thickness(E) are given. 
be seen, in normal karyotype no alteration of trophoblastic area is shown over the examined gestational period. Logarithmic mean trophoblastic area significantly decreases in trisomic placentae, whereas contrastingly, in triploid placentale mean trophoblastic area increases. Table 5 shows that the same trends are seen for chorionic villous profile area and stromal area, implying that both parameters diminish in trisomic and enlarge in triploid karyotypes with gestational age.

\section{Discussion}

From his studies Philippe (1973) concluded that, irrespective of gestational age, villi of triploid placentae were larger than those of karyotypically normal placentae. Furthermore, trisomic abortions also showed larger villi, although these were smaller than those of triploid placentae. More recently, Röckelein, Ulmer and Schröder (1990) confirmed these observations.

In the present study, on the group level, median villous profile, stromal and trophoblastic areas were found to be increased in triploid abortions only. In normal abortions we could not demonstrate an influence of gestational age on villous profile area. However, villous profile areas in triploid placentae increased with longer duration of pregnancy. Villi of trisomic cases, in contrast, appeared to decrease in size with longer duration of pregnancy. The decrease of villous profile areas in trisomic cases during the first trimester of pregnancy in our analysis is remarkable since all different types of trisomy showed the same phenomenon suggesting a rather uniform mechanism of growth and development of placental villi.

The relationship between gestational age and chorionic villus size for differ- ent karyotypic groups has also bee investigated by Philippe (1973). H studly indicated that the diameter o chorionic villi of karyotypically norms placentae was smaller in spontaneou abortions of 8 weeks than of 5 week gestational age. We are unable to con firm these findings since in our serie there were only three chromosomally normal cases of 8 or less weeks gesta tional age. Stoz, Schuhmann and Sche besta (1988) found smaller villus size: in spontaneous abortions of 14-18 week: than in induced abortions of less than 14 weeks of gestation. These differences might be the result of unknown differ. ence in karyotype distribution in both groups or by the nature of the abortions, i.e. spontaneous or induced.

In the present study, on the individual case level, area parameter values above the median $+47.5 \%$, were associated with mainly triploidy and a few trisomy cases. Rehder et al. (1989) also found a higher probability for abnormal karyotype on the basis of large villus size. Such extreme values, however, occurred rather infrequently $( \pm 10 \%)$ in our series and, therefore, appear to be insensitive predictors of abnormal karyotype. Although in some cases with trisomy extreme values for the parameters were observed, the prevalence of these values did not exceed that of normal abortions. To our opinion, therefore, it is not possible to reliably detect trisomy by means of the studied quantitative histological features. The same applies to unbalanced translocations being of interest to genetic counselling, also.

More detailed analysis revealed that increase of villous profile area in triploidy was due to enlargement of the stromal as well as the trophoblastic component with predominance of the former. The increase in trophoblastic area was not associated with an increase or decrease in thickness, indicating that 
Normal karyotype

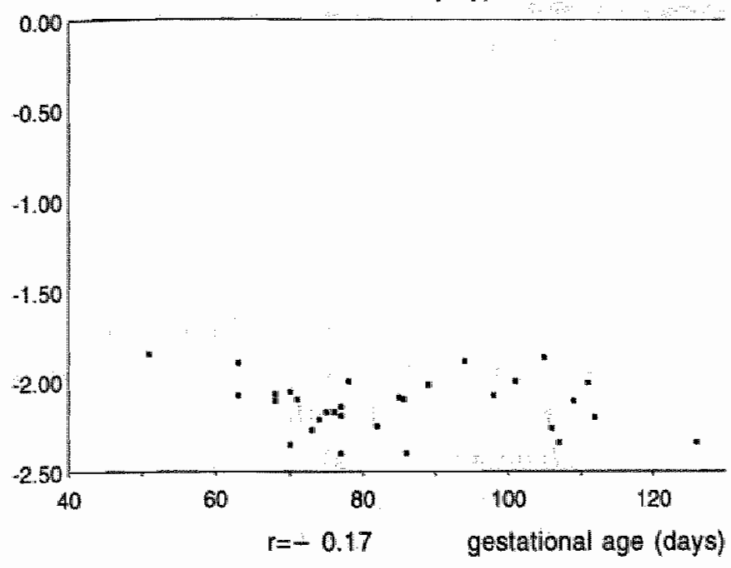

Trisomy

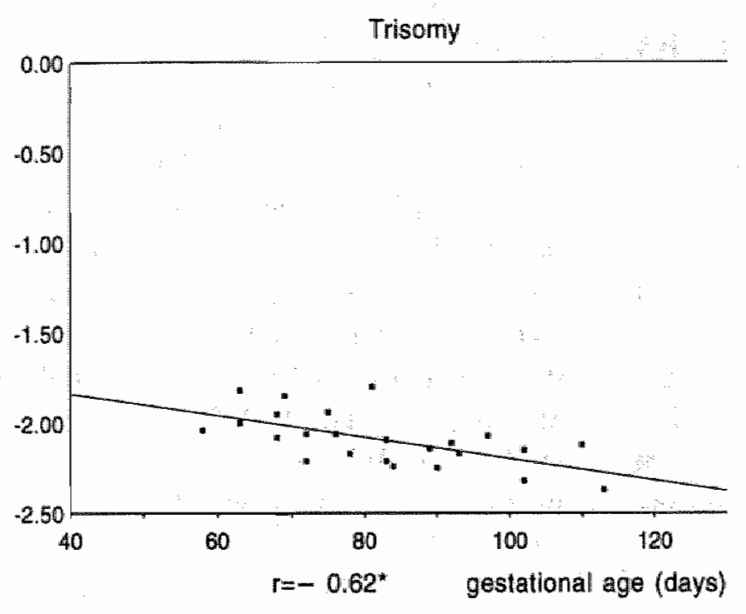

Triploidy

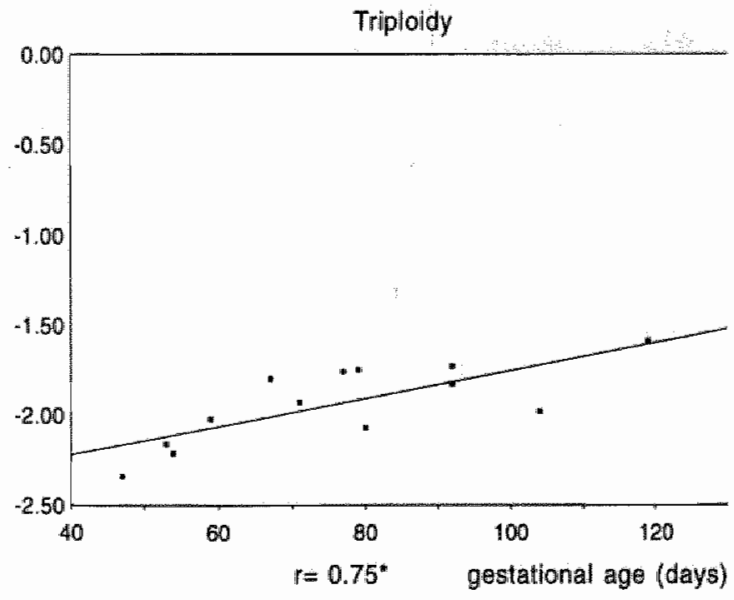

Figure 3. Relation between gestational age corrected for menstrual cycle length ( $\mathrm{X}$-axis, days) and logarithmic of mean trophoblastic area ( $Y$-axis) for normal karyotype, trisomy and triploidy. Regression lines are drawn and Pearson correlation coefficients are given.

$*=\mathrm{p}<0.01$ 
Table 5. Pearsion correlation coefficients for the relationship between gestational age and logarithmics for the three parameters listed for normal karyotype, trisomy and triploidy

\begin{tabular}{lrcc}
\hline Parameter & Nomal & Trisomy & Triploidy \\
\hline $\log ($ chorionic villous profile area) & 0.10 & $-0.59^{*}$ & $0.70^{\star}$ \\
$\log ($ stromal area) & 0.17 & $-0.53^{*}$ & $0.67^{\text {*t }}$ \\
$\log ($ trophoblastic area) & -0.17 & $-0.62^{*}$ & $0.75^{\text {* }}$ \\
\hline
\end{tabular}

$*=0.01$

increase in trophoblast volume is proportional to the enlargement of villi. Therefore, to our opinion, there is no true hypertrophy of trophoblast in triploidy. Since our conclusions are based on mean values, our method does not rule out irregularity of trophoblastic growth. The mechanisms behind the increase of villous profile area in triploidy remain to be elucidated, but in this context it is interesting that triploid pregnancies are associated with high initial human chorionic gonadotrophin levels in the maternal serum (Bogart et al., 1989).

There are methodological and biological explanations to account for the discrepancies observed between our data and those of other authors. Methodological aspects concern differences in fixation and processing of tissue, which within a study can only result in a systemic error, but in comparison with other studies may lead to different parameter values (Mayhew, 1988).

Since in the present study placentae of early spontaneous abortions derived by curettage or spontaneous expulsion were often incomplete when sent to laboratory, two dimensional parameters were calculated without attempting to extra- polate these to three dimensional characteristics. This made the comparison of our data with those of Boyd (1984), Jauniaux et al. (1991) and Jackson, Mayhew and Boyd (1992), who studied three dimensional data, difficult. A biological factor shown in our study, is the variation due to sampling. The range of values obtained for different samples from the same placenta demonstrated a sizeable heterogeneity of histologic features in different areas in some placentae. Such heterogeneity is more readily appreciated and accounted for in qualitative assessments. This also explains the discrepancies between our qualitative and quantitative data. In the qualitative study size did not discriminate between normal and abnormal karyotype (van Lijnschoten et al., 1993), whereas the quantitative data denoted that larger villous profile areas correspond with abnormal karyotype.

We conclude that simple morphometric measurements appear to be of little diagnostic value, since analysis showed chorionic villous profile, stromal and trophoblastic areas to be rather insensitive, but highly specific predictors for abnormal karyotype, mainly pointing to triploidy.

\section{References}

Alberman, E., Elliott, M., Creasy, M. \& Dhadial, R. (1975) Previous reproductive history in mothers presenting with spontaneous abortions. British Journal of Obstetrics and Gynaecology, 82, 366-373.

Bogart, M.H., Golbus, M.S., Sorg, N.D. \& Jones, O.W. (1989) Human Chorionic Gonadotropin levells in pregnancies with aneuploid fetuses. Prenaral Diagnosis, 9, 379-384.

Botue, J. \& Boue, A. (1973) Chromosomal analysis of two consecutive abortuses in abortuses in each 
of 43 women. Humangenetik, $19,275-280$.

Boyd, P.A. (1984) Quantitative structure of the normal human placenta from 10 weeks of gestation to term. Early Humam Development, 9, 297-307.

Gundersen, HJ.G. (1977) Notes on the estimation of the numerical density of arbitrary profiles the edge effect. Journal of Microscopy, 11, part 2, 219-223.

Gundersen, HJ.G. \& Osterby, R. (1981a) Optimizing sampling efficiency of stereological situdies in biology: or 'Do more less welll' Joumal of Microscopy, 121, part 1, 65-73.

Gundersen, H.J.G., Boysen, M. \& Reith A. (1981b) Comparison of Semiautomatic Digitizer-Tablet and Simple Point Counting Performance in Morphometry. Wirchows Archives B (Cell Pathology) 37,317 325 .

Gundersen, H.J.G., Bendtsen, T.F., Korbo; L., Marcussen, N., Molller, A., Nielsen, K., Nyengaard, J.R., Pakkenberg, B., Serensen, F.B., Vesterby, A. \& West, M.J. (1988) Some new, simple and efficient stereological methods and their use in pathological research and diagnosis. APMIS, 96, 379-394.

Hassold, T.J. (1980) A cytogenetic study of repeated spontaneous abortions. American Journal of Human Genetics, 32, 723-730.

Honoré, L.H., Dill, F.J. \& Poland B.J. (1976) Placental morphology in spontaneous human abortuses with normal and abnormal karyotypes. Teratology, 14, 151-166.

Jackson, M.R., Mayhew, T.M. \& Boyd P.A. (1992) Quantitative description of the elaboration and maturation of villi from 10 weeks of gestation to term. Placenta, 13,357-370.

Jauniaux, E., Burton, G.J., Moscoso, G.J. \& Hustin, J. (1991) Development of the Early lifuman placenta: A Morphometric Study. Placenta, 12, 269-276.

Kajii, T. \& Ferrier, A. (1978) Cytogenetics of aborters and abortuses. American Journal of Obstetrics and Gynecology, 131,33-38.

Kline, J. \& Stein, Z. (1985) Very early pregnancy. In Reproductive Toxicology (Ed.) Dixon, R.L. pp. 251-265. New York: Raven Press.

Lauritsen, J.G. (1976) Aetiology of spontaneous abortion: a cytogenetic and epidemiological study of 288 abortuses and their parents. Acta Obstetricia ef Gynecologica Scandinavica, supplement 52 , 1 . 29.

Lippman-Hand, A. (1980) Genetic counseling and human reproductive loss. In Human embryonic and fetal death (Ed.) Porter, I.H. \& Hook, E.B. pp. 299-314. New York: Academic Press.

Lijnschoten van, G., Arends, J.W., Fuerite de la, A.A., Schouten, H.J.A. \& Geraedts, J.P.M. (1993) Intra-and inter-observer variation in the interpretation of histological features suggesting chromosomal abnormality in early abortion specimens. Histopathology, 22, 25-29.

Lijnschoten van, G., Arends, J.W., Leffers, P., Fuente de la, A.A., Looij van der, H.J.A.M. \& Geraedts, J.P.M. (1993) The value of histomorphological features of chorionic villi in early spontaneous abortion for the prediction of karyotype. Histopathology, 22, 557-563

Mayhew, T.M. (1983) Stereology: Progress in quantitative microscopical anatomy. In Progress in Anatomy (Ed.) Navaratman, N.V. \& Harrison, R.J. Volume 3, pp. 81-112. Cambridge: University Press.

Mayhew, T.M. \& Burton, G.J. (1988) Methodological Problems in Placental Morphometry: Apologia For the use of Stereology based on Sound Sampling Practice. Placenta, $9,565-581$.

Philippe, E. (1973) Consequences des anomalies chromosomiques sur le developpement. In Les accidents chromosomiques de la reproduction (Ed.) Boué, A. \& "Thibault, C. pp. 119-126. Paris: INSERM.

Philippe, E. (1986) Pathologie Foeto-placentaire pp. 108-128. 2nd ed. Paris: Masson.

Rehder, H., Coerdt, W., Eggers, R., Klink, F. \& Schwinger, E. (1989) Is there a correlation between morphological and cytogenetic findings in placental tissue from early missed abortions? Human Genetics, 82,377-385.

Röckelein, G., Ullmer, R. \& Schröder, J. (1990) Karyotype and placental structure of tirst-trimester spontaneous abortions: a morphometrical study. European Journal of Obstetricis \& Gynecology and Reproductive Biology, 38, 25-32.

Stoz, F., Schuhmann, R.A. \& Schebesta B. (1988) The Development of the Placental Villus During Normal Pregnancy: Morphometric Data Base. Archives of Gynecology and Obstertics, 244: 23-32.

Szulman, A.E., Philippe, E., Boué, J.G. \& Boué A. (1981) Human triploidly: association with partial hydatidiform moles and nonmolar conceptuses. Human Pathology $12,1016 \mathrm{~m} 1021$.

Warburton, D., Stein, Z., Kline, J. \& Susser, M. (1980) Chromosome abnormalittes in spontaneous 
abortion: data from the New York city study. In Humar embryonic and fetal death (Ed.) Porter, IH. \& Hook, EB. pp 261-287. New York: Academic Press.

Warburton, D., Klime, J., Stein, Z, Hutzler, M., Chin, A. Hassold, T. (1987) Does the karyotype of a spontaneous abortion predict the karyotype of a subsequent abortion?- Evidence from 273 women with two karyotyped spontaneous abortions. American Jourmal of Hunam Genetios, 41, 465-483.

Weibel, E.R. (1979) Stereological methods. Volume 1. Practical Methods for Biological Morphometry. London: Academic Press.

Weibel, ER. (1980) Stereological methods. Volume 2. Theoretical Foundations: London: Academic Press.

Wilcox, A.J., Weinberg, C.R. O'Connor, J.F., Baird, D.D., Schlatterer, J.P., Canfield, R.E, Armstrong, E.G. \& Nisula, B.C. (1988) Incidence of early loss of pregnancy. New England Journal of Medicine, $319,189.194$. 


\title{
Comparison of histological features in early spontaneous and induced trisomic abortions
}

\author{
G van Lijnschoten, JW Arends, JPM Geraedts, Submitted for publication.
}

Qualitative and quantitative histological features of a series of induced $(n=6)$ and spontaneous $(n=24)$ trisomic abortions were compared. The chorionic villi of induced abortions were large and of irregular contour. The stroma contained many blood vessels and did not show fibrohyalinic change. The intact trophoblast demonstrated 'hyperplasia'. Contrastingly, spontaneous abortions were composed of smaller villi with somewhat inore fibrohyalinic stroma containing a few blood vessels. The trophoblast did not show "hyperplasia' "However, many syncytial knots were present. Although some of histological features were shown to relate to gestational age, which could not be completely matched for, it was unlikely that duration of pregnancy could account for the observed differences. Analysis restricted to induced and spontaneous abortions of comparable gestational age demonstrated the same differences. The time-lag between first blood loss and final gestationall loss in spontaneous abortions only appeared to be of influence on the degree of hydrops and the integrity of the trophoblastic layer. Longer time-lags were associated with less hydrops and more frequent loss of trophoblastic continuity. The striking thistopathological differences between induced and spontaneous abortions are mainly considered to be due to cessation of circulation at some time and to disintegration of trophoblast as a result of ischaemia in spontaneous abortions.

\section{Introduction}

In previous studies we analyzed observer variation and predictive value of histological features claimed to be associated with abnormal karyotype in abortions (van Lijnschoten et al., 1993a,b). These analyses yielded greatly varying data on the studied parameters amongst three observers and led to the conclusion that only the presence of trophoblastic lacunae, severely hydropic stroma and moderate to abundant trophoblastic hyperplasia appeared to be rather reproducible scoring items, being at the same time predictive of abnormal karyotype. However, triploidy was the karyotype almost exclusively detected. Amongst our series of abortions 6 cases of induced abortion with trisomic karyotype featured and these showed a striking homogeneity in histological appearance as scored by the observers. Such uniformity in observation at first hand was not apparent in the spontaneous abortions with trisomic karyotype. It was hypothesized that the heterogeneity in morphology of spontaneous abortions could be the reflection of the time-lag between first blood loss and final expulsion. This report, therefore, compares the histological appearances and morphometric data on a set of 6 induced and 24 spontaneous trisomic abortions and tries to explain the observed differences. 


\section{Materials and Methods}

In an extensive study to analyze the relation between histologica! features and karyotype a consecutive series of 99 spontaneous and 10 induced abortions was assembled over a two years period. Details about the karyotypic analysis as well as hisstological preparation and assessment have been reported previously (van Lijnschoten et. al. 1993 a,b).

Briefly, the series was assessed for all items compiled in table 1 by three independent observers. By syncytial knots was meant the aggregation of nuclei in the syncytiotrophoblast (Fox, 1967; Boyd \& Hamilton, 1970). Furthermore, the series was also subjected to morphometric analysis according the point counting method (Weibel, 1979,1980; Gunderson and Østerby, 1981; Gundersen et al., 1988; Mayhew, 1983). The mean chorionic villous profile area, mean stromal area, mean trophoblastic area, trophoblast/stroma ratio and trophoblastic thickness were measured (van Lijnschoten et. al., 1993c). Without knowledge of two observers about the inclusion of induced abortions, these were randomly distributed over the series. Yet, at final analysis the induced abortions appeared to have been scored rather homogeneously at first sight. This preliminary observation triggered a more detailed analysis of the histological differences between induced and spontaneous abortions. In order to exclude an influence of karyotype the 6 trisomic induced abortions were compared to the 24 trisomic spontaneous abortions present in the series.

The induced abortion group consisted of trisomy $21 \quad(n=4)$, trisomy $18 \quad(n=1)$ and $47, X X Y$ karyotype $(n=1)$. The spontaneous abortion group was composed of trisomy $16(n=9)$, trisomy $15(n=3)$, trisomy $22(\mathrm{n}=2)$, trisomy $18(\mathrm{n}=2)$ and $\mathbb{1}$ case of trisomy $21,2,8,10,13,14$ and
17 and 1 double trisomy of chromosome 15 and 21 .

The induced trisomic abortions were performed by dilatation and curettage $(n=5)$, in 1 case sustained by application of extra-amniotic prostaglandin $\mathrm{PGE}_{2}$, or by Sulprostone (Nalador ${ }^{\text {S) }}$ infusion $(n=1)$. In 20 of 24 spontaneous abortions curettage was performed.

For the induced abortions gestational age at induction ranged from 78 to 93 days with a median and mean of 83.5 days. Gestational age of the spontaneous abortions at final loss ranged from 58 to 113 days with a median of 82 and mean of 83 days. Thus, the gestational age for the induced abortion group did not match completely with the spontaneous abortion group. The time-lag between first vaginal blood loss and final loss ranged from 0 to 36 days with a median of 10 and mean of 12 days (in one spontaneous abortion the clinical symptoms were not available).

\section{Statistical analysis}

Firstly, both groups were compared by means of the non-parametric MannWhitney test $U$ not corrected for ties (SPSSPC) for both the qualitative and quantitative data. The hypothesis that both groups were equal was rejected in case of $p$-values $<0.05$. This non-parametric statistical test was employed because of the ordinal character of the qualitative data and the non Gaussian distribution of scores in the quantitative data. It was decided not to correct for ties because of the small number of induced abortions.

Features and gestational age

In order to analyze the influence of gestational age at final abortion on the qualitative items the rank correlation coefficients of Spearman were computed for the spontaneous abortion group. For this analysis the data of only one observer, not essentially different of those 
Table 1. In the first collumns the scores for induced abortions $(\mathrm{in}=6)$ and in the second columns for spontaneous abortions ( $n=24$ ) are given for the three observers

\begin{tabular}{|c|c|c|c|c|c|c|c|}
\hline \multirow{2}{*}{$y^{3}$} & \multirow{2}{*}{$\begin{array}{l}\text { observer } \\
\text { Number of cases }\end{array}$} & \multicolumn{2}{|c|}{1} & \multicolumn{2}{|c|}{ II } & \multicolumn{2}{|c|}{ III } \\
\hline & & 6 & 24 & 6 & 24 & 6 & 24 \\
\hline \multicolumn{8}{|l|}{ General } \\
\hline \multirow{2}{*}{ Shape } & regular & 0 & 15 & 0 & 8 & 0 & 9 \\
\hline & irregullar-very inregular & 6 & 9 & 6 & 16 & 6 & 15 \\
\hline \multicolumn{8}{|l|}{ Stromal characteristics } \\
\hline \multirow{3}{*}{ Bloodvessels } & few & 0 & 13 & 0 & 17 & 1 & 21 \\
\hline & moderate & 4 & 10 & 2 & 5 & 5 & 3 \\
\hline & abundant & 2 & 1 & 4 & 2 & 0 & 0 \\
\hline \multirow[t]{2}{*}{ Basophylic staining present } & yes & 3 & 1 & 1 & 5 & 5 & 9 \\
\hline & no & 3 & 23 & 5 & 19 & 1 & 15 \\
\hline \multirow[t]{2}{*}{ Pseudoinclusions } & none-few & 0 & 10 & 0 & 11 & 0 & 2 \\
\hline & moderate-abundant & 6 & 14 & 6 & 13 & 6 & 22 \\
\hline \multirow[t]{4}{*}{ Hydrops } & none & 1 & 10 & 0 & 7 & 0 & 2 \\
\hline & moderate & 5 & 13 & 1 & 13 & 5 & 12 \\
\hline & abundant & 0 & 1 & 4 & 4 & 1 & 8 \\
\hline & lacunae & 0 & 0 & 1 & 0 & 0 & 2 \\
\hline \multirow[t]{3}{*}{ Fibro-hyalinization } & none-moderate & 6 & 14 & 3 & 2 & 6 & 18 \\
\hline & intermediate & 0 & 8 & 3 & 14 & 0 & 2 \\
\hline & abundant: & 0 & 2 & 0 & 8 & 0 & 4 \\
\hline \multicolumn{8}{|l|}{ Trophoblastic characteristics } \\
\hline \multirow[t]{2}{*}{ Grossly intact } & yes & 6 & 24 & 6 & 21 & 6 & 19 \\
\hline & no & 0 & 0 & 0 & 3 & 0 & 5 \\
\hline \multirow[t]{2}{*}{ Trophoblastic hyperplasia } & yes & 5 & 10 & 6 & 17 & 5 & 9 \\
\hline & no & 1 & 14 & 0 & 7 & 1 & 15 \\
\hline \multirow[t]{2}{*}{ quantity } & none-little & 3 & 21 & 0 & 18 & 2 & 23 \\
\hline & moderate-abundant & 3 & 3 & 6 & 6 & 4 & 1 \\
\hline \multirow[t]{2}{*}{ Lacunae } & yes & 0 & 0 & 0 & 0 & 3 & 19 \\
\hline & no & 6 & 24 & 6 & 24 & 3 & 5 \\
\hline \multirow[t]{2}{*}{ Many syncytial knots } & yes: & 0 & 12 & 0 & 16 & 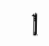 & 20 \\
\hline & no & 6 & 12 & 6 & 8 & 5 & 4 \\
\hline \multicolumn{8}{|l|}{ Intervillous space } \\
\hline \multirow[t]{3}{*}{ Fibrin deposits } & few & 0 & 2 & 2 & 2 & 4 & 10 \\
\hline & moderate & 6 & 22 & 2 & 6 & 2 & 8 \\
\hline & abundant & 0 & 0 & 2 & 16 & 0 & 6 \\
\hline \multirow[t]{2}{*}{ Many trophoblastic buds } & yes & 6 & 23 & 0 & $\| 1$ & 0 & 12 \\
\hline & no & 0 & 1 & 6 & 13 & 6 & 12 \\
\hline
\end{tabular}


from the others, were used for the purpose of simplification. The analysis was repeated for the time lag between first blood loss and final expulsion. Statistical significance was considered to be reached if $p<0,01$ as the number of specimens was small. Finally, for the qualitative items, shown to be gestational age dependent, the induced abortion group was compared to the spontaneous abortions of similar gestational age. For this analysis of qualitative data the MannWhitney $U$ test not corrected for ties was used. The hypothesis that both groups are equal was rejected if the pvalues were $<0.05$.

Age-dependency of the logarithmics of the mean chorionic villous profile area, mean stromal area and mean trophoblastic area in trisomic abortions was measured as described before (van Lijnschoten et. al., 1993c). In order to compare the data of the induced abortion group with spontaneous abortions of comparable age the t-test with separate variance estimates was used. For these selected data the distribution of values was comparable in both groups. Again the hypothesis that both groups are equal was rejected if $p$-values were $<0.05$.

\section{Results}

\section{Qualitative data}

From table 1 it can be seen that induced abortions show a homogeneous score on several items such as shape, number of pseudoinclusions, status of trophoblast, presence of trophoblastic hyperplasia and number of syncytial knots. In contrast, the scores in the spontaneous abortion group for these parameters appeared to be rather heterogeneous. Induced abortions demonstrated more blood vessels (Mann-Whitney, p-value 0.001), a higher degree of hydrops ( $p$-value 0.003 ), less fibro-hyalinization ( $p$-value
0.03 ), a larger amount of hyperplasia ( $P$ value 0.003 ) and less syncytial knots ( $p$ value 0.01 ) than spontaneous abortions.

In spontaneous abortions some of the studied items were found to be gestational age related (table 2). Hydrops decreased in older pregnancies and a more frequent loss of trophoblastic integrity was noticed. The number of syncytial knots increased with gestational age.

An influence of the period of regression could also be shown, in that less hydrops and more frequent loss of trophoblastic continuity were seen in gestations with a longer time-lag between first symptoms and final pregnancy loss.

In order to analyze a possible influence of gestational age in the observed histological differences between induced and spontaneous abortions, the scores on the age-related items and a set of all spontaneous abortions of comparable age are given in table 3. Statistical analysis revealed that there was still a significant difference between both groups in respect of hydrops $(p=0.01)$ and syncytial knots $(\mathrm{p}=0.01)$, but not for the integrity of trophoblastic layer.

Table 2. Statistically significant rangcorrelation coefficients for the qualitative scores for the spontaneous abortions

\begin{tabular}{lcc}
\hline Iten & $\begin{array}{c}\text { finall loss } \\
\mathrm{n}=24\end{array}$ & $\begin{array}{c}\text { time-lag* } \\
\mathrm{n}=23\end{array}$ \\
\hline Hydrops & $-.73^{* *}$ & $-.50^{*}$ \\
Trophoblastic layer & $.56^{*}$ & $50^{*}$ \\
Syncytial layer & $-.52^{*}$ & -.13 \\
\hline
\end{tabular}

- Time-lag between first blood loss and final expulsion. Spearman correlation coefficient for gestational age at final loss and time-lag between first vaginal bllood loss and final loss for the 23 cases with known clinical symptoms was 0.34 .

* $p<0.01$

** $p<0.001$ 
Table 3 The results for the induced abortions (first column, $n=6$ ) and the spontaneous abortions (second column, $n=9$ ) of comparable age for the age related qualitative items

\begin{tabular}{llccc}
\hline & & induced & spontaneous \\
\cline { 3 - 4 } Hydrops & none & 6 & 9 \\
& moderate & 0 & 2 \\
& abundant & 1 & 6 \\
Trophoblastic layer grossly intact & lacunae & 4 & 1 \\
& yes & 1 & 0 \\
Many syncytial knots & no & 6 & 9 \\
& yes & 0 & 0 \\
\hline
\end{tabular}

\section{Quantitative data}

In figure 1 the quantitative data are plotted for all cases. From the data it can be seen that the median mean chorionic villous profile area of induced abortions is $0.050 \mathrm{~mm}^{2}$ (range 0.033 $0.065 \mathrm{~mm}^{2}$ ) as against $0.029 \mathrm{~mm}^{2}$ (range $0.013-0.081 \mathrm{~mm}^{2}$ ) of spontaneous abortions $(p=0.0027)$. Induced abortions show a median mean stromal area of $0.038 \mathrm{~mm}^{2}$, whereas median mean stromal area of spontaneous abortions is $0.019 \mathrm{~mm}^{2}(p=0.006)$. Mean trophoblastic area of induced abortions ranges from $0.010 \mathrm{~mm}^{2}$ to $0.017 \mathrm{~mm}^{2}$ (median $0.012 \mathrm{~mm}^{2}$ ) and that of spontaneous abortions from $0.004 \mathrm{~mm}^{2}$ to $0.016 \mathrm{~mm}^{2}$ (median $\left.0.008 \mathrm{~mm}^{2}\right) \quad(\mathrm{p}=0.003)$. The trophoblast/stroma ratio as well as the trophoblastic thickness, however, did not differ in both groups (p-values 0.59 and 0.06 resp.).

In figure 2 the logarithmic mean chorionic villous profile area, mean stromal and mean trophoblastic area are plotted against gestational age at final loss. It can be seen that the values for the induced abortions are higher than those of the spontaneous abortions of comparable age. None of the parameters related statistically significant to the length of the regression period.

The comparison of the induced abortions with the 9 spontaneous abortions of comparable age at final loss revealed that there still was a statistically significant difference between both groups for logarithmic mean chorionic villous profile area, mean stromal and mean trophoblastic area (p-values $0.01,0.02$ and 0.001 respectively).

\section{Discussion}

Our comparison of histological features between induced and spontaneous trisomic abortions revealed data with possible biological and practical implications. The general, remarkably homogeneous picture of induced abortions emerging from this study is that of relatively large, irregular, hydropic chorionic villi with pseudoinclusions and on qualitative assessment 'hyperplastic' trophoblast. Furthermore, the stroma contains many blood vessels and does not show pronounced fibrohyalinization. Contrasting $\| y$, the more heterogeneous general picture of spontaneous abortions is characterized by relatively small chorionic villi lined by a not "hyperplastic " trophoblast on qualitative assessment. In the somewhat more fibrohyalinic stroma blood vessels are not very prominent and there are many syncytial knots in the trophoblastic layer. The most marked differw ences between both abortion varieties 

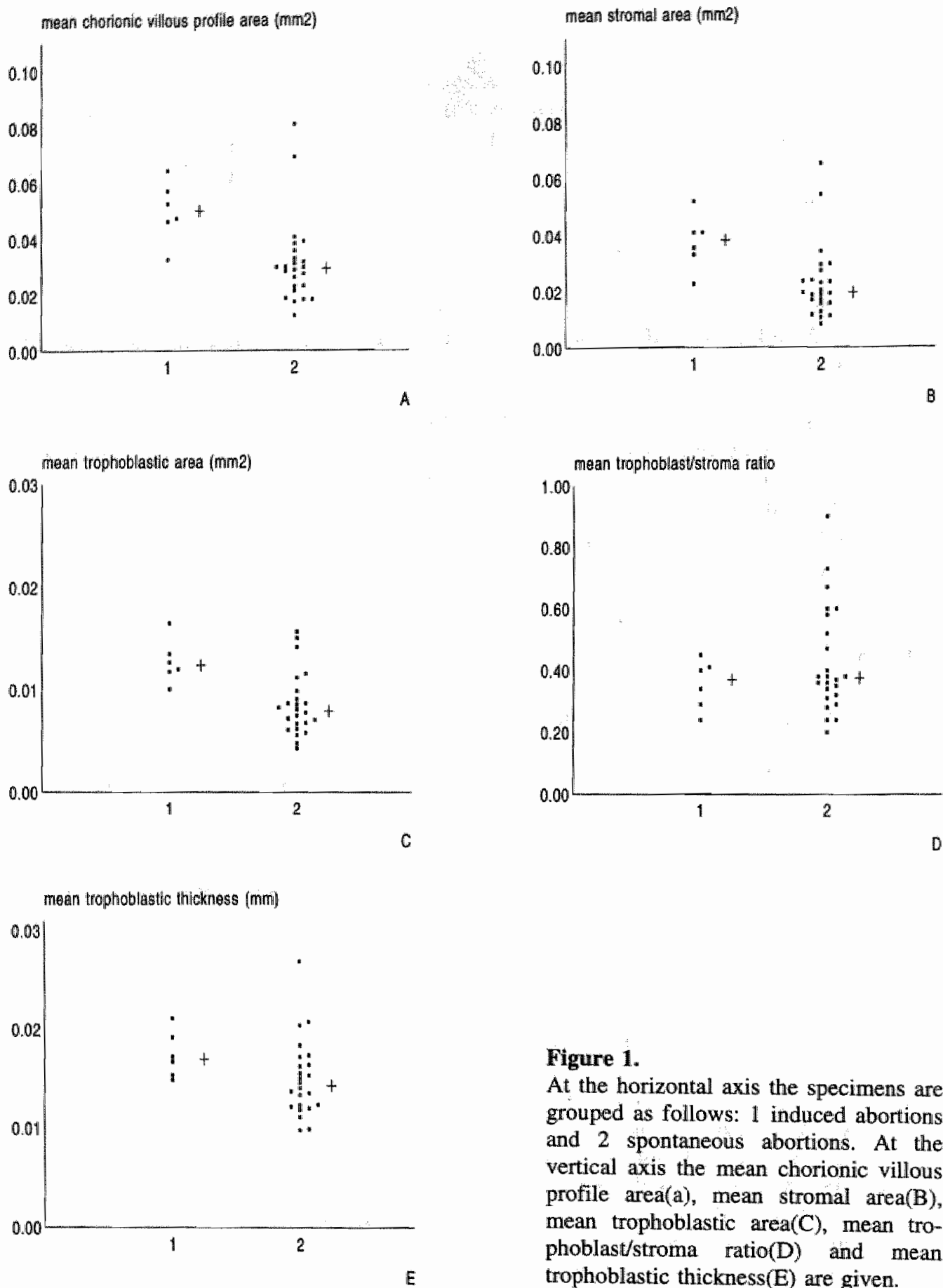

\section{Figure 1.}

At the horizontal axis the specimens are grouped as follows: $\mathbb{1}$ induced abortions and 2 spontaneous abortions. At the vertical axis the mean chorionic villous profile area(a), mean stromal area(B), mean trophoblastic area(C), mean trophoblast/stroma ratio(D) and mean trophoblastic thickness $(\mathrm{E})$ are given. 

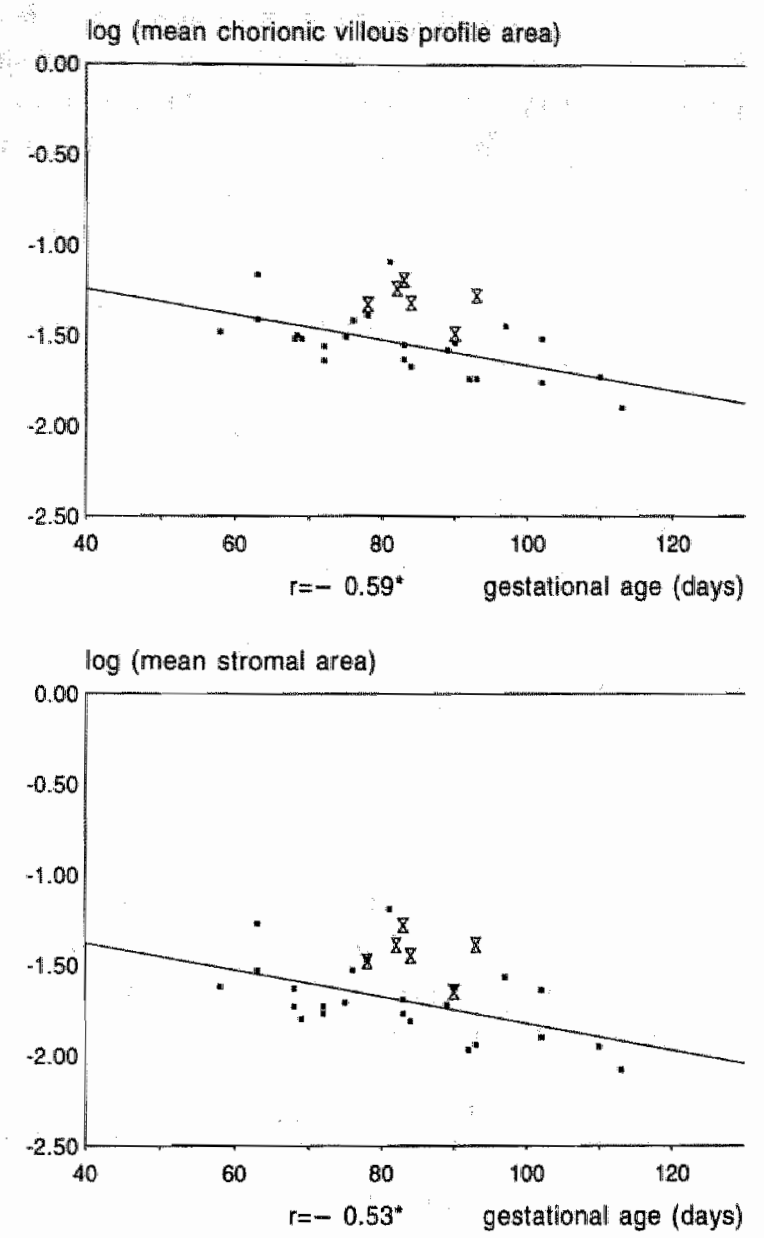

$\log$ (mean trophoblastic area)

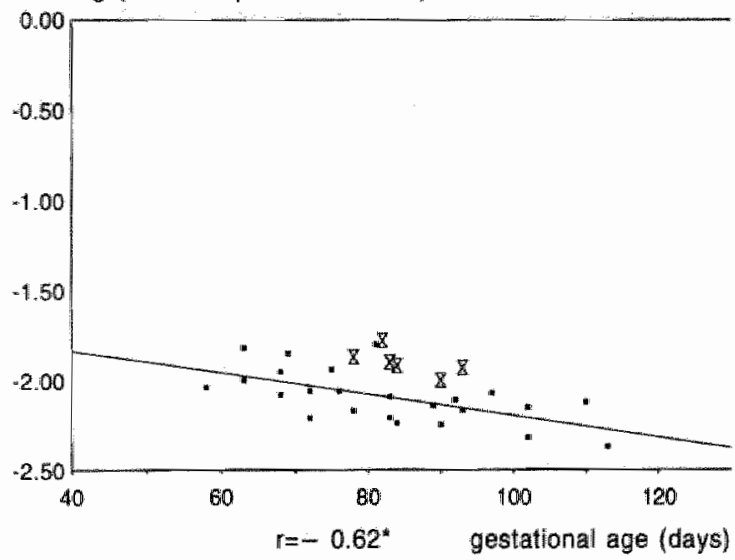

Figure 2. Relation between gestational age corrected for menstrual cycle length (X-axis, days) and logarithmic of mean chorionic villous profile area, mean stromal area and mean trophoblastic area (Y-axis). Dots represent spontaneous abortions " diabolos induced abortions. Regression lines are drawn and Pearson correlation coefficients are given. $*=\mathrm{p}<0.01$ 
are villus size, number of blood vessels, hydrops, fibrohyalinization and status of trophoblastic layer.

In an attempt to explain these findings several issues have to be discussed. Firstly, it is important to exclude an influence of the method of abortion induction on histological features. Extraamniotic application of prostaglandin does not seem to influence chorionic villus morphology (Fox, 1978). We are not aware of any report asserting that the same applies for Sulprostone. Our case of Sulprostone induction, however, did not mark itself from the other induced abortions. Secondly, gestational age could be a confounder in this study for some reasons. One reason is, that we were unable to completely match our study group for gestational age whereas several of the studied items, i.e. villus size, number of syncytial knots, fibrohyalinization and stromal hydrops, indeed, showed a relation with gestational age. Also, the issue of regression time i.e. the time between the decease of the concept and its expulsion heavily interferes with the interpretation of the data.

Our finding that the comparison of the restricted set of specimens selected according to comparable gestational age still showed the same trends in that induced abortions displayed larger villi and fewer syncytial knots than spontaneous abortions, makes us believe that the first reason is not of very much influence in the discussion. More so, because the data in respect of fibrohyalinization and stromal hydrops did not significantly change. A much more refractory issue, however, is the influence of regression time, which is impossible to define exactly, since the exact moment of decease of the gestational product cannot be indlicated and might be utterly variable. Blood loss may be the first sign of a dead fetus or inviable placenta. On the other hand it is known that at least two-third of pregnancies with vagi nal blood loss will not end in spontane ous abortion (Speert and Gutmache 1954, Peckham 1970). That almost al placentae are to a certain extent viabl at curettage is also supported by th high success rate of tissue cultures fo chromosomal analysis.

Yet, differences between induced an spontaneous abortions in villous profill areas and the number of blood vessel: may be explained by the circulatory changes occurring in spontaneous abor tions. When circulation stops blooc vessels, which form the frame work of : villus, collapse inducing shrinkage of : villus. In contrast, villi of induced abortions retain their circulation and blooc vessel frame work and therefore appeal expanded in histological sections. The observed differences in the status of trophoblast, however, could be due tc regressive alterations. Our observations confirm earlier notions that syncytial knots might be an adaptation to reduced villous blood flow (Fox, 1965). The presence of many of these knots is considered only physiologic after the 37 th week of pregnancy in increasing number with advancement of gestation (Alvarez, 1967). In the present study syncytial knots were found to be almost entirely absent induced abortions and prominently present in spontaneous abortions, their number increasing with gestational age. Alternatively, however, these knots might be due to trophoblastic collapse after shrinkage of the villus because of cessation of the circulation. In favour of this notion is the declining production of human chorionic gonadotrophin in imminent abortions.

Although the striking differences observed between spontaneous and induced abortions may be explained in the above ways, it should be realized that both series concerned trisomies, which were, however, differently distributed over the 
two studied abortion groups. Further studies including different karyotypes, however, are mandatory to sort out this issue. In the meantime, our data indicate that histological features of induced and spontaneous abortion may differ to such an extent that pathologists should be aware of the origin of an abortion to be able to interpret features adequately.

\section{References}

Alvarez H. \& Benedetti W.L. (1967) Syncytial proliferation in normal and toxemic pregnancies. Obstetrics and Gynecology, 29, 637-643.

Boyd J.D. \& Hamilton W.J. (1970) The human placenta. W.Heffer and Sons, Cambridge.

Fox, $\mathrm{H}$. (1965) The significance of villous syncytial knots in the human placenta. Journal of Obsterrics and Gynaecology of the British Commonwealih, 72, 347-355.

Fox, H. (1978) Morphological changes in the placenta and decidua after induction of abortion by extraamniotic prostaglandin. Histopathology, 2, 145-151.

Gundersen, H.J.G. \& Østerby, R. (1981a) Optimizing sampling efficiency of stereological studies in biology: or 'Do mone less well!'. Journal of Microscopy, 121, part 1, 65-73.

Gundersen, H.J.G., Bendtsen,T.F., Korbo, L., Marcussen, N., Maller, A, Nielsen, K., Nyengaard, J.R., Pakkenberg, B., Sørensen, F.B., Vesterby, A. \& West, M.J.1988) Some new, simple and efficient stereological methods and their use in pathological researh and diagnosis. APMIS, 96, 379-394.

van Lijnschoten G., Arends J.W., de la Fuente A.A., Schouten H.J.A., Geraedts J.P.M. (1993) Intraand interobserver variation in the interpretation of histological indications of chromosomal abnormality in early abortion specimens. Histopathology, 22, 25-29.

van Lijnschoten G., Arends J.W., Leffers P., de la Fuente A.A., van der Looij H.J.A.M., Geraedts J.P.M. (1993) The value of histomorphological features of chorionic willi in early spontaneous abortion for the prediction of karyotype. Histopathology, In Press.

van Lijnschoten G., Arends J.W., Thunnissen F.B.J.M., Geraedts J.P.M. A morphometric approach to the relation of karyotype, gestational age and histological features in early spontaneous abortion. Placenta, submitted for publication.

Peckham C.H. (1970) Uterine Blleeding during Pregnancy. I. When not followed by immediate Termination of Pregnancy. Obstetrics and Gynecology, 35, 937-941.

Speert H. \& Guttmacher A.F. (1954) Frequency and significance of bleeding in early pregnancy. $J A M A, 155,712-715$.

Weibel, E.R. (1979) Stereological methods. Volume 1. Practical Methods for Biological Morphometry. London:Academic Press.

Weibel, E.R. (1980) Stereological methods. Volume 2. Theoretical Foundations. London: Academic Press. 


\title{
The value of macroscopic examination of early spontaneous abortion for the prediction of karyotype.
}

\author{
G van Lijnschoten, JPM Geraedts. Submitted for publication.
}

The value of macroscopic analysis of spontaneous abortions for the prediction of karyotype was retrospectively investigated in a consecutive series of 98 early spontaneous abortions, which were obtained in 80 out of 98 cases $(84 \%)$ after dilatation and curettage. Chromo. some analysis was successful in 95 cases, which were included in the present study. Normal karyotype was found in 38 and abnormal karyotype in 57 abortions. The macroscopic descriptions made at the time of initiation of the celll cultures for chromosome analysis were analyzed. Our study indicates that the presence of an embryo as such is not predictive for karyotype. However, very early developmental arrest (the nodular/stunted or cylindrical embryol is suspect for chromosomal abnormality. However, in an embryo show. ing macroscopically normal and not early arrested development a chromosome abnormality can not be excluded. Also, the presence of an umbilical cord stump seems to be highly indicative for a chromosomal abnormality. Almost all specimens with large vesicles were triploid. Long, thin stem villi with branches at its terminal end only, were present in the karyotypically abnormal group solely. On the other hand bichorial twinning seems to be strongly related to normal karyotype, whereas, all monochorial and biamniotic twins were chromosomally abnormal. It is concluded that macroscopic analysis is promising for the prediction of abnormal karyotype, but this has to be proven in a prospective study.

\section{Introduction}

Spontaneous abortion is a very common phenomenon that is manifesting itself during all stages of early pregnancy ${ }^{1,2}$. As a category, chromosome abnormalities are the most frequent cause of early abortion'. In the majority of cases an aberration is found and about half this number is made up of trisomies ${ }^{2,3,4,5,6,6}$. Trisomies 13,18 and 21 , representing about $20 \%$ of this group are said to predispose to a live born child with one of these trisomies ${ }^{2,5,7,8,9,10,11,12}$. Besides these numerical abnormalities resulting from non-disjunction also structural defects are found, although in a much lower percentage $e^{2,3,4,5,6}$. These aberrations can arise the novo but in a significant proportion of the cases one of the parents is carrier of a balanced rearrangement ${ }^{\mathrm{i3}}$. This means that gametogenesis in this parent repeatedly can lead to malsegregation at the meiosis resulting in recurrent abortion or a combination of abortion with severely malformed live born children. The recurrence risk will vary depending on the chromosomes and the breakpoints involved, but can be very significant.

For these reasons, the clinicians dealing with the problem of spontaneous abortion would like to be informed about the presence or absence of cytogenetic abnormalities. Some authors have claimed that histological analysis could 
be of help in the discrimination between chromosomally normal and abnormal

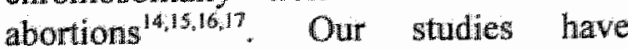
shown that this approach is of no value except in the case of triploidy ${ }^{18: 19}$.

Therefore it was decided to look for alternative approaches. One of these could be the analysis of macroscopic findings as a method to predict the chromosomal status. This issue is still controversial since the meaning of the diverse classification systems is unclear. Generally, it is assumed that the classification systems of Fujikura and Rushton have no predictive value for karyotype but rather are predictive for the moment of disturbance, which is only partially related to karyotype ${ }^{15,20,21}$.

\section{Material and Methods}

The same collection of spontaneous abortions was used as previously studied for the value of histological features for the prediction of karyotype ${ }^{11}$. The collection was composed of 98 consecutive early abortions. For the present study, three cases with failling chromosome analysis were excluded, leaving 95 cases. The chromosome patterns are listed in tables 1 and 2. The population consisted of 38 karyotypically normal and 57 karyotypically spontaneous abortions. In the total population 3 pregnancies occurred after induction of ovulation by clomiphene citrate (monosomy $X(n=2)$, triploidy $(n=1))$ and 4 after in vitro fertilization procedure (normal karyotype $(n=3)$, trisomy $15(n=1))$. Mean gestational age corrected for menstrual cycle length was 84.7 days (range 51-126) for the chromosomally normal $(\mathrm{n}=38)$ and 82.8 days (range $45-128$ ) for the chromosomally abnormal group $(n=57)$.

Spontaneous expulsion was experienced in 10 out of 38 normals $(26 \%)$ and 13 out of 57 abnormals (23\%). Dila-
Table 1. Number of spontaneous abortions li ed against karyotype

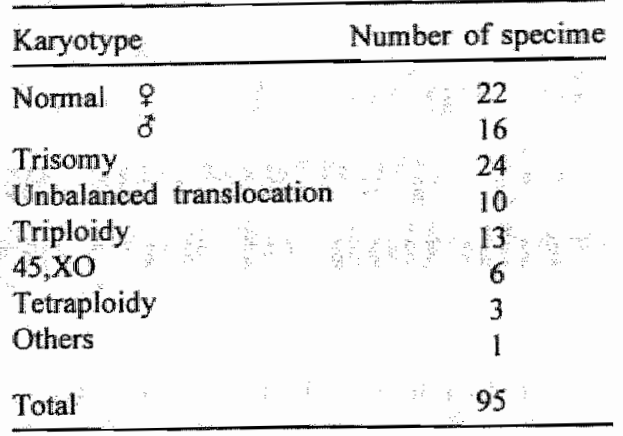

tation and curettage (DC) was performe in 78 out of 95 cases, 31 out of 38 bc ing normal $(82 \%)$ and 47 out of 5 being abnormal ( $83 \%$ ). In 6 cases spor. taneous expulsion was followed by DC The abortion specimens were stored $\mathrm{i}$ Hank's medium at room temperature During the scrutinizing of tissues fc cell cultures for chromosome analysis with the naked eye, a macroscopic de scription was made by the first authot After collection had been closed, al descriptions were analyzed according to the items listed in table 3 and 4 .

No description means that the descrip tion of the item could not be used fo analysis or that the item was not men. tioned.

Table 2. Number of trisomic cases listed to the extra chromosome

\begin{tabular}{cc}
\hline Chromosome & $\begin{array}{c}\text { Number of speci- } \\
\text { mens }\end{array}$ \\
\hline 16 & 9 \\
15 & 3 \\
22 & 2 \\
18 & 2 \\
21 & 1 \\
2 & 1 \\
8 & 1 \\
10 & 1 \\
13 & 1 \\
14 & 1 \\
17 & 1 \\
15,21 & 1 \\
Total & 24 \\
\hline
\end{tabular}


Table 3. General analysis of the presence of the described structures

\begin{tabular}{llcc}
\hline & & \multicolumn{2}{c}{ Karyotype } \\
\cline { 2 - 4 } Item & & Normal $(\mathrm{n}=38)$ & Abuormal (n=57) \\
\hline Yolk sac & present & $5(13 \%)$ & $9(16 \%)$ \\
& absent & $11(29 \%)$ & $11(19 \%)$ \\
no description & $22(58 \%)$ & $37(65 \%)$ \\
Embryo/foetus & present & $11(29 \%)$ & $22(39 \%)$ \\
& absent & $27(71 \%)$ & $34(60 \%)$ \\
Chorionic villi & no description & $0(0 \%)$ & $1(2 \%)$ \\
& present & $37(97 \%)$ & $55(96 \%)$ \\
Membranes & absent & $1(3 \%)$ & $2(4 \%)$ \\
& present & $32(84 \%)$ & $53(93 \%)$ \\
Umbilical cord stump & $6(16 \%)$ & $4(7 \%)$ \\
& absent & $0(0 \%)$ & $7(12 \%)$ \\
& present & $38(100 \%)$ & $49(86 \%)$ \\
Gemelli & absent & $0(0 \%)$ & $1(2 \%)$ \\
& no description & $6(16 \%)$ & $3(5 \%)$ \\
& present & $32(84 \%)$ & $53(93 \%)$ \\
& absent & $0(0 \%)$ & $1(2 \%)$ \\
\hline
\end{tabular}

\section{General analysis}

The presence of any sign of yolk sac, embryo/foetus, chorionic villi and membranes was scored as positive. An umbilical cord stump was defined as maximally $3 \mathrm{~cm}$ long, with at one end a piece of chorionic membrane and at the other end a piece of embryonic skin and/or bowel, the embryo/foetus being absent. Gemelli gestation was scored as bichorial if more than one chorionic sac was present or as one closed chorionic sac and a separate piece of chorionic membrane with chorionic villi or a separate embryo/foetus. A monochorial twin was scored as biamniotic if two separate amniotic cavities were present or if the sac contained a closed amnion which took only a small part of the total space and a separate embryo was present. Monochorial and monoamniotic was defined as the presence of two umbilical cords with or without an embryo/foetus in one cavity. In case of multiple chorial pregnancy the most advanced member was used for further analysis.

\section{Specific analysis}

Firstly, it was noted whether the embryo/foetus was complete or fragmented. The developmental status of the embryo/fetus was described in three categories: nodular/stunted/cylindrical (embryonic tissue without further differentiation); more than 1 week developmentally arrested and conform gestational age corrected for menstrual cycle length. For staging of the embryo the system of O'Rahilly and Müller (1987) was used ${ }^{22}$. If possible, foetal age was determined on the basis of the medial foot length, the longest hand length and the crown-rump length (CRL) as given in the tables of Kalousek et al. ${ }^{23}$.

The number of villi was subjectively assessed as few or normal-abundant. Only if the chorionic membrane was largely present the "few' score could be used. Polarization of the chorionic villi, visible in normal pregnancies from eighth weeks onwards, was only assessed if the chorionic membrane showed a lot of villi and simultaneously 


\begin{tabular}{|c|c|c|c|}
\hline \multirow[b]{2}{*}{ 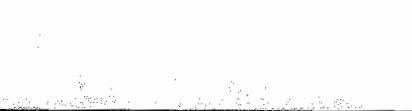 } & & \multicolumn{2}{|c|}{ Karyotype } \\
\hline & & Nomal & Abnormal \\
\hline \multicolumn{4}{|l|}{ Embryo/foetus } \\
\hline \multirow[t]{3}{*}{ statug: } & compllete & $811(73 \%)$ & $18 / 22(82 \%)$ \\
\hline & fragmented & $3 / 11(27 \%)$ & $4 / 22(18 \%)$ \\
\hline & no description & $0 / 11(0 \%)$ & $0 / 22(0 \%)$ \\
\hline \multirow[t]{4}{*}{ development: } & stunted & $1 / 11(9 \%)$ & $8 / 22(36 \%)$ \\
\hline & arrested & $8 / 11(73 \%)$ & $12 / 22(55 \%)$ \\
\hline & cf.gestational age & $2 / 11(18 \%)$ & $1 / 22(5 \%)$ \\
\hline & no description & $0 / 11(0 \%)$ & $1 / 22(5 \%)$ \\
\hline \multicolumn{4}{|l|}{ Chorionile villi } \\
\hline \multirow[t]{3}{*}{ number: } & few & $8 / 37(22 \%)$ & $14 / 55(25 \%)$ \\
\hline & normal-abundant & $22 / 37(59 \%)$ & $22 / 55(40 \%)$ \\
\hline & no description & $7 / 37(19 \%)$ & $19 / 55(35 \%)$ \\
\hline \multirow[t]{3}{*}{ pollarization: } & present & $15 / 37(41 \%)$ & $20 / 55(36 \%)$ \\
\hline & absent & $2 / 37(5 \%)$ & $5 / 55(9 \%)$ \\
\hline & no description & $20 / 37(54 \%)$ & $30 / 55(55 \%)$ \\
\hline \multirow[t]{3}{*}{ arborizationts: } & few & $7 / 37(19 \%)$ & $16 / 55(29 \%)$ \\
\hline & normal-abundant & $19 / 37(51 \%)$ & $20 / 55(36 \%)$ \\
\hline & no description & $11 / 37(30 \%)$ & $19 / 55(35 \%)$ \\
\hline \multirow[t]{3}{*}{ "umbrella"-shape: } & present & $0 / 37(0 \%)$ & $5 / 55(9 \%)$ \\
\hline & absent & $28 / 37(76 \%)$ & $36 / 55(65 \%)$ \\
\hline & no description & $9 / 37(24 \%)$ & $14 / 55(25 \%)$ \\
\hline \multirow[t]{4}{*}{ vesicles: } & present - small & $4 / 37(11 \%)$ & $3 / 55(5 \%)$ \\
\hline & - large & $0 / 37(0 \%)$ & $8 / 55(15 \%)$ \\
\hline & absent & $25 / 37(68 \%)$ & $37 / 55(67 \%)$ \\
\hline & no description & $8 / 37(22 \%)$ & $7 / 55(13 \%)$ \\
\hline \multicolumn{4}{|l|}{ Membranes } \\
\hline \multirow[t]{4}{*}{ intact sac: } & present - embryo + & $1 / 32(3 \%)$ & $8 / 53(15 \%)$ \\
\hline & P & $5 / 32(16 \%)$ & $6 / 53(11 \%)$ \\
\hline & - embryo - & $26 / 32(81 \%)$ & $39 / 53(74 \%)$ \\
\hline & $\begin{array}{l}\text { absent } \\
\text { no description }\end{array}$ & $0 / 32(0 \%)$ & $0 / 53(0 \%)$ \\
\hline
\end{tabular}

a part with poorly developed villi (see figure 1A). It was only scored if the chorionic sac was largely complete. After the 6th week, all over the villus stems, arborizations need to be present, showing branching as well. If only a few branches were present, the villi looked quite simple and the arborization score was few (figure 1B). If a fairly well-formed cloud was present arborization was scored as normal. If the villous border was small, the degree of arborization was not assessed. If no villi were present or the villi were completely embedded in fibrotic tissue scoring was not possible. A specific type of arborization was distinguished, i.e. long thin villi with only branches at the end ("umbrella'-type, see figure 1C). If macroscopically visible vesicles were present they were subdivided in small and large up to $2-4 \mathrm{~mm}$. In single pregnancies 

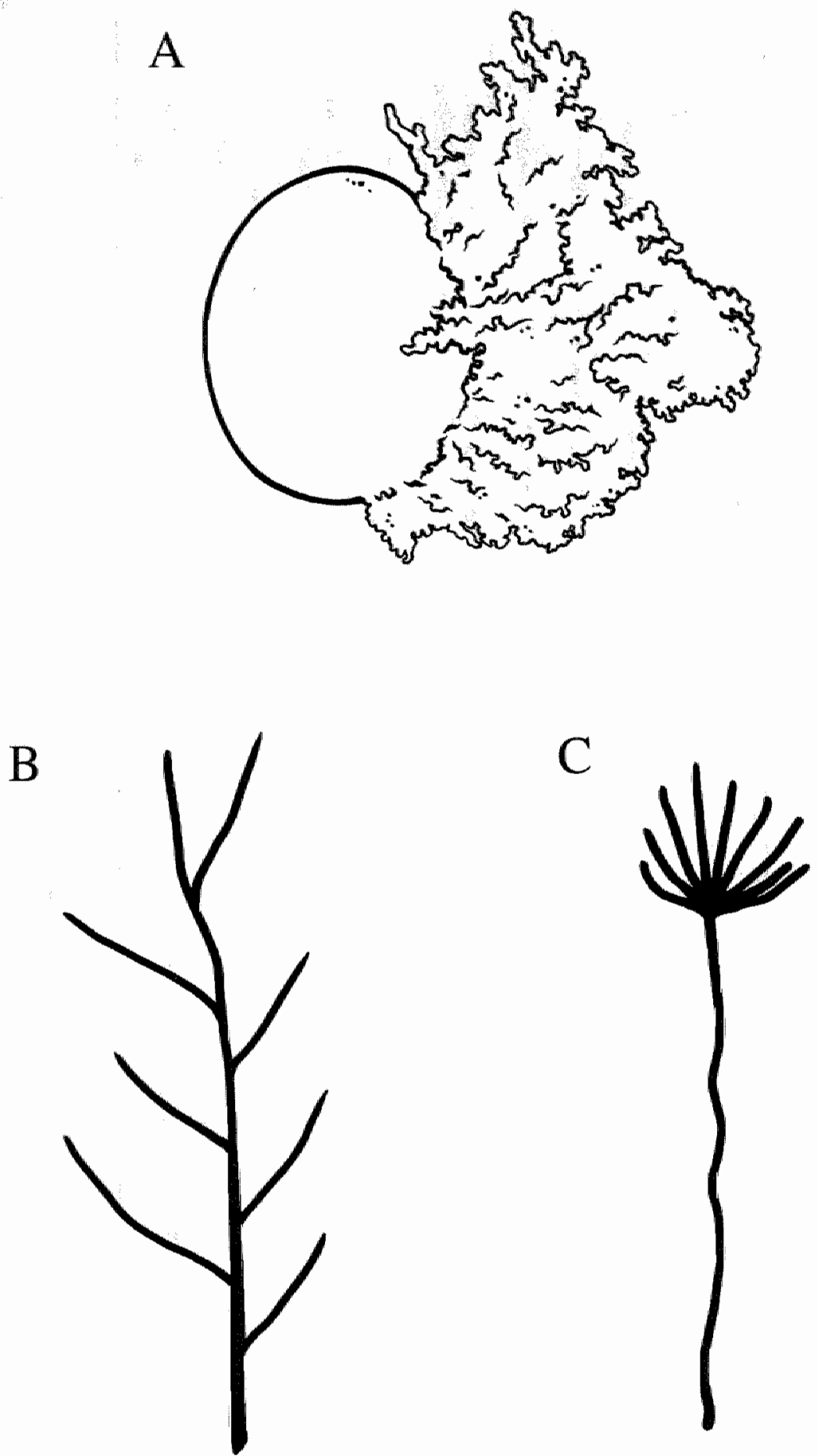

Figure 1. A) chorionic sac with a large number of villi at only one side of the membrane: polarization. B) only a few branches are present, the arborization score was few. C) long thin villi with only branches at the end: "umbrella'-type. 


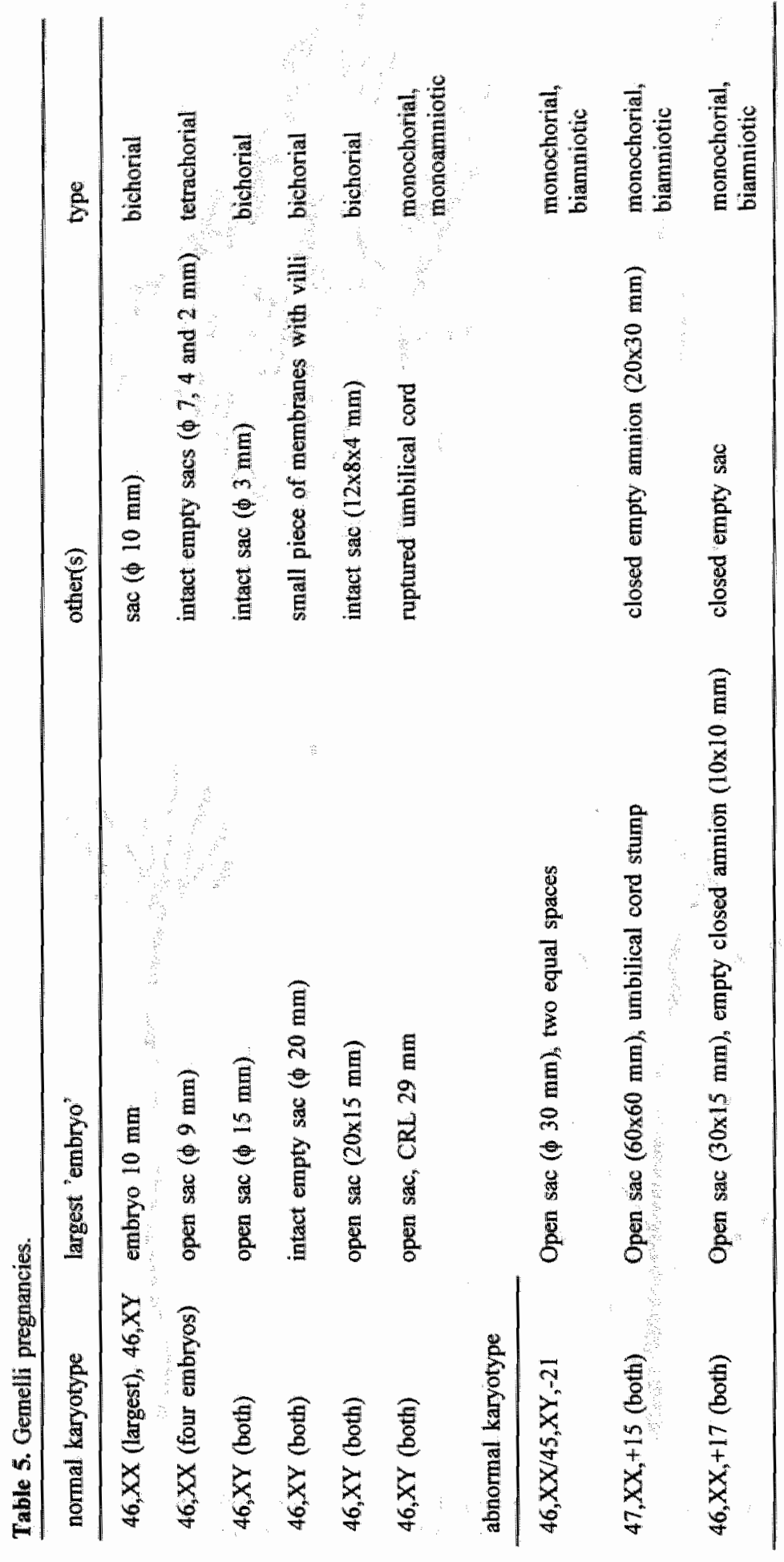


and in the largest twin member, it was noted whether the membranes consisted of an intact $\mathrm{sac}$, i.e. if the amnion was closed.

\section{Analysis of descriptions}

Firstly, the proportions of descriptions of the presence of yolk sac, embryo/foetus, chorionic membranes, umbilical cord stump, membranes and gemelli for both the normal and the abnormal group were compared. Only, if the numbers were equivalent; i.e. a difference of less than $10 \%$, the groups were compared for the presence of these structures. The predictive value of the presence of yolk sac, embryo/foetus and umbilical cord stump for abnormal karyotype was analyzed. If indications for predictivity were found, the abnormal karyotypes were further analyzed. Secondly, the specific analysis of embryo/foetus, chorionic villi and membranes was carried out in the same way. The availability of specific descriptions was analyzed and then correlated with karyotype.

\section{Results}

\section{General analysis}

On the basis of the descriptions it was possible to be certain about the presence of five out of six macroscopically visible items given in table 3. Only the yolk sac revealed a high number of missing descriptions. No differences between both chromosome groups were noted for the presence of chorionic villi and gestational membranes. In contrast, more embryos/fetuses were present in the chromosomally abnormal group. Umbilical cord stumps were exclusively present in the abnormal karyotype group. The karyotypes of these 7 abortions were: monosomy $X(n=3)$, trisomy 15 $(\mathrm{n}=2)$, trisomy $18(\mathrm{n}=1)$ and
46; $\mathrm{XY},-13,+\mathrm{t}(13 / 14) \quad(\mathrm{n}=1)$. Gemelli were present in 6 normal (16\% of all normal cases) and 3 abnormal ( $5 \%$ of all abnormal cases). One normal case was the result of in vitro fertilization. The other gemelli resulted from natural conceptions. 8 out of $88(9 \%)$ natural conceptions were gemelli gestations (gemelli in $5 / 35(14 \%)$ karyotypically normal conceptions and $3 / 53(6 \%)$ in karyotypically abnormal conceptionsy. A description of the gemelli cases is given in table 5. All chromosomally abnormal cases were monochorial and biamniotic: The majority of the chromosomally normal gemelli was bichorial, while the two remaining cases were tetrachorial and monochorial/monoamniotic.

Specific analysis.

The results of the specific analysis are listed in table 4 . The majority of embryos/foetuses was complete. Among the 7 fragmented embryos/foetuses one manifested itself as a $8 \mathrm{~cm}$ long umbilical cord only. The development for the length of gestation was almost always abnormal in both groups. In the abnormal group no fetuses, defined as CRL $>30 \mathrm{~mm}$, were present, whereas in the normal group 3 arrested foetuses and 1 conform gestational age were present. In the chromosomally normal group $8 / 11$ showed a developmental arrest, whereas this was the case in $12 / 22$ abnormal cases. In $8 / 22$ abnormal cases only a nodular/stunted/cylindrical embryo was present. This was far more often than in the chromosomally normal group indicating more severe developmental disturbances in the abnormal group. In this respect there was a difference with the abnormal karyotype group showing an amorphous embryo in 8 cases and a normal development in one case only $(69, \mathrm{XXX})$. If the fetuses would be left out the arrested embryos would be normal in 5 out of 17 cases. 
The description of chorionic villi was more often lacking in the abnormal karyotype group, thus no conclusion could be drawn from this item. The descriptions for the chorionic villous number, polarization, arborizations, "umbrella" assessable in respectively $12 / 26,16 / 50$, $19 / 30,13 / 21$ and 11/15 cases. Descriptions of polarization were equally frequent made in both groups. The figures for presence seem to be identical in both groups. Arborization revealed a relatively high number of abnormal cases in the chromosomally abnormal group. Long, thin stem villi with only branches at the ends of the villi were present in 5 cases, all karyotypically abnormal (trisomy 16 $(n=2)$, trisomy $22 \quad(n=1)$, tetraploidy $(\mathrm{n}=1)$, monosomy $X(\mathrm{n}=1))$.

With respect to the presence of vesicles a difference was also noted with more cases in the abnormal group. The karyotypes of these cases were $46, X Y(n=4)$, 11 abnormals (triploidy ( $\mathrm{n}=7$ ), trisomy $16(\mathrm{n}=1)$, trisomy $18(\mathrm{n}=1)$, structural anomalies $(n=2)$ ). If the vesicles are subdivided in small and large, all triploidies $(n=7)$ and the trisomy 18 case had large vesicles.

Intact sacs were seen in 20 cases, almost equally divided over both groups. In two cases it was the largest member of a gemelli gestation. In 1 chromosomally normal and 8 abnormal cases an embryo was present. The other sacs were empty. The embryo had developed conform gestational age in the intact sac with normal karyotype and in one of the abnormally karyotyped intact sacs. The other 7 embryos with abnormal karyotype were nodular/cylindrical/stunted $(n=2)$ or developmentally arrested $(n=5)$.

\section{Diseussion}

The nature of this retrospective study of descriptions which were uniquely mad at one particular point in time by oni observer and which could not be repeat. ed or completed by another observer: asks for a modest presentation of the results. A learning effect during the study has also influenced the extensiveness of the descriptions. The first ones were shorter than the last ones, giving rise to more missing assessments in the beginning. However, this could not have been of influence regarding the comparison of the chromosomally normal and abnormal groups, since at the time of macroscopic analysis the results of the cytogenetic study were not available.

It is possible that some of the missing descriptions of the features were in fact not assessable due to the state of the material. In the tables these assessments were included in the same way as the missing ones due to absence of the type of tissue.

Another circumstance which might be of influence is that the majority of cases was obtained in the hospital after dilatation and curettage. This contrasts with some earlier studies and especially with the large series of Boué et al. (1976) in which mainly complete specimens were collected at home ${ }^{3}$.

Because of the expected collection artifacts, already existing classification systems of Fujikura ${ }^{20}$ and Rushton ${ }^{21}$ could not be used. Despite these objectives, justifications for this study were several. Firstly, the descriptions were very carefully made. Secondly, it should be realized that our study mimics the practical situation the pathologist is confronted with and that the study material is more or less representative for a general abortion population. Finally, the descriptions were made in advance of knowledge of the karyotype. Therefore, it is difficult to imagine how an eventual bias could be related to the karyotypic outcome. Also, with respect to the re- 
sults a comparison with pathological findings should be made very carefully.

In the present study the

normal:abnormal karyotype ratio was 1:1.5. Therefore, features related to the karyotype needed to deviate from this ratio.

It was found that if an embryo was present; this occurred at least as frequent in the abnormal karyotype group as in the normal group. This was also found by Byrne et al. ${ }^{24}$, if the foetuses were eliminated from their data before analysis. In our study the ratio

normal:abnormal changed from $1: 1.5$ to $1: 8$ if a nodular/cylindrical/stunted embryo was present. Byrne et al..$^{24}$ used the term growth-disorganized type 2 for 'tiny, white, solid structures apparently attached directly to the amnion with little or no body stalk', and found $61 \%$ to be chromosomally abnormal, which was more or less equal to the percentage of chromosomally abnormal early pregnancies. The results of Kalousek et al. $^{25}$ are in between Byrne's and ours.

Umbilical cord stumps were only observed in the karyotypically abnormal group. This feature has been reported before for monosomy $X$ and other $a b-$ normal karyotypes $(2,26,27)$. Our chromosome abnormalities (monosomy X, trisomy 14,15 and 18) were present in 20 out of 23 cases with cord stumps observed by Lauritsen ${ }^{2}$.

The high frequency of twinning $(9 \%)$ in this study does not need to be unexpected. Ultrasound studies have revealed up to $5 \%$ of twinning in early pregnancy. In about a quarter of these both members survive and result in twins at birth $^{26}$. The resolution of ultrasound at present is such that gestational sacs of $4 \mathrm{~mm}$ can be distinguished. Only one case report is available, wherein the vanished twin was confirmed by macroscopic and histologic examination of a echoscopically detected multiple preg- nancy giving rise to birth of one child. This vanished twin was suggested to have been an emply $\operatorname{sac}^{27}$. If pregnancy had proceeded, it is likely that all bichorial twins from our study would have ended in the birth of one child. The presence of twins in spontaneous abortion is only rarely mentioned (Creasy et al. ${ }^{28}$ ). In this study $2 \%$ of all abortions were found to be twins ${ }^{28}$.

Monochorial twinning is seen as a developmental disturbance and monoamniotic twins are thought to be rarely delivered alive (Boyd et al..$^{29}$ ).

Almost all specimens with large vesicles were triploid. It is known that triploidy presents itself in the majority of cases with macroscopic villus enlargement ${ }^{30}$.

'Umbrella'-type villi were noted in the chromosomally abnormal group only. This feature is very rarely described in the literature.

The total number of intact empty sacs in our series was $11 / 95(12 \%)$. This frequency was also found in other series (Kalousek $(11 \%)^{25}$, Fantel et al. $(13 \%)^{31}$ but it is not as high as reported by Lauritsen $(33 \%)^{2}$. Our empty sacs were detected among the singletons and the largest members of the gemelli gestations. The ratio between both chromosomal groups for intact empty sacs was about 1 . If the smallest members of the twin pairs would have been included the ratio would change in favour of the chromosomally normal group. This is in agreement with the study of Creasy et al. ${ }^{28}$. In this study the population consisted of $45 \%$ fetuses, leaving out these, then $52 \%$ of the total population would be abnormal, whereas $64 \%$ of the empty sacs were chromosomally abnormal. Also Kalousek found a $59 \%$ chromosome abnormality rate of intact empty sacs in her population with gestational age up to 12 completed weeks which is exactly identical to the abnormality rate 
of the total population ${ }^{25}$. Warburton et al. also did not find a raised number of chromosomal abnormalities for intact empty sacs, if the fetuses were left out ( $50 \%$ of empty sacs were chromosonally abnormal versus $48 \%$ of abnormals in the total population) $)^{5}$. On the other hand, in the chromosomally normal group the percentage of empty sacs was $28 \%$ and in the chromosomally abnormal group it was $45 \%$.

The relationship between macroscopy and karyotype can be analyzed in two directions, i.e. starting with the description and examining of its relationship with karyotype or the other way round. As in our study differences in the occurrence of the features in both groups might reveal useful parameters for the prediction of karyotype. Other investigators have started with a collection of abortions with particular karyotype and described the macroscopic characteristics.

Monosomy X spontaneous abortions were studied by Boué et al. ${ }^{32}$, and Canki et al. ${ }^{33}$. At least half of these abortions consisted of a chorionic and amniotic sac measuring $5-8 \mathrm{~cm}$ in diameter with a $2-3 \mathrm{~cm}$ umbilical cord with a small piece of embryonic tissue to its end. A quarter of the abortions revealed a small embryo developmentally arrested at 40-44 days after conception or a gestational age of 8 weeks. The remaining abortions revealed fetuses with the commonly described monosomy X characteristics or largely incomplete abortions. The implantation pattern of villi was remarkable in the sense that groups of small villi and groups of better developed villi were seen (Göcke et al. ${ }^{34}$ ). Our cases of monosomy $X$ presented with cord stumps and large chorionic sacs in 3 out of 6 cases. Two of the others also had a large chorionic sac with an embryo developed to 38 and 49 days. The remaining embryo was $18 \mathrm{~mm}$ and was sent without gestational sac. is interesting to note that 2 out of monosomy $X$ cases resulted from co ceptions after use of clomiphene wher as clomiphene was used in $3 / 95$ cases total. This finding could be coincident: but needs further study. In the literatur there is no convincing evidence on th role of ovulation induction and in vitr fertilization on the spontaneous abortio. rate due to chromosome abnormalities Boué et al. have found an increase number of chromosome abnormalities $i$ conception had occurred in the first tw months of ovulation induction, especial ly the non-disjunction disorders wer more frequent ${ }^{3}$.

In complete triploid abortions chorion, amnion and embryo can be seen. In the paternally derived cases, i.e. $80 \%$ of al! triploidies, the chorionic villi are swollen to 2-4 mm diameter. The maternally derived triploids do not show macroscopically enlarged villi nor any other specific sign (Szulman et al. ${ }^{30}$ ). Our cases of triploidy presented with large vesicles in 7 out of 13 cases, which means that these are most probably paternally derived. In this group one nodular/cylindrical/stunted embryo and one embryo arrested at a later stage were present. In the two cases with gestational ages of 47 and 53 days no assessment of vesicles was possible. The remaining four cases, probably derived maternally, had no vesicles. Three of these had an embryo: one embryo was developed conform gestational age, two were developmentally arrested.

Generally trisomic abortions are poorly developed: the number of chorionic villi is small (Boué et all. ${ }^{32}$; Philippe ${ }^{35}$ ). In trisomies $1-3,6,11,19$ and 20 no embryonic formation has been observed leading to empty sacs (Boué et al. $^{32}$ ). Only one case belonging to this group was observed. It presented as an incomplete sac without embryo and was 
karyotyped as trisomy 2. Trisomy 16 abortions, comprising about $30 \%$ of all spontaneous abortions, are characterized by a chorionic sac measuring $2-3 \mathrm{~cm}$ in diameter, and an embryo with a development arrested at 5 weeks of gestational age. In the chorionic sac, an amnion and sometimes a smaller, primary, yolk sac are found with a barely visible embryonic disk in between. However, intact sacs with trisomy 16 karyotype without any contents are described al$\mathrm{so}^{32,34,35}$. Chorionic villi show a few branches and sometimes hydropic enlargement $^{34}$. In our study 9 trisomy 16 cases were found. In cases which could be assessed small gestational sacs were present $(n=8)$. Three cases had a nodular embryo inside. In the same number of cases few villi were present, whereas in four only a few branches were seen.

In conclusion, our results are in agreement with the literature if the karyotypic data are used as starting point. The other way around, macroscopic features seem to be promising as predictors for abnormal karyotype. However, they need to be studied prospectively. Especially the following items should be included in this study: umbilical cord stumps, gemelli, stunted embryos, the number of chorionic villi and their degree and type of arborization.

\section{References}

1. Edwards RG. Causes of early embryonic loss in luman pregnancy. Human Reprod. 1986; 1; 185198.

2. Lauritsen JG. Aetiology of spontaneous abortion. A cytogenetic and epidemiologic study of 288 abortuses and their parents. Acta Obstet.Gynecol.Scand. 1976; suppl. 52; 1-29.

3. Boué $\mathbf{J}$, Boué A, Lazar P. Retrospective and prospective epidemiological studies of 1500 karyotyped spontaneous human abortions. Teratology $1975 ; 12 ; 11-26$.

4. Kajii T, Ferrier A. Cytogenetics of aborters and abortuses. Am. J.Obstet.Gynecol. 1978; 131; 33-38.

5. Warburton $\mathrm{D}$, Stein $\mathrm{Z}$, Kline J, Susser M. Chromosome abnormalities in spontaneous abortion: data. from the New York city study. In: Porter IH, Hook EB (eds.) Human embryonic and fetal death. New York: Academic Press. 1980; 261-287.

6. Eiben B, Bartels 1, Bahr-Porsch, Borgmann S, Gatz G. et al.. Cytogenetic analysis of spontaneous abortions with the direct-preparation method of chorionic willi and its implications for studying genetic causes of pregnancy wastage. Am.J.Hwm.Genet. 1990; 47;656-663.

7. Boué J, Boué A. Chromosomal analysis of two consecutive abortuses in each of 43 women. Humangenetik $1973 ; 19 ; 275-280$.

8. Alberman E, Elliott M, Creasy M, Dhadial R. Prewious reproductive history in mothers presenting with spontaneous abortions. Br.J.Obstet Gynaecol. 1975; 82; 366-373.

9. Hassold TJ. A cytogenetic study of repeated spontaneous abortions. Am.J.Hum.Genet. 1980; 32; $723-730$.

10. Lippman-Hand A. Genetic counseling and reproductive loss. In: Porter $I H$, Hook EB (eds.) Human embryonic and fetal death. New York: Academic Press. 1980, 299-314.

11. Warburton D, Kline J, Stein $Z$, Hutzler M, Chin A, Hassold T. Does the karyotype of a spontaneous abortion predict the karyotype of a subsequent abortion? - Evidence from 273 women with two karyotyped spontaneous abortions. Am.J.Hum. Genet. 1987; 41; 465-483.

12. Stene J, Stene $\mathrm{E}$, Mikkelsen M. Risk for chromosome abnormality at amniocentesis following a child with a non-inherited chromosome aberration. Prenatal Diagnosis 1984; 4;81-95.

13. Boué J \& Boué A. Anomalies chromosomiques dans les avortements spontanés. In Boué A \& Thibault C (eds.) Les accidents chromosomiques de la reproduction. Paris: INSERM; 1973; 29-55. 
14. Honore LH, Dill FJ, Poland BJ. Placental morphology in spontaneous abortuses with normal and abnomal karyolypes. Teratology 1976 ; 14: 151-166.

15. Rôckelein $\mathrm{G}$, Ulmer $\mathrm{R}$, Schröder J. Korrelation von Karyotyp und Plazentamorphologie beim Fruinabort. Pothologe 1989; 10; 306-314.

16. Rehder $H_{3}$ Coerdt $W$, Eggers $\mathrm{R}$. Klink $\mathrm{F}$, Schwinger $\mathrm{E}$. Is there a correltation between morphological and cytogenetic findings in placental tissue from early missed abortions? Hum.Gener. 1989; 82; 377.385 .

17. Novak R, Agamanolis D, Dasu $S$ et al. Histologic analysis of placental tissue in first trimester abortions. Pediatric Pathology 1988, 8; 477-482.

18. Van Lijnschoten $G$, Arends JW, Leffers $P$, de la Fuente AA, van der Looij HIAM \& Geraedts JPM. The value of histomorphological features of chorionic villi in early spontaneous abortion for the prediction of karyotype. Hitropathology $1993 ; 22 ; 555-563$.

19. Fox H. Histological classification of tissue from spontaneous abortions: a valueless exercise? Histopiathology 1993; 22; 599-600.

20. Fujikura T, Froelich LA, Driscoll A. A simplified anatomic classification of abortion. Am J Obstet Gymecol. 1966; 95; 902-905.

21. Rushton DI. Simplified classification of spontaneous abortions. J.Med.Genet. 1978; 15; 1-9.

22. O'Rahilly $R$, Müller F. Developmental stages in human embryos. Including a revision of Streeter"s 'Horizons' and a survey of the Carnegie Collection. Washington: Carnegie Institution of Washington. 1987, publication 637 .

23. Kalousek DK, Fitch N, Paradice BA. Pathology of the human embryo and previable fetus. An atlas. New York, Springer-Verlag, 1990; 227-228.

24. Bytne J, Warburtion D, Kline J, Blanc W S Stein Z. Morphology of early fetal deaths and their chromosomal characteristics. Teratology 32; 297-315.

25. Kalousek DK. Anatomic and chromosome anomaltes in specimens of early spontaneous abortion: seven-year experience. Birth Defects: Original Article Series, 1987; 153-168.

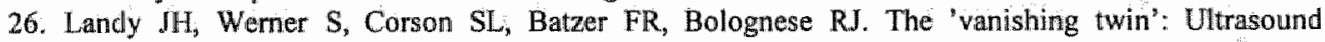
assessment of fetal disappearance in the first trimester. Am.J.Obstet.Gynecol. 1986; 155; 14-19.

27. Sulak $L E_{0}$, Dodson MG. The vanishing twin: pathologic confirmation of an ultrasonographic phenomenon. Obstet.Gynecol. $1986 ; 68 ; 811-815$.

28. Creasy M, Crolla JA, Alberman E. A cytogenetic study of human spontaneous abortions using banding techniques. Hum.Genet. 1976; 3; 177-196.

29. Boyd JD, Hamilton WJ. The Human Placenta. 1970 Cambridge: W.Heffers \& Sons.

30. Szulman AE, Philippe E, Boué JG, Boué A. Human triploidy: association with partial hydatidiform moles and nonmolar conceptuses. Hum. Pathol. 1981; 12; 1016-1021.

31. Fantel AG, Shepard TH, Vadheim-Roth $C$, Stephens TD, Coleman C. Embryonic and fetal phenotypes: prevalence and other associated factors in a large study of spontaneous abortion. In Porter 1H, Hook EB (eds.) Human embryonic and fetal death. New York: Academic Press. 1980; $71-87$.

32. Boue I, Philippe E, Giroud A \& Boué A. Phenotypic expression of lethal chromosome anomalies in human abortuses. Teratology 1976; 14; 3-20.

33. Canki $N$, Warburton D. \& Byme J. Morphological characteristics of monosomy $X$ in spontaneous abortions. Amn.Genét. 1988; 31:4-13.

34. Gocke H, Scliwanitz G, Maradow I, Zerres K. Pathomorphologie und Genetik in der Frühschwangerschaft. Pathologe, $1985 ; 6 ; 249-259$.

35. Phillippe E ed. Pahologie Foeto-Placentaire. 2nd ed. Paris: Masson, 1986. 


\title{
The presence of cytomegalovirus antigens in karyotyped abortions
}

\author{
G van Lijnschoten, F Stals, ILH Evers, CA Bruggeman, MH Havenith, IPM \\ Geraedts. Submitted for publication.
}

About one out of six pregnancies ends in spontaneous abortion. In mone than half of these a chromosome abnormality is present, which explains the abortion. The role of cytomega lovirus (CMV) infections in early pregnancy failure is unclear. If there is a role for CMV, a preponderance of infections would be expected in a chromosomally normal group. The significance of CMV in abortions has been studied by scireening 80 spontaneous and 9 induced abortions with known karyotype for the presence of phosphoprotein pp65, an early CMV antigen. Endometrial biopsies $(n=55)$ and menstruum $(n=10)$ were also screened. of 11 patients more than one specimen was available for study. The protein was present in the gllandular epithelium of the decidua of spontaneous as well as induced abortions in 34 out of $89(35 \%)$ cases, irrespective of chromosomal constitution. Trophoblastic cells were pp65 positive in $6 / 89$ cases. A total of 17 embryos could be studied, 7 of which were positive. Positive staining of embryonic organs correlated strongly with the presence of the antigen in the decidua. The endometrial biopsies and menstrual discharges from women of comparable ages showed the same percentages of positive tests for pp65: 35 and $20 \%$. Histologically, positive and negative specimens could not be differentiated other than by the specific staining. In 10 out of 11 patients with more than one specimen avallable, the results were consistent. One patient had two positive and 1 negative specimen. The find. ings indicate that in early pregnancy cytomegalovirus is transmitted from the decidual glands to the embryo. However, the presence of cytomegalovirus infection as shown by the presence of antigen is most probably not pathogenic in early pregnancy.

\section{Introduction}

About one in six clinically recognized pregnancies ends in spontaneous abortion $^{1,2,3}$. More than half of the aborions can be explained by the presence of a chromosomal abnormality ${ }^{4,5,6,7,8,8}$.

The role of CMV infections in early pregnancy failure is unclear, but if there is a role for $\mathrm{CMV}$, a preponderance of infections would be expected in the chromosomally normal abortions as compared to the chromosomally abnormal abortions. It is known that about $20 \%$ of second and third trimester pathology is caused by infections". Cyto- megalovirus (CMV) infection is one of the most frequent. In western countries between 40 and 60 percent of fertile women have been infected as shown by the presence of IgG antibodies against $\mathrm{CMV}^{10,11}$. After primary infection, which occurs mostly without clinical symptoms in an immunocompetent host the virus persists in the body (latency). Reactivation from this latent state occurs in an immunocompromised host but also during pregnancy reactivation has been described ${ }^{11}$. The number of infected women rises with age ${ }^{12}$. A small number of women suffers from this viral infection for the first time during preg- 
nancy ${ }^{1,33}$. In $20-50$ percent of these primary infections the virus is transmitted to the child in utero ${ }^{1 \mathrm{I}_{\mathrm{i}} \text {. Of }}$. Of the women who have been infected be-fore pregnancy, the infection reactivates during pregnancy in $1-20 \%{ }^{16,15,16,17}$, Between 0.2 and 2.2 percent of all newborns excrete CMV at birth ${ }^{18}$. In $10 \%$ of these children the infection is symptomatic: $20-30 \%$ will die and $90 \%$ of the survivors will have mental impairment and hearing loss. About $10 \%$ of the children infected during pregnancy, but asymptomatic at birth, will show hearing loss and mild cognitive impairment in young childhood ${ }^{14,19,20}$. After primary maternal infection the sequelae are more severe than after recurrent infection ${ }^{21}$.

A literature survey revealed 8 case-reports of histologically examined abortions with gestational age less than 17 weeks and being associated with CMV infection ${ }^{22,23,24,25,26,27,28,29}$.

This number is small despite the high prevalence of lethal CMV disease. In contrast, about 100 second and third trimester histologically examined $\mathrm{CMV}$ cases have been described in the literature $^{30}$. The scarceness of spontaneous abortions associated with CMV from the literature might indicate that the infeotion is rarely lethal in early pregnancy. However, it might also indicate that sequelae of CMV infection are hard to detect in early abortion specimens. Generally, in second and third trimester pregnancy failures with proven $\mathrm{CMV}$ infection, inclusion bodies are only found in the placenta after meticulous searching. A second feature easily recognized and frequently reported in 'late' CMV infection, namely extensive infiltration of the chorionic villi with foetal plasma cells, may not occur in early pregnancy due to the inability of the embryonic immune system to produce plasma cells ${ }^{25,29}$.
The opportunity to identify CMV antigens by immunohistochemical means enabled the present systematic study of a series of spontaneous and induced early abortions with known karyotype. A monoclonal antibody was used directed against a phosphoprotein, which appears within 24 hours after CMV infection and persists during the complete infection cycle ${ }^{10,31}$.

The aims of this investigation were to document the distribution of the early CMV antigen in the mother, the embryo and the pregnancy secundinae, and to study the possible deleterious role of CMV-infection in early pregnancy.

\section{Material and methods}

A consecutive hospital series of 108 spontaneous and induced abortions was used for this study. In all cases, placental and, if available, embryonic tissues were cultured for cytogenetic studies. If karyotyping was successful and at least 50 chorionic villi were present in the histological slides the abortion was included in the study. These criteria were met in 93 cases $(86 \%)$. In three cases chromosome analysis failed and twelve cases were excluded because of an insufficient number of villi.

Of the 93 cases, 83 were spontaneous and 10 induced abortions. The spontaneous abortions had normal $(n=31)$, trisomic $(\mathbf{n}=24)$, unbalanced translocation $(n=8)$, triploid $(n=13)$, monosomy $X$ $(n=5)$ and tetraploid $(n=2)$ karyotype. Induced abortions, which all had developed conform gestational age; were karyotyped as follows: normal $(n=1)$, trisomy $(\mathrm{n}=6)$, unbalanced translocations $(\mathrm{n}=2)$ and triploidy $(\mathrm{n}=1)$.

Three couples had two spontaneous abortions. In one couple, triploidy was found twice, the second abortion lacking decidua. In the second couple, a first 
abortion had normal karyotype and this was followed by a triploid abortion. In the third couple, the first abortion was due to an unbalanced translocation, the second had a normal karyotype. One couple had two induced abortions for unbalanced translocation. The second abortion in the same patient was only used to examine whether the results are a constant finding in repetitive abortions. Therefore 3 spontaneous and 1 induced abortion were excluded from further analysis, leaving 80 spontaneous abortions $=$ spontaneous abortion group), 30 normal and 50 abnormal karyotype, and 9 induced abortions $(=$ induced abortion group). In all these abortions decidua and chorionic villi were present for examination.

In table 1 the mean durations of pregnancy as well as the ranges are given for the different groups. In the same table the mean maternal ages at the day of abortion as well as the ranges are shown.

Tissues were analyzed without knowledge of the karyotype, the nature of the abortion and the name of the patient.

Embryonic tissues were available in all cases of induced $(n=10)$ and in 7 cases of spontaneous abortion. If present, kidney, liver and pancreas were selected, as these organs are supposed to be the most frequently affected by CMV. In 7 , only other organs (skin and intes- tine) were present. The gestational age ranged from 71 to 126 days with a median of 84 . The embryos were analyzed without knowledge of the results of the chorionic villi and decidua. Endometrial biopsies were obtained from a group of 55 non-pregnant women ( $=$ endometrial biopsy group). From 49 patients one biopsy was obtained, from 5 patients two and from one patient four biopsies were obtained during different menstrual cycles. For analysis only the first biopsy from an individual patient was used: The second, third and fourth biopsy were only used to examine whether the findings in one patient remain constant.

In the biopsy cycle, 18 patients had serum human chorionic gonadotrophin ( $\mathrm{hCG}$ ) sampling as well, which was negative in all cases. The other patients did not have hCG sampling but neither of them did develop clinical pregnancy in the cycle during which the biopsy had been taken. Six other biopsies were from patients who later proved to have conceived in the biopsy cycle. HCG had risen in these patients; 5 were clinically pregnant after biopsy and 1 menstruated 3 days later than expected on the basis of monitored ovulation. Another very early pregnancy specimen was obtained of a patient, who had had hCG rise and menstruated three days after the expected day but had not had an endometrial biopsy. These 7 specimens together

Table 1. Group characteristics, age of the women and if appropriate gestational age

\begin{tabular}{lcccccc}
\hline & & \multicolumn{2}{c}{ maternal age } & & \multicolumn{2}{c}{ gestational age } \\
Group & number & mean & range & & mean & range \\
\hline Spontaneous abortion & 80 & 30.5 & $19.1-43.9$ & & \\
$\quad$ normal karyotype & 30 & 30.2 & $19.2-37.4$ & 85.0 & $51-126$ \\
$\quad$ abnormal karyotype & 50 & 30.7 & $19.1-4.9$ & 82.2 & $45-119$ \\
Induced abortion & 9 & 36.0 & $28.0-40.9$ & 81.7 & $72-93$ \\
Endometrial biopsy & 55 & 31.3 & $21.8-39.4$ & & \\
Very early pregnancy & 7 & 29.9 & $23.0-37.6$ & & \\
Menstrual group & 10 & 32.0 & $27.6-36.0$ & & \\
\hline
\end{tabular}


form the very early pregnancy group (table 1). Menstrual discharge samples containing glandular tissue, were obtained in 10 non-pregnant patients $(=$ menstrual group (see table 1)). HCG had been sampled in the same cycle in 8 patients and no hCG rise had been found. Two patients delivered specimens in three menstrual cycles. These were scored independently.

Deeply frozen serum samples from 20 out of 62 patients of the endometrial biopsy group and the very early pregnancy group, were available for the latex agglutination test for CMV antibody testing ${ }^{32,33}$. The serum samples were taken within 3 days of the biopsy in 18 patients, 5 days before the endometrial biopsy in one patient and 2 months after endometrial biopsy in another patient. The results of the latex agglutination test were compared with the endometrial findings. Due to the retrospective nature of this part of the study, no further serum samples were available.

There was no overlap of patients between groups. All patients with abortions and biopsies gave informed consent for additional karyotyping and morphologic study of their tissues.

\section{Immunohistochemistry}

Tissue sections $(3 \mu \mathrm{m})$ were mounted on gelatin-chrome alum-coated glass slides. After storage overnight at $37^{\circ} \mathrm{C}$, the slides were deparaffinized and blocked for endogenous peroxidase activity by incubation (15 min) in 100\% methanol, containing $0.6 \% \mathrm{H}_{2} \mathrm{O}_{2}$.

The sections were preincubated for 30 $\min$ at room temperature with $0.1 \%$ pepsin in $0.1 \mathrm{~N} \mathrm{HCl}$, washed with phosphate buffered saline (PBS), incubated (10 min) in $2 \%$ bovine serum albumin (BSA) in PBS and washed $(2 \mathrm{~min})$ with PBS containing $0.1 \%$ Tween 20 , to free the antigens which were masked by formaldehyde. Then the slides were incubated $(45 \mathrm{~min})$ with a mouse monoclonal antibody (Mc222, see below), directed against the phosphoprotein pp65 of CMV (ppUL83(PK)), diluted in PBS containing $0.1 \%$ bovine serum albumin (BSA) and $0.1 \%$ Tween 20. Again, sections were washed with $0.1 \%$ Tween 20 in PBS, three times 5 min each. For the next $30 \mathrm{~min}$ the slides were incubated with biotinylated affinity -purified sheep anti-mouse Ig antibody (Amersham Nederland BV, Houten, The Netherlands). This biotinylated antibody was diluted 1:200 in PBS. This procedure was followed by three washes with $0.1 \%$ Tween 20 in PBS $(5 \mathrm{~min})$. Next the slides were incubated with a conjugate of streptavidin-horse-radish-peroxidase complex (Amersham Nederland BV,'s Hertogenbosch, the Netherlands) at $37^{\circ} \mathrm{C}$. This complex had been diluted $1: 400$ in PBS containing $0.1 \%$ BSA and $0.1 \%$ Tween. This step was again followed by three washes with $0.1 \%$ Tween 20 in PBS. The slides were stained by incubation in $3,3^{\prime}$. diaminobenzidin-tetrachloride in Tris$\mathrm{HCl}$ buffer $(\mathrm{pH} 7.6)$. After a brief rinse in tap water the slides were counterstained with hematoxylin. Finally they were washed in tap water $(10 \mathrm{~min})$, dehydrated and embedded in Entellan (Merck; Darmstadt, Germany). In all runs a positive control, derived from a congenitally CMV infected and succumbed neonate, was included and in $2 / 3$ of instances a control slide, which had had the same procedure except addition of $\mathrm{Mc222}$. Instead of the monoclonal addition, the slides were incubated with PBS containing $0.1 \%$ bovine serum albumin (BSA) and $0.1 \%$ Tween 20 only.

Mc222 is directed against the $65 \mathrm{kDa}$ tegument protein of the virus particle pp65 $(=$ ppUL $83(\mathrm{PK}))$. This antigen 
appears in the CMV infected cells within the first 24 hours after infection ${ }^{10,31}$. The specificity of the monoclonal for the phosphoprotein pp65 of the CMV was confirmed in the laboratory of Dr.S. Michelson, Institut Pasteur, Paris, by using an astrocytoma cell line which produces ppUL83 (personal communication, publication in preparation).

In figure 1 , an example is given of the specific positive staining of the cells with small brown cytoplasmic granules. The slides were examined by light microscopy with a magnification of $200 \mathrm{x}$.

\section{Results}

The results are summarized in table 2 .

\section{Decidua}

In the spontaneous abortion group 27 out of $80(34 \%)$ decidual specimens showed staining of the glandular epithelium. In the induced abortion group 4 out of 9 cases showed staining of the cytoplasm of decidual glands in a granu-

Figure 1. The antigen pp65 staining in kidney tubules (arrows)

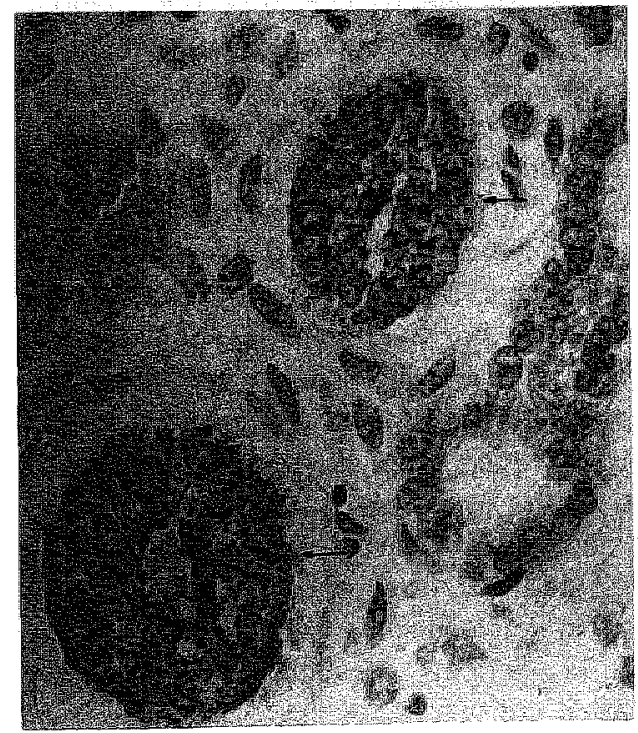

lar pattern (figure 1). Individual epithelial cells were positive, but rows of positive cells in the midst of negative epithelium predominated. Positive glands were found in between negative ones. CMV inclusion bodies were not observed. The 53 other decidua specimens were negative for $\mathrm{pp} 65$. Some of the pp65 expressing epithelial cells showed moderate cytoplasmic enlargement or had lost their contact with the stroma. Histologically, the positive decidual specimens could not be discerned from the negative specimens other than by the specific staining. The prevalence of positive decidual specimens in the chromosomally normal and abnormal groups was almost identical: $11 / 30(37 \%)$ and $16 / 50(32 \%)$. The karyotypes of the latter were trisomy $(n=9)$, unbalanced translocation $(n=1)$, triploidy $(n=4)$ and monosomy $X(n=2)$.

The decidual fibroblastic stromal cells surrounding the glands stained positive in 8 cases, all of which also had positive glandular epithelium.

\section{Chorionic villi}

Trophoblastic cells were positive in 5 cases of spontaneous abortion $(6 \%)$ (normal karyotype $\mathrm{n}=2$, abnormal karyotype $n=3$ ) and in 1 induced abortion (trisomic karyotype). All these cases also had positive decidual glands.

Some of the cells staining for pp65 showed enlargement of their cytoplasm. The positive trophoblastic cells were located at the decidual site of the placenta in 4 of 6 cases. In the other cases it was not possible to localize the infected trophoblast. Specific staining of chorionic stromal cells and Hofbauer cells could not be identified.

\section{Embryos}

Embryos were positive in 7 out of 17 cases $(41 \%)$ and negative in the remaining 10 . One of the positive staining em- 
Table 2. Presence of pp65 in the different tissues examined

\begin{tabular}{|c|c|c|c|c|c|c|c|}
\hline \multirow{2}{*}{ Group } & \multirow[b]{2}{*}{ number } & \multicolumn{2}{|c|}{$\begin{array}{l}\text { decidual/enifometrial } \\
\text { glands }\end{array}$} & \multicolumn{2}{|c|}{ decidual stromal cells } & \multicolumn{2}{|c|}{ trophoblastic cells } \\
\hline & & positive & regative & positive & negatiwe & positive & negative \\
\hline Spontaneous abortion & 80 & $27(34 \%)$ & $53(66 \%)$ & 7 & 73 & 5 & 75 \\
\hline nomal karyotype & 30 & $11(37 \%)$ & $19(63 \%)$ & 3 & 27 & 2 & 28 \\
\hline abnormal karyotype & 50 & $16(32 \%)$ & $34(68 \%)$ & 4 & 46 & 3 & 47 \\
\hline Induced abortion & 9 & $4(44 \%)$ & $5(56 \%)$ & 1 & 8 & 1 & 7 \\
\hline Endometrial biopsy & 55 & $19(35 \%)$ & $36(65 \%)$ & & & & \\
\hline Verry early pregnancy. & 7 & $1(14 \%)$ & $6(86 \%)$ & & & & \\
\hline Menistrual group & 10 & $2(20 \%)$ & $8(80 \%)$ & & & & \\
\hline
\end{tabular}

bryos lacked a decidual sample: of the remaining 16 decidual specimens, 14 cases $(88 \%)$ had concordant results with the decidua: 5 cases had positive staining for pp65 in the embryo and decidua and 9 did not have staining for pp65 in the embryo nor in the decidua. From the remaining two abortions at least one showed a discrepancy: the decidua being negative and the embryo positive. The remaining case had positive decidua but a negative embryo. The results in the examined embryonal organs are summarized in table 3 . Especially the epithelial cells were infected, i.e. tubuli of the kidney, pancreatic islands, epithelial layer of tongue, intestine and skin and ductules of the testis.

Table 3. The results of screening the embryos for MC222

\begin{tabular}{lcc}
\hline Organ & Positive & Negative \\
\hline Kidney & 5 & 2 \\
Intestine & 4 & 4 \\
Liver & 1 & 5 \\
Skin/muscle & 4 & 8 \\
Tongue & 1 & \\
Pancreas & 1 & 1 \\
Testis & 1 & \\
Eye & & 4 \\
\hline
\end{tabular}

\section{Endometrium}

Endometrial biopsies were positive in $19 / 55$ cases $(35 \%)$ and negative in the remaining. The positive cells were locat- ed in the glandular epithelium. The same pattern of staining was present as seen in the decidua of the abortions: cytoplasmic granules of contingent epithelial cells stained positive. Again, histologically positive and negative specimens could not be differentiated from each other by features other than $\mathrm{Mc} 222$ staining. The very early pregnancy group showed 1 out of 7 specimens to be positive, the others were negative. The menstruum specimens were positive in 2 out of 10 patients.

\section{Repeated sampling}

The three couples with two abortions with presence of decidua had consistent results for all tissues, i.e. one couple with induced abortions had positive glands, the other two couples with decidua present, had negative glands.

Repeated endometrial biopsies, obtained during different cycles from the same patient revealed that all biopsies were concordant, i.e. of one patient both biopsies were positive, whereas of the other 5 patients all biopsies were negative. One patient delivered 3 menstrual specimens, which were all negative. Howev$\mathrm{er}$, in the second patient of whom three menstrual samples were available, the first and last one were positive and the one in between negative. Thus, in 10 out of 11 patients repeated sampling revealed consistent results, 2 being repeat- 
edly positive and 8 being repeatedly negative for $\mathrm{CMV}$.

The latex agglutination test revealed 11 positive, 7 negative and 2 ambiguous sera. The 11 positive sera corresponded with 4 positive and 7 negative endometrial biopsies. The 7 negative sera corresponded with 4 positive and 3 negative biopsies. The 2 ambiguous serum samples corresponded with two negative biopsies.

\section{Discussion}

The most important result of this study is the demonstration of CMV antigen in 7 out of 17 embryos studied. This figure is about ten times higher than expected on the basis of published epidemiological findings. The localization of the virus, i.e. in kidney tubuli, pancreas and sometimes liver, is comparable to perinatal findings of cytomegalovirus infection. Skin has not been reported in the literature but was positive in 4 cases. Inclusion bodies were not seen.

A literature search revealed a total of 8 case reports of spontaneous abortion in which the presence of CMV was mentioned (see table 4). Other causes of abortion were not excluded (such as karyotypic abnormalities). From table 4 it can be seen that in 2 out of 8 cases decidual glands were reported to be CMV positive. The antigen was present in the decidua as well as embryos and trophoblast but could not be found in the stromal cells of the chorionic villi. This finding is not unexpected, since even after clinically manifest infection frequently only after meticulous screening a few inclusion bodies can be found. That the trophoblastic cells are permissive of CMV infection has been demonstrated in in vitro experiments by Amirhessami-Aghili et al. ${ }^{34}$. Also, endothelial cells are permissive for CMV.
This could not be demonstrated in the present study due to lack of intact endothelial cells in the chorionic villi of early abortions.

Our study did not show the whole range of expected cytopathological effects of active infection i.e. cellular enlargement and nuclear enlargement with inclusion bodies in any of the tissues. Cellular decay being the end stage of the cell infected by cytomegalovirus was seen, but this decay was also present in abortions not positive for pp65 and might also be due to degeneration of abortive tissues.

Plasma cellular infiltrates in the placenta were not seen either. It is not sure at which time the embryo is first able to produce plasma cells ${ }^{25,29}$. The presence of plasma cells is twice reported in the literature, both gestational ages being 14 weeks ${ }^{25,26}$. It has been suggested that the cellular immune system of the fetus is able to produce plasma cells at that particular gestational age ${ }^{29}$. The 3 youngest cases in the table match best with our study group. These cases did not show any sign of inflammation. The finding of a high number of specimens containing $\mathrm{CMV}$-antigens without signs of inflammation might be expalined by either immunological tolerance or by the latent state in which the virus is present. First, the idea of immunological tolerance of the embryo in early pregnancy has been stressed before: Silverstein hypothesized that it is the immuno-incompetence of the embryo to react to syphilis infection which protects the embryo for deleterious sequelae ${ }^{35}$. One embryo was negative while the maternal decidua was positive. This embryo might be at risk of clinically manifest CMV infection later in pregnancy. The case with a positive embryo but negative decidua might be explained by the fact that not all glands were pp65 positive in any positive specimen and therefore it is 


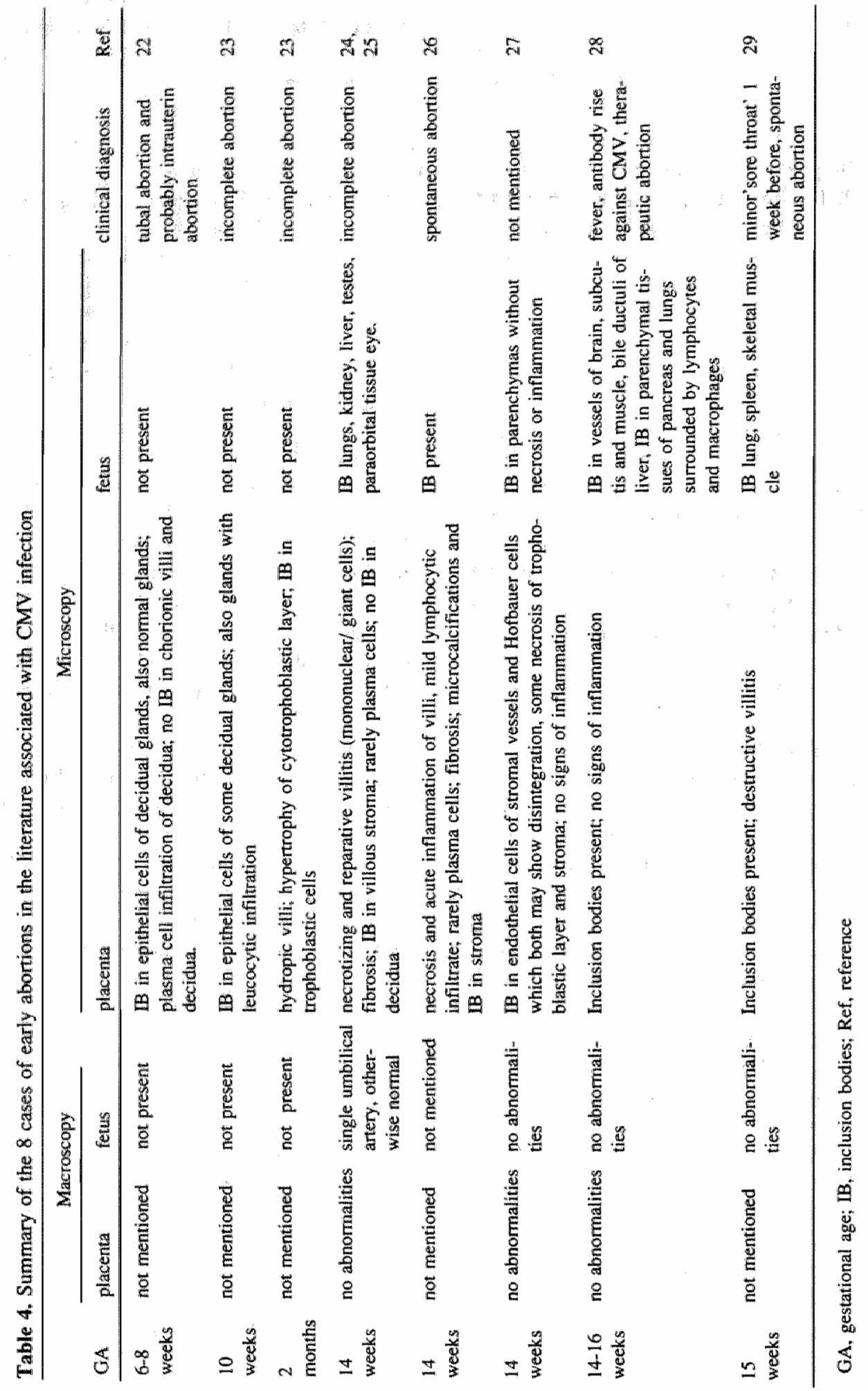


likely that no positive decidua was in cluded in that case. The leucocyte infiltration which was seen both in positive and negative decidua, is considered to be physiological in pregnancy ${ }^{36}$. Secondly, latency of CMV might explain that Boué et al. were not able to demonstrate virus in any of the 76 abortions examined by using of classic cell culture techniques $^{37}$. However, by using polymerase chain reaction and Southern blotting analysis of 35 pooled samples of 10 karyotyped spontaneous abortions each, no CMV DNA could be detected in the series of Putland and coworkers ${ }^{38}$. This might be due to the use of chorionic villi and membranes only, as decidual tissue had been carefully removed before the processing. As indicated in our study the amount of CMV in chorionic villi will be very small if present at all.

For the discrepant results between the latex agglutination tests and the endometrial findings we do not have an explanation.

Our findings support the already reported hypothesis on the mechanism of CMV transmission to the foetus ${ }^{39}$. During implantation and trophoblastic invasion, trophoblastic cells come into direct contact with maternal surface epithelium and glands (which form a continuum). Cytomegalovirus is transmitted by cellcell contact. This explains the localization of the trophoblast staining for the antigen. The transmission route from the placenta to the embryo is not known but presumably the virus is transported via the chorionic blood vessels to the foetus. However, it is not completely excluded that the initial transmission is via the gametes although the affinity of CMV for cells of epithelial origin would suggest otherwise.

From a comparison of the presence of the virus in both chromosomal groups it is clear that early infection with $\mathrm{CMV}$ is not a significant cause of abortion. In that case, the percentage in the chromosomally normal abortions would have been expected to be higher than in the abnormal group. Furthermore, the prevalence of CMV would be expected to be higher in the spontaneous abortion than in the induced abortion group, but this study demonstrated the prevalence to be equal in both groups. However, from this result it may not be concluded that CMV infection in pregnancy is harmless.

In conclusion, the sequence of events leading to the findings observed may be summarized as follows: the uninfected preimplantation embryo reaches the infected decidua and the virus is transmitted via the trophoblast at a very early stage of pregnancy. This explains the high concordance between mother and embryo (14/16) and the high prevalence of CMV in endometrial biopsies. The only case of real discrepancy between embryo (positive) and mother (negative) could be due to a sampling error of the decidua. Also the patient with two positive and one negative endometrial biopsies could be explained by a sampling error. The consequences of these findings for pregnancy and prenatall diagnosis might be that CMV infection is not as dangerous as described, provided the infection takes place before the foetal immune system is able to respond to the infection. The detection of CMV antigens seems to be not sufficient to judge the foetus' fate $e^{40,41,42}$.

\section{Acknowledgements}

Paola Dalmonte, Susan Michelson, Unite d'Immunologie Virale, L'institut Pasteur. 


\section{References:}

1. Warburton $D_{\text {i }}$ Fraser FC. Spontaneous abortion risks in man: data from reprodiuctive histories collected in a medical genetics unit. Hum Genet 1964;16:1-25.

2. Harlap S, Shionio $\mathrm{PH}_{s}$ Ramcharan S. A life table of spontaneous abortions and the effects of age,

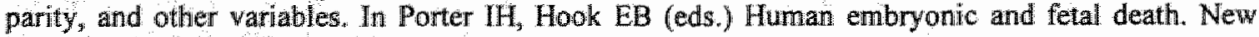
York: Academic Press 1980;145-159.

3. Miller JF, Williamson $E_{q}$ Glue J, Gordon $Y B$, Grudzinkas JG, Sykes A. Fetal loss after implantation: A prospective study. Lancet $1980 ; \mathrm{i} i: 554-556$.

4. Boué J, Boue A Lazar P. Retrospective and prospective epidemiological studies of 1500 karyotyped spontaneous human abortions. Teratology 1975:12:11-26.

5. Lauritsen JG. Aetiology of spontaneous abortion. A cytogenetic study of 288 abortuses and their parents. Acta Obstet Gynecol Scand 1976; [suppl.] 52: 1-29.

6. Hassold T, Chen $\mathbb{N}$, Funkhouser $J$, et al. A cytogenetic study of 1000 spontaneous abortions. Ann Hum Genet 19:80;44:151 178.

7. Warburton $D$, Stein $Z$, Kline I, Susser M. Chromosome abnormalities in spontaneous abortion: Data from the New York city study. In Porter $\mathrm{NH}$, Hook EB (eds.) Embryonic and fetal death. New York: Academic Press 1980;261-287.

8. Eiben $\mathbb{B}$, Bartels 1, Bähr-Porsch S et al. Cytogenetic analysis of 750 spontaneous abortions with thedirect-preparation method of chorionic villi and its implications for studying genetic causes of pregnancy wastage. Am J Hum Genet 1990;47:656-663.

9. Hardwick DF, Dimmick JE, Kalousek DK, Baldwin VJ, Lockitch G. Concepts of intrauterine development and embryo and fetal pathology. In Dirmmick JE, Kalousek DK (eds.) Developmental pathology of the embryo \& fetus. Philadelphia: JB Lippincot Company 1992;41-55.

10. Griffiths PD, Grundy JE. Molecular biology and immunology of cytomegalovirus. Biochem J $1987 ; 241: 313-324$.

11. Gaudy $V_{\text {, Lamy }} \mathrm{ME}$, Van Lierde $M$. Cytomégalovinus et grossesse. J Gynecol Obstet Biol Reprod 1992;21:779-790.

12. Ho M. (ed.) Cytomegalovirus: biology and infection. (second edition) New York: Plenum Medical Book Company. 1991;157-158.

13. Stagno $S$, Whitley RJ. Herpes infections of pregnancy. Part I: Cytomegalovirus and Epstein-Barn virus infections. N Engl J Med 1985;313:1270-1274.

14. Griffiths PD, Baboonian C. A prospective study of primary cytomegalovirus infection during pregnancy: final report. Br J Obstet Gynaecol 1984;91:307-315.

15. Griffiths BP, Lavallee JT, Jennings TA, Hsiung GD. Transmission of maternal cytomegalovirusspecific immunity in the guinea pig. Clin Immunol Immunopathol $1985 ; 35: 169-181$.

16. Nankervis GA, Kumar ML; Cox FE, Gold E. A prospective study of maternal cytomegalovirus infection and its effects on the fetus. Am J Obstet Gynecol 1984;149:435-440.

17. Doerr HW. Cytomegalovirus infection in pregnancy. J Virol Meth 1987;17:127-132.

18. Stagno S, Pass RF, Dworsky ME, Alford CA. Congenital and perinatal cytomegalovirus infections. Sem Perinatol $1983,7: 31-42$.

19. Preece PM, Pearl KN, Peckham CS Congenital cytomegalovirus infection. Arch Dis Child 1984; $59: 1120-1126$.

20. Yow MD, Williamson DW, Leeds $\mathrm{LJ}$ et al. Epidemiologic characteristics of cytomegalovirus Infection in mothers and their infants. Am J Obstet Gynecol 1988;158:1189-1195.

21. Fowler KB, Stagno PH, Pass RF, Britt WJ, Boll TJ, Alford CA. The outcome of congenital cytomegalovirus infection in relation to maternal antibody status. N Engl J Med 1992;326:663-667.

22. Dehner LP, Askin FB. Cytomegalowirus endometritis. Report of a case associated with spontaneous abortion. Obstet Gynecol 1975;45:211:214.

23. Goranov 1, Gancev S. Fehlgeburt bei Zytomegalie. Zentralb Gynaek 1963;85:1037-1040.

24. Altshuler O. Implications of two cases of human placental plasma cells. Am I Pathol 1973;70:18a.

25. Altshuler $G$. Immunologic competence of the immature human fetus. Mor-phologic evidence from intrauterine cytomegalovirus infection. Obstet Gynaecol 1974;43:811-816.

26. Schwartz DA, Khan $R$, Stoll B. Characterization of the fetal inflammatory response to cytomegalovirus placentitis. Arch Pathol Lab Med 1992;1 16:21-27. 
27. Blanc WA. Pathology of the placenta and cord in some viral infections. In Hanshaw IB, Dudgeon IA (eds.) Viral diseases of the fetus and newborn. Philadelphia: $\mathbb{N}$. B. Saunders Company 1978 ; 237-258.

28. Benirschke K, Mendoza GR, Bazeley PL. (1974) Placental and fetal manifestations of cytomegalovirus infection. Virchows Arch B Cell Pathol 1974;16:121-139.

29. Benirschke $K$, Kaufmann $P$. (eds.) Virus infections and villitides: cytomegalowirus infection. In Pathology of the human placenta. 2ed. Heidelberg: Springer-Verlag 1990;585-590,613-635.

30. Garcia AGP, Ferreira F, Souza Marques R, Lobato YY. Placental morphology in cytomegalovirus infection. Placenta 1989;10:1-18.

31. Rüger B, Klager S, Walla B et al. Primary stricture and transcription of the genes coding for the two virion phosphoproteins pp65 and pp7l of human cytomegalovirus. I Virol 1987;61:446-453.

32. Adler SP, McVoy M, Biro VG, Britt WJ, Hider P, Marshall D. Detection of cytomegalovirus antibody with the latex agglutination. J Clin Microbiol 1985;22:68-70.

33. Gray JJ, Alvey B, Smith DJ, Wreghitt TG. Evaluation of a commerciall latex agglutination test for detecting antibodies to CMV in organ donors and transplant recipients. J Virol Methods 1987:16: $13-19$.

34. Amirhessami-Aghili $N$, Manalo P, Hall MR, Tibbitts FD, Ort CA, Afsari A. Human cytomegalovirus infection of human placental explants in culture: histologic and immunohistochemical studies. Am J Obstet Gynecol 1987;156:1365-1374.

35. Silverstein AM. Congenital syphilis and the timing of immunogenesis in the human fetus. Nature 1962;194:196-197.

36. Schneider L. Über Vorkommen und Bedeutung leucocytärer Infiltrate im Ablösungsbereich der spontan geborenen Placenta. Arch Gynäk 1970;208:247-254.

37. Boué $A$, Hannoun $C_{x}$ Boué JG, Plotkin SA. Cytological virological and chronosomal studies of cell strains from aborted human fetuses. Proc Soc Exp Biol Med 1966;122:11-16.

38. Putland RA, Ford J, Korban $\mathrm{G}_{3}$ Evdokiou $A$, Tremaine $M$. Investigation of spontaneously aborted concepti for microbial DNA: Investigation for Cytomegalovirus DNA using polymerase chain reaction. Ausi NZ J Obstet Gynaecol 1990;30:248-250.

39. Blanc WA. Pathology of the placenta, membranes, and umbilical cord in bacterial, fungal and viral infections in man. In Naeye RL, Kissane JM, Kaufman $\mathrm{N}$ (eds.) Perinatal diseases. Baltimore/London: Williams \& Wilkins, $1981 ; 67-132$.

40. Grose $C$, Weiner CP. Prenatal diagnosis of congenital cytomegalowirus infection: two decades later. Am J Obstet Gynecol 1990;163:447-450.

41. Demmler GJ. Summary of a workshop on surveillance for congenital cytomegalovirus disease. Rev Inf Dis 1991;13:315-329.

42. Hogge WA, Buffone GJ, Hogge JS. Prenatal diagnosis of cytomegalovirus (CMV) infection: a preliminary report. Prenatal Diagnosis 1993;13:131-136. 


\section{Fluorescence in situ hybridization on paraffin-embedded abortion material as a means for retrospective chromosome analysis}

G van Lijnschoten, J Albrechts, M Vallinga, AHN Hopman, JW Arends, JPM Geraedts. Submitted for publication.

A fluorescence in situ hybridization (FISH) procedure was used to detect chromosome abnormalities in archival abortion material. Nuclei were isolated from $50 \mu \mathrm{m}$ thick tissue blocks from 18 selected and karyotyped abortions. Five probes for repetitive centromeric sequences of chromosomes $1,16,18, X$ and $Y$ were used. For each chromosome, at least 200 nuclei were scored blindly, i.e. without knowledge of the karyotype. The FISH results obtained were compatible with the cytogenetic data in 14 cases. There were four discre pancies. Two of these were observed for cases karyotyped as trisomy 16. Furthermore, FISH results showed trisomy 18 in two cases in which traditional karyotyping had demonstrated normal chromosomes and $46, \mathrm{XX}, 18 q+$, respectively. The latter case was not discrepant if the structural rearrangement involved chromosome 18 material. The remaining discrepancies could be explained by chromosomal mosaicism. Admixture of normal maternal cells was also noted. It is concluded that FISH can be used to study retrospectively the presence of chromosome abnormalities in abortion material. However, the quality obtained after the use of fresh material is superior.

\section{Introduction}

Early spontaneous abortion probably occurs in more than one in six clinically recognized pregnancies (Kline and Stein, 1985). In the majority of cases a chromosome abnormality is present (Edwards, 1986). However, for financial and logistic reasons, routine cytogenetic analysis is not indicated. It involves a long term culture of the fresh material combined with a time consuming analysis by a well trained technician. In selected cases one would like to be informed about the presence of karyotypic abnormalities, and sometimes even a considerable period of time after the occurrence of the aborti- on. This information might be needed for genetic counselling purposes but also for the management of the problem of recurrent abortion, which by definition can only be diagnosed in retrospect.

Since in most cases paraffin-embedded material from hospital abortions is stored it was decided to apply fluorescent in situ hybridization (FISH) technology to this material. This so called interphase cytogenetics has now been applied to a number of tissues, mostly from malignancies (Hopman et al., 1991). Also a series of hydatidiform moles and hydropic abortions was studied this way using sex chromosome specific probes, in or-der to discrimina- 
te between maternal and trophoblast cells (Van de Kaa et al., 1991). The purpose of this study was to test the validity of FISH for the detection of numerical chromosome abnormalities, which represent more than 95 percent of all aberrations in abortions. To this end FISH was done using alphoid probes for chromosomes 1,16 and 18 and both sex chromosomes. These probes were selected for the following reasons. Trisomy 1 has never been observed in spontaneous abortions. This means that the presence of three interphase copies of this chromosome indicates tri-ploidy. Trisomy 16 is the most frequently occurring chromosome abnormality in spontaneous abortions. Trisomy 18 is less frequent but from the clinical point of view more relevant. Sex chromosome analysis was used in order to identify eventual admixtures of maternal cells. Only after the results of the interphase cytogenetic study were obtained the code was broken and the data were compared with the results of the conventional karyotypic analysis.

\section{Material and methods}

The 18 cases of spontaneous abortion studied were selected from a larger series studied cytogenetically, histologically and morphometrically (Van Lijnschoten et al., 1993 a,b).

\section{Cytogenetic studies}

Embryonic tissue and umbilical cord were selected for culture if available. Furthermore, amnion, chorion and villi were used. Cultures from 98 spontaneous abortions were started. Usually after four to six weeks the dividing cells were spread. In three cases the culture was unsuccessful. All specimens were routinely G-banded. For karyotyping at least ten cells were scored, if available. Only if one cell showed an exira chromosome among a normall cell line, or a normal cell was observed in a trisomic cell line, additional cells were karyotyped.

\section{Selection of karyotypes}

The cases selected had the following karyotypes: $46, \mathrm{XX}(\mathrm{n}=3) ; 46, \mathrm{XY}$ $(\mathrm{n}=2) ; 45, \mathrm{XO}(\mathrm{n}=2) ; 47, \mathrm{XXY}^{\prime}(\mathrm{n}=1)$; $69, \mathrm{XXY}, 7 \mathrm{q}-(\mathrm{n}=1) ; 69, \mathrm{XXY}(\mathrm{n}=1)$; $84, X X X,-1,-4,-5,-6,-13,-15,-16,-X$ $(n=1) ; 47, X X,+16(n=2) ; 47, X Y,+16$ $(n=2) ; 47, X Y,+18 \quad(n=1) ; 46, X X, 18 q+$ $(n=1) ; 46, X Y, 18 q+(n=1)$. Of these cases $50 \mu \mathrm{m}$ thick sections were made and coded in random order from 1 to 18.

\section{Preparation of interphase nuclei}

Paraffin-embedded tissue blocks containing chorionic villi were deparaffinized in two successive changes of xylene (20 minutes each) and then hydrated through a decreasing alcohol series. The suspension obtained was boiled for 5 minutes in milli-Q water and proteinase $K(500 \mu \mathrm{g}$ proteinase in $10 \mathrm{mM}$ Tris with $2 \mathrm{mM} \mathrm{CaCl}$ ) treated for 30 minutes. Cytospin preps were made using poly-L-lysin coated slides. Thereafter the slides were fixed using an increasing alcohol series.

\section{DNA probes}

The chromosome specific probes used are listed in table 1. The probes were labeled by nick translation, either with biotin-11-dUTP or digoxygenin-11dUTP and purified on a Sephadex G 50 column.

\section{ISH procedure}

Hybridization with chromosome specific probes was achieved in a mix containing $60 \%$ formamide, $2 \times \mathrm{SSC}(0.3$ $\mathrm{M} \mathrm{NaCL}, 30 \mathrm{mM}$ Na-citrate $\mathrm{pH} 7.0$ ), $10 \%$ dextran sulphate (Pharmacia), 50 
Table 1. Chromosome specific probes

\begin{tabular}{|c|c|c|c|c|}
\hline Chromosome & $\begin{array}{c}\text { Name of } \\
\text { probe }\end{array}$ & $\begin{array}{l}\text { Insert } \\
(\mathrm{kB})\end{array}$ & Type & Reference \\
\hline $\mathbb{1}$ & pUC 1.77 & 1.77 & satellite III & Cooke et al. 1979 \\
\hline 16 & PSE 16 & 0.68 & alphoid & Greig et al 1989 \\
\hline 18 & L1.84 & 0.68 & alphoid & Devilee et al. 1986 \\
\hline $\mathrm{X}$ & pBamXs & 2.00 & allphoid & Willard et al, 1983 \\
\hline$Y$ & $\mathrm{DYZ3}$ & 2.1 & satellite III & Cooke et al. 1982 \\
\hline
\end{tabular}

ng/ $\mu$ l yeast RNA (Sigma), $50 \mathrm{ng} / \mu \mathrm{l}$ herring sperm DNA (Sigma) and 1 $\mathrm{ng} / \mu \mathrm{l}$ of the labelled probe. $10 \mu \mathrm{l}$ of this mix was applied to the slide and sealed under a coverslip.Probe and target were simultaneously denatured for 5 minutes at $80^{\circ} \mathrm{C}$. Overnight hybridization at $37^{\circ} \mathrm{C}$ was followed by two washing steps of 5 minutes in $60 \%$ formamide $/ 2 \times$ SSC with $0.05 \%$ Tween $20(\mathrm{pH} 7.0)$ at $42^{\circ} \mathrm{C}$ and two rinses of 5 minutes in $2 \times \mathrm{SSC}$ at $42^{\circ} \mathrm{C}$. The biotinylated DNA was immunocytochemically detected using fluorescein isothiocyanate (FITC)-conjugated avidin. All incubation steps were followed by washing steps in $4 \times$ SSC $/ 0.05 \%$ Tween 20. Finally the slides were dehydrated in an alcohol series and $\mathrm{m}$ ounted in propidium-iodide and covered with a slide.

Evaluation of ISH signals
Slides were examined using a fluorescence microscope equipped with filter sets for the green FITC signal. For each of the probes 200 nuclei were scored. Overlapping interphase nucle were not used for evaluation. Multiple signals within the same nucleus needed to be separated and were only scored if showing more or less the same size and intensity. Paired ISH spots (split spots) were counted as one signal. Smaller signals with less intensity were ignored (minor binding sites).

The whole ISH procedure, including the analysis, was done unaware of the outcome of the cytogenetic analysis.

\section{Results}

In 16 out of 18 cases interpretable results were obtained with all probes at the first instance. From the missing

Table 2. All cases in which the modal number of ISH spots is in agreement with the karyotype

\begin{tabular}{lcccccc}
\hline & \multicolumn{5}{c}{ Modal number of ISH spots for chromosome: } \\
\cline { 2 - 7 } Karyotype & No of cases & $X$ & $\mathrm{X}$ & 1 & 16 & 18 \\
\hline $46, \mathrm{XX}$ & 2 & 2 & 0 & 2 & 2 & 2 \\
$46, \mathrm{XY}$ & 2 & 1 & 1 & 2 & 2 & 2 \\
$45, \mathrm{XO}$ & 2 & 1 & 0 & 2 & 2 & 2 \\
$47, \mathrm{XXY}$ & 1 & 2 & 1 & 2 & 2 & 2 \\
$69, \mathrm{XXX}, 7 \mathrm{q}-$ & 1 & 3 & 0 & 3 & 3 & 3 \\
$69, \mathrm{XYY}$ & 1 & 1 & 2 & 3 & 3 & 3 \\
$84, \mathrm{XXX},-1,-4,-5,-6,-13,-15,-16,-\mathrm{X}$ & 1 & $2 / 4$ & 0 & $2 / 4$ & $2 / 4$ & $2 / 4$ \\
$47, \mathrm{XX},+16$ & 2 & 2 & 0 & 2 & 3 & 2 \\
$47, \mathrm{XY},+18$ & 1 & 1 & 1 & 2 & 2 & 3 \\
$46, \mathrm{XY}, 18 \mathrm{q}^{+}$ & 1 & 1 & 1 & 2 & 2 & 2 \\
\hline
\end{tabular}


Table 3. All cases in which the ISH results are not in agreement with the karyotype

\begin{tabular}{cllcccc}
\hline & & \multicolumn{5}{c}{ Modal number of ISH spots for chromosome } \\
\cline { 3 - 6 } case no & Karyotype & $\mathrm{X}$ & $\mathrm{Y}$ & 1 & 16 & 18 \\
\hline 1 & $46, \mathrm{XX}$ & 2 & 0 & 2 & 2 & $2 / 3$ \\
9 & $46, \mathrm{XX}, 18 \mathrm{q}^{+}$ & 2 & 0 & 2 & 2 & $2 / 3$ \\
14 & $47, \mathrm{XY},+16$ & 1 & 1 & 2 & $?^{*}$ & 2 \\
18 & $47, \mathrm{XY},+16$ & 1 & 1 & 2 & 2 & 2 \\
\hline
\end{tabular}

* sce text

case, with all probes having falled, another tissue block was processed successfully during a second attempt. From case 14 the results for chromosome 16 were too poor to interpret (see below). The FISH results obtained were compatible with cytogenetic data in 14 out of 18 cases (table 2). The four discrepant cases are given in table 3.

Case 1: This sample had a normal karyotype after conventional chromosome analysis whereas the FISH result was compatible with trisomy 18 mosaicism. The interphase staining for chromosome 18 clearly showed a modal number of two. However, $10.5 \%$ of the cells showed three spots, which was concluded to be very indicative for mosaicism.

Case 9: Cytogenetic analysis revealed a $46, X_{n}, 18 q+$ karyotype, which was present in mosaic. The origin of the extra material could not be traced. Both parents showed normal karyotypes: To our surprise not less than $27 \%$ of the cells showed three chromosome 18 interphase spots, indicating a chromosome 18 origin of the extra material.

Case 14: A straightforward trisomy 16 was discovered after karyotyping: $47, X Y,+16$. As mentioned above the results at first attempt were not interpretable due to weak intensity of the hybridization signals. Some extra tissue samples of this case were processed during a second experiment together with a number of other cases. As in the original study all scores were done blindly. The second experiment revealed a tissue clearly showing trisomy as the modal number (see table 4). However, also a sample in which disomy dominated was found. In this material a side line showing trisomy was discovered. Besides this apparently mosaicism, the interpretation of the sex chromosome data revealed that this sample most

Table 4. Trisomy 16 cases with discrepancies between karyotype and FISH

\begin{tabular}{|c|c|c|c|c|c|c|c|c|}
\hline \multirow[b]{2}{*}{$\begin{array}{l}\text { case } \\
\text { no }\end{array}$} & \multirow[b]{2}{*}{ Material } & \multicolumn{5}{|c|}{ number of chromosome 16 spots } & \multicolumn{2}{|c|}{$\begin{array}{l}\text { Modal number(s) of } \\
\text { spots for chromosone }\end{array}$} \\
\hline & & 0 & 1 & 2 & 3 & 4 & $\mathrm{x}$ & $\mathrm{Y}$ \\
\hline \multirow[t]{3}{*}{14} & chorion/ amnion, villi & $?$ & $?$ & $?$ & $?$ & $?^{* *}$ & 1 & 1 \\
\hline & chorion/ amnion, villi & 8 & 14 & 44 & 134 & 0 & 1 & 1 \\
\hline & villi, decidua & 0 & 23 & 151 & 23 & 3 & $1 / 2^{*}$ & $1 / 0$ \\
\hline \multirow[t]{2}{*}{18} & chorion/amnion, villi & 26 & 46 & 128 & 0 & 0 & 1 & 1 \\
\hline & villi & 2 & 1 & 15 & 177 & 5 & 1 & 1 \\
\hline
\end{tabular}

* female karyotype dominates

**? see text 
probably also contained admixture of maternal cells, which was compatible with the histological analysis showing decidua.

Case 18: Also this case had shown trisomy 16 on chromosome analysis: $47, \mathrm{XY},+16$. FISH indicated an $\mathrm{XY}$ karyotype without autosomal abnormalities. A repeat sample, again scored blindly, revealed almost exclusively trisomic cells (table 4). Also in this case the tissue types of both samples were different.

\section{Discussion}

This study was initiated in order to compare the results of conventional karyotyping after cell culture with the data obtained by FISH technology using archival material from the same abortion products. The exploration of the new approach seems worthwhile since cytogenetic analysis is not only very time consuming and therefore expensive but also biased by the clonal selection operating during cell culture and the limited numbers of cells analyzed. However, it should be kept in mind that in this study not only two different methods were compared, but also that for this comparison two types of material were used (fresh $v$. fixed). The application of FISH technology on fresh material will be quicker and cheaper and give better results.

FISH is only less time consuming if standard techniques can be applied to the different sources of material. In this respect the efficiency of the methodology was satisfying: only one out of 18 samples had to be repeated.

The application of specific repetitive probes from five different chromosomes on 18 samples gave 90 results for comparison. Only four of these comparisons showed a more or less clear difference: Since chromosomes 1, X and $Y$ gave excellent results and showed no discrepancies it might be that some probes hybridized more optimally than others. However, it is more likely that the involvement of chromosomes 16 and 18 has a biological significance, since some discrepancies were based on the presence of an extra hybridization signal in stead of a missing one.

With regard to the structural chromosome abnormality $(18 \mathrm{q}+)$ giving rise to a numerical abnormality (mosaic trisomy 18), this discrepancy could probably be explained on the basis of the chromosome 18 origin of the extra material on the structural rearranged chromosome.

All other findings might be explained on the basis of confined placental mosaicism (Kalousek et al., 1989a). This term has been adopted for a type of mosaicism confined to specific placental or embryonic cell lineages. Kalousek et al. (1992) studied 54 spontaneous abortions and found 11 of them to be mosaic. Previously it was reported that $10 \%$ of autosomal trisomies are trisomy/normal mosaics (Warburton et al., 1978).

Most probably confined placental mosaicism results from a postzygotic nondisjunction event. Other mechanisns are multiple pregnancy and contamination with normal cells (Pindar et al., 1992). If non-disjunction occurs relatively late during the development of the placenta, only a part of it shows the chromosome abnormality. As long as standard cytogenetic techniques are employed, many mosaics will be missed due to the number of cells analyzed and the clonal selection during cell culture. Furthermore, it is difficult to establish the proportions of the different cell lines contributing to the mosaicism. Cell selection during culture may result in an over- or underestimate 
of the trisomic cell line. Cytogenetic analysis of placentas from live newborn infants or from terminated pregnancies with trisomies 13 and 18 revealed that all were mosaic (Kalousek et al., 1989b).The mosaicism was confined to the cytotrophoblast and not detected in villus stroma, chorionic plate or amnion. The percentage of cells with a normal karyotype varied from 12 to $100 \%$. Also cases of trisomy 16 confined to placental tissue have been reported (Simoni et al.; 1992). However, in almost all of these cases there was a complete dichotomy between the karyotypes of the fetal and placental cells. Only one example of placental mosaicism was observed. This may be related to the selection of discrepant cases after CVS. It therefore needs to be confirmed that confined placental mosaicism can be present in about half (i.e. two out of four) cases of trisomy 16 :

This study was based on nuclei isolated from paraffin-embedded tissue blocks. This material is less favorable with regard to morphology. The nuclei of the interphase cells are frequently damaged as a result of their isolation and centrifugation on the glass slide. The way in which the slides are made has also disadvantages with respect to the topological information which is lost during slide preparation. For the future it is therefore important to repeat the study on sections of paraffin-embedded tissues, without isolation of nucleil and fit for hist analysis, or on frozen sections. This way the localization of the placental mosaicism can also be studied. Topological and morphological information can also help to solve the problem of admixture of maternal cells.

After these improvements retrospective cytogenetics can be regarded as a real option for the study of abortions in archival material. Not only the retrospective diagnosis of numerical abnormalities is possible but also structural rearrangements can now be studied as long as is known which abnormalities are to be expected. This information might be available from parental karyotyping. A further prerequisite is the availability of probes. This problem will become less serious in the future.

It is therefore allowed to conclude that retrospective karyotyping will be applied on indication, will give a direct insight in the presence of chromosome abnormalities at the time of abortion, is very suitable for the study of mosaicism, in combination with topological and morphological information.

\section{References}

Cooke HJ \&indley J. (1979) Cloning of human satellite III DNA: different components are on different chromosomes. Nucleic Acid Res 6:3177-3197.

Cooke HJ. Schmitke J \& Gosden JR. (1982) Characterization of a human Y-chromosome repeated sequence and related sequences in higher primates. Chromosoma 87:491-502.

Devilee P, Cremer T, Slagboom P, Bakker E, Schol HP, Hager HD, Stevenson AFG, Cornelisse CJ \& pearson PL. (1986) Two subsets of human alphoid repetitive DNA show distinct preferential localization in the pericentric regions of chromosomes 13,18 and 21. Cytogen Cell Genet 41:193202.

Edwards RG. (1986) Causes of early embryonic loss in human pregnancy. Hum Reprod 1:185-198

Greig GM, England SB, Bedford M, Willard HF (1989) Chromosome-specific alpha satellite DNA from the centromere of human chromosme 16. Am J Hum Genet 45:862-872.

Hopman AHN, Van Hooren E, Van de Kaa CA, Vooijs PG \& Ramaekers FCS. (1991) Detection of numerical chromosome aberrations using in situ hybridization in paraffin sections of routinely 
processed bladder cancer. Modem Pathology 4:503-513

Kalousek DK. (1989a) Tissue specific trisomy-The significance of confined placental mosaicism. Molecular and Cytogenetic Studies of Non-Disjunction. Prog Clin Biol Res 311:153-163

Kallousek DK, Barrett If \& MoGillivray BC. (1989b) Placental mosaicism and intrauterine survival of trisomies: 13 and 18. Am J Hum Genet 44:338-343.

Kalousek DK, Barrett IJ \& Gärtner AB. (1992) Spontaneous abortion and confined chromosomal mosaicism. Hum Genet 8:8:642-646.

Kline I \& Stein Z. (1985) Very early pregnancy. In: Dixon RL (ed.) Reproductive Toxicology. New York: Raven Press, 251-265.

Pindar L, Whittehouse M \& Ocraft K. (1992) A rare case of a fallse-negatiwe finding in both direct and culture of a chorionic villus sample. Pren Diagn 12:525-527.

Simoni $G$, Brambati $B$, Maggi $F$ \& Jackson $L$ (1992) Trisomy 16 confined to chorionic villi and unfavourable outcome of pregnancy. Ann Génét 35:110-112.

Van de Kaa CA, Nelson KAM, Ramaekers FCS, Vooijs GP \& Hopman AHN. (199l) Interphase cytogenetics in paraffin sections of routinely processed hydatidiform moles and hydropic abortions. I Pathol 165:281-287.

Van Lijnschoten G, Arends JW, Leffers P, de la Fuente AA, van der Looij HJAM \& Geraedts JPM. (1993a) The value of histomorphological features of chorionic villi in early spontaneous abortion for the prediction of karyotype. Histopathology 22:557-563.

Van Lijnschoten G, Arends JW, Thunnissen FBJM \& Geraedts JPM. (1993b) A morphometric approach to the relation of karyotype, gestational age and histological features in early spontaneous abortions. Placenta, in press.

Warburton D, Yu CY, Kline Z \& Stein Z. (1978) Mosaic autosomal trisomy in culltures from spontaneous abortions. Am J Hum Genet 30:609-617.

Willard HF, Smith KD \& Sutherland J. (1983) Isolation and characterization of a major tandem repeat family from the human X chromosome. Nucleic Acid Res 11:2017-2023. 


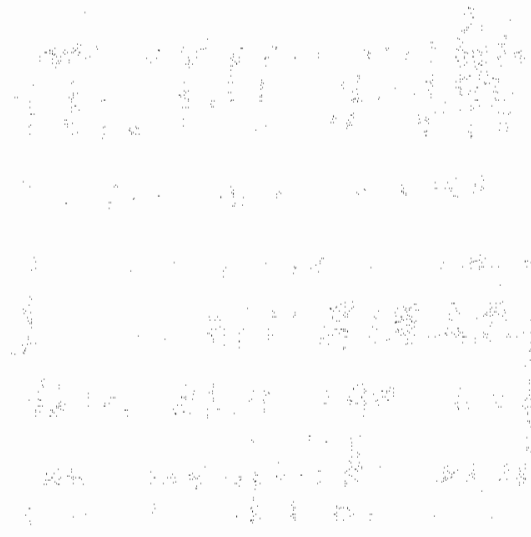




\section{Epilogue}

Karyotypic abnormalities are frequently detected in spontaneous abortions. With respect to the relationship between chromosome abnormalities and cause of abortion a few observations seem to be relevant. In man the trisomies form a heterogeneous group with respect to survival (Martin et al., 1990). Some trisomies are lethal at a specific point in time (Boué et al., 1976; Kleinebrecht et al., 1984; Byrne et al., 1985; Canki et al., 1988). Trisomy 1 has only been observed after fertilization in vitro but is lethal at the time of implantation (Watt et al., 1987). The development of trisomy 16 is relatively normal at the start but is completely blocked at the end of the first trimester. On the other hand some trisomies abort throughout the whole prenatal period. An example of this kind of trisomy is Down syndrome. It is assumed that only $20 \%$ of cases survive to term. However, there is no specific stage at which lethality is concentrated. With respect to the development of specific trisomies more is known from the work of Gropp in mice (Gropp et al., 1975). There it seems that each abnormality has its phenotypic characteristics reflected by a specific stage at which no further development is possible.

Some karyotypic aberrations are likely to recur in subsequent pregnancies and may result in another abortion or birth of a severely handicapped child. These abnormalities are of prognostic value and, their detection is of value for genetic counselling. Traditional karyotyping, however, is very demanding in terms of skills, manpower and money, and therefore can not be performed on a routine basis in all spontaneous abortion cases. Hence, some form of pre-screening procedures in order to select cases for more detailed cytogenetic analysis would be worthwhile to explore. Histological examination of abortion products would be a candidate for such a prescreening procedure, since in the literature several histological features have been claimed to be associated with special karyotypes. The majority of studies reporting on the relation between histology and karyotype of early placentae, however, started from a well defined, given karyotype and subsequently described the associated histological features. Such studies provide information about the sensitivity of histological features in this context.

However, if histological examination is to be used as a pre-screening method for detection of karyotypic abnormalities, information on its specificity should be obtained as well.

The goal of our first study was to assess intra- and inter-observer variation for histological features in a consecutive series of spontaneous abortions. Subsequently, the relationship of these features with karyotype was studied. In addition, the histological features of potential interest regarding sensitivity and specificity with acceptable intra- and interobserver variation, were analyzed as valuable screening tools for specific chromosome abnormalities. The results of these analyses were disappointing in that the histological parameters which had an acceptable degree of intra- and interobserver variation and at the same 
time were of value in the prediction of karyotype, turned out to be indicative of triploidy only. This karyotype, however, is not of paramount interest for genetic counselling. Furthermore, for the past decades, it was already known to be relatively easily recognizable by experienced pathologists (Szulman et al., 1981). Moreover, objective assessment of some of the examined features by morphometries did not change the pictu$\mathrm{re}$, since this analysis also highlighted triploid placentae only.

It is concluded that histological assessment of abortions is not helpful in the detection or the prediction of karyotypes of interest for genetic counselling.

Although somewhat neglected in pathological practice macroscopic examination might reveal clues to the prediction of abnormal karyotype. In the present thesis, the preliminary study of the predictive value of macroscopic features for abnormal karyotype revealed some characteristics which seem to be promising with respect to specificity, even if dilatation and curettage have been performed. The results of this study are only suggestive and need confirmation by prospective studies. However, pathological examination should not be restricted to histological analysis. Macroscopic scrutiny of the abortion specimen might be the most rewarding part of the examination process in a Department of Pathology.

It should be realized that the meaning of the findings is twofold. Presently, it is not only impossible to select cases with an abnormal chromosome pattern other than triploidy by histological investigation. The chromosomally normal cases can also not be discriminated from the abnormals. From the point of view of treatment and preventive measures this means that it is hardly possible to select cases which are amenable for interventi- on. Alternative methods, therefore, should be explored.

\section{In situ hybridization}

It might be that fluorescence in situ hybridization (FISH) will fulfill this function in the future. A prerequisite for this is the availability of valid probes for all relevant chromosomes which can be applied simultaneously. In this respect a set is needed consisting of probes for chromosomes 1, 13, 18 and 21. As is shown in chapter 9 , valid probes for chromosomes 1 and 18 are available. However, separate probes for chromosome 13 and 21 are lacking at present:

It should be realized that FISH is not yet a simple procedure which can be used routinely. It might be expected that industrial developments will result in kits which will make this technique more applicable but at the same time more expensive in terms of material costs. At this point in time FISH already has advantages over traditional karyotyping in a number of situations. First of all, as shown in chapter 9, retrospective karyotyping is possible this way. This means that in recurrent abortion, provided that each sample has been stored in fixative or frozen, an attempt can be made to establish if and which chromosome abnormalities are present. If no abnormalities are detected the presence of structural abnormalities is not excluded since it is impossible at the present time to cover the whole genome. However, all cases without abnormalities might be used for detailed studies for the presence of aberrations in the newly discovered developmental genes. This is a rapidly developing field and it might be expected that in the near future more and more molecular techniques will become available and will be are applicable for the detection of these genes.

FISH can also be applied if there is severe lysis of an embryo/fetus hampe- 
ring traditional karyotyping while a diagnosis based on macroscopical findings needs laboratory confirmation. For example when trisomy 18 is suspected, it is easy to confirm the diagnosis after hybridization with two probes: one for chromosome 18 and one for a control chromosome to exclude triploidy (chromosome 1). Finally, it might be expected that in future more fundamental and experimental studies will be conducted making use of FISH technology. In this respect one can think of a detailed analysis of the incidence of confined placental mosaicism.

Commenting on our results of the variability study and the study on the predictability of chromosome abnormality, Fox concluded that histological screening for other reasons than confirmation of pregnancy and exclusion of trophoblastic disease is valueless (Fox, 1993). To our opinion this point of view may be too radical. Histological examination may reveal the presence of infectious agents.
Some of these, such as Toxoplasma gondii, Human Parvovinus B19 and Cytomegalovirus (CMV), might cause abortion in case of an active infection. This infection may reveal itself by the presence of bradyzoiets (Toxoplasma gondii) or inclusion bodies (Human Parvovirus B19, CMV). Although it is obvious, that, compared with chromosomal abnormalities, infections play a much less prominent role as cause of spontaneous abortion, their detection in abortions still remains important in view of individual patient care. In the study on CMV, the presence of CMV-antigens without any histological reaction was demonstrated in about one third of the abortion specimens, irrespective of chromosomal constitution. From such notions, it is apparent that more research is necessary to unravel the significance of the presence of CMV-antigens and the embryonic/fetal immunologic response to these antigens in early spontaneous abortion.

\section{References}

Boué J, Philippe E \& Boué A. (1976) Phenotypic expression of lethal chromosomall anomalies in human abortuses. Teratology, 14: 3-20.

Byme J, Warburton D, Kline $\mathfrak{J}$, Blanc W \& Stein Z. (1985) Morphology of early fetal deathis and their chromosomal characteristics. Teratology, 32: 297-315.

Canki N, Warburton D \& Byme J. (1988) Morphological characteristics of monosomy X in spontaneous abortions. Annals de Gênétic, 31: 4-13.

Fox H. (1993) Histological classification of tissue from spontaneous abortions: a valueless exercise? Histopathology" 22: 599-600.

Gropp A, Kolbus U Giers D. (1975) Systematic approach to the study of trisomy in the mouse. II Cytogenetics and Cell Genetics, 14: 42-62.

Kleinebrecht $\mathrm{J} \&$ Geisler M. (1984) Embryonen mit Chromosomenaberrationen beim Spontanaborten. Anat. Anz., Jena, 157: 3-33.

Martin RH, Rademaker A. (1990) The frequency of aneuploidy among individual chromosomes in 6,821 human sperm chromosome complements. Cytogenetics Cell Genetics, 53: 103-107.

Szulman AE, Philippe E, Boué JG \& Boué A. (1981) Human triploildy: association with partial hydatidiform moles and nonmolar conceptuses. Human Pathology, 12: 1016-1021.

Watt JL, Templeton AA, Messinis I, Bell L, Cunningham P \& Duncan RO. (1987) Trisomy 1 in an eight cell human pre-embryo. Journal of Medical Genetics, 24: 60-64. 



\section{Summary}

Early spontaneous abortion is a common phenomenon, with more than $50 \%$ of early cases showing chromosomal abnormalities. There are several reasons why it is interesting to know the karyotype of an abortion. Firstly, couples who have had an abortion with an extra chromosome 13,18 and 21 , which make up $10 \%$ of all abortions, are said to have an increased risk of a chromosomally abnormal child in future pregnancy. Secondly, few abortions have an unbalanced structural abnormality, which is the result of a balanced abnormality in one of the parents in many cases. These parents have a high recurrence risk of an unbal-anced chromosomal constitution in a future pregnancy.

It is practically impossible to karyotype all spontaneous abortions. The value of microand macroscopical examination of abortions is described in chapters 3 to 7 . In chapter 8 the role of cytomegalovirus infection as a cause of abortion is described. Finally, the merit of fluorescence in situ hybrization on formalin-fixed paraffin-embedded abortions is reported.

\section{Microscopy}

The first aim of the study was to evaluate the reproducibility of histological diagnosis of features associated with chromosomal abnormality. An intra- and inter-observer variation study was conducted (chapter 3). Slides of early placentae of 95 abortions were screened for several histological features by three independent observers. The agreement beyond chance was expressed by Cohen kappas.

Good intra-observer kappa coefficients were found for size, shape, number of blood vessels, basophilic staining under the basement membrane and the number of trophoblastic pseudo-inclusions. For hydrops, trophoblastic hyperplasia, the number of syncytial knots and trophoblastic buds in the intervillous space, kappa values were acceptable for at least two observers.

Considerably lower agreement beyond chance was found in the inter-observer variation study. The best results for all three observers together were obtained for size and shape of the chorionic villi and for the number of pseudo-inclusions.

Thus, the intra-individual variation for most histological features, claimed to be associated with karyotypically abnormal abortions, was smail. However, the agreement beyond chance between two or more observers in judging histological features of early abortion placentae only reached clinically relevant values for size and shape of the chorionic villi and for the number of trophoblastic pseudo-inclusions.

The second aim of the study was to evaluate the value of the histological features studied in chapter 4 for prediction of chromosomal abnormality. To this end, slides of 83 early spontaneous abortions were used. The a priori chance of chromosomal abnormality was $60 \%$.

Assessments and karyotype were compared and likelihood ratios computed.

For none of the features all three observers did reach likelihood ratios of $\leq 0.40$ or $\geq 2.50$, corresponding with a chance of chromosomal abnormality of $\leq 40 \%$ and $\geq 80 \%$, respectively. Likelihood ratios of $\geq 2.50$ were obtained for lacunar stromal hydrops, presence of 
trophoblastic hyperplasia, moderate to abundant trophoblastic hyperplasia, presence of trophoblastic lacunae, few intervillous fibrin deposits and few intervillous trophoblastic buds. Likelihood ratios of $\leq 0.40$ were found for small chorionic villi and presence of basophilic staining. Lacunar stromal hydrops and trophoblastic lacunae were predictive of triploid karyotype, but not specific for any other type of chromosomal abnormality.

After application of data previously obtained on Cohen kappas, lacunar stromal hydrops, moderate to abundant trophoblast-ic hyperplasia and presence of trophoblastic lacunae remained as possibly useful features, again mainly pointing to triploidy.

Most of the items claimed to be related to abnormal karyotype, however, were not predictive at all.

In chapter 5 chorionic villus size and proliferation of trophoblast of 82 placentae were quantified by use of a point counting method. The results were related to karyotype and gestational age.

At the group level there appeared to be no difference in the median mean crosssectional villus-, stromal and trophoblastic area, trophoblast/stroma ratio and trophoblastic thickness between chromosomally normal and abnormal placentae. of the abnormal placentae only triploid placentae showed areas larger than normal and other abnormal placentae. Villous profile area increased with gestational age in triploid placentae, but decreased in trisomic abortions.

At the individual case level parameter values outside the 'normal' range appeared to be rather insensitive, but highly specific for the prediction of karyotypic aberrations, again mainly triploidy.

This finding confirms the conclusion of the study described in chapter 4 that morphology of the chorionic villi is not of any help in the detection of abnormal karyotypes other than triploidy.

In chapter 6 it was determined whether features said to be related to karyotype were in fact related to degeneration. To this end, morphology of a series of induced $(n=6)$ and of spontaneous $(n=24)$ trisomic abortions were compared.

The chorionic villi of induced abortions were large and of irregular contour. The stroma contained many blood vessels and did not show fibro-hyalinic change. The intact trophoblast demonstrated 'hyper-plasia'. Contrastingly, spontaneous abortions were composed of smaller villi with somewhat more fibrohyalinic stroma containing a few blood vessels. The trophoblast did not show 'hyperplasia'. However, many syncytial knots were present.

Although some histological features were shown to be related to gestational age, which could not be completely matched for, it was unlikely that duration of pregnancy could account for the observed differences. Analysis restricted to induced and spontaneous abortions of comparable gestational age demonstrated the same differences.

Longer time-lags between first blood loss and final gestational loss in spontaneous abortions appeared to be associated with less hydrops and more frequent loss of trophoblastic continuity.

The striking histological differences between induced and spontaneous abortions are mainly considered to be due to cessation of circulation at some time and to disintegration of trophoblast as a result of ischaemia in spontaneous abortions.

\section{Macroscopy}

Since it was concluded that microscopy was of little help for determining karyo- 
type, the value of macroscopical features was examined in a consecutive series of 98 early spontaneous abortions (chapter 7). Normal karyotype was found in 38 and abnormal karyotype in 57 abortions.

The macroscopical descriptions made at the time of initiation of the cell cultures for chromosome analysis were analyzed. The results indicated that the presence of an embryo as such is not predictive for karyotype. However, very early developmental arrest (the nodular/stunted or cylindrical embryo) is suspect for chromosomal abnormality. Also, the presence of an umbilical cord stump seems to be highly indicative for a chromosomal abnormality. Almost all specimens with large vesicles were triploid. Long, thin stem villi with branches at their terminal ends only, were present in the karyotypically abnormal group solely. On the other hand bichorial twinning seems to be strongly related to normal karyotype, whereas, all monochorial and biamniotic twins were chromosomally abnormal.

\section{Cytomegalovirus}

The role of cytomegalovirus (CMV) infections in early pregnancy failure is examined in chapter 8 . If there is a role for $\mathrm{CMV}$, a preponderance of infections would be expected in the chromosomally normal group. Furthermore, an increased prevalence of CMV was expected in women with spontaneous abortions compared to women with induced abortions or to nonpregnant women. Therefore, 80 spontaneous and 9 induced abortions with known karyotype, 55 endometrial biopsies and 10 menstruum were screened for the presence of phosphoprotein pp65, an early CMV antigen.

The protein was present in the glandu- lar epithelium of the decidua of spontaneous as well as induced abortions in 31 out of $89(35 \%)$ cases, irrespective of chromosomal constitution. Trophoblastic cells were positive in 6 cases. A total of 17 embryos could be studied, 7 of which were positive. Positive staining of embryonic organs correlated strongly with the presence of the antigen in the decidua. The endometrial biopsies and menstrual discharges from women of comparable ages showed the same percentages of positive tests for $\mathrm{pp} 65$.

These findings indicate that in early pregnancy cytomegalovirus is transmitted from the decidual glands to the foetus. However, the presence of cytomegalovirus infection as shown by the presence of antigen is most probably not pathogenic in early pregnancy.

\section{Fluorescence in situ hybridization}

A fluorescence in situ hybridization (FISH) procedure was used to detect chromosome abnormalities in 18 archival abortion specimens. Probes for repetitive centromeric sequences of chromosomes $1,16,18, \mathrm{X}$ and $\mathrm{Y}$ were used. For each chromosome, 200 nuclei were scored without knowledge of the karyotype.

The FISH results obtained were compatible with the cytogenetic data in 14 cases. However, three abortions proved to be mosaic trisomic for chromosome 16 or 18 , whereas this had not been found in traditional karyotyping. One case of mosaic $18 \mathrm{q}^{+}$unexpectedly proved to be mosaic trisomy 18 with the FISH-method.

In conclusion, FISH can be used to study the presence of chromosome abnormalities in abortion material, retrospectively. 



\section{Samenvatting}

Spontane abortus voor de $17^{\mathrm{e}}$ week van de zwangerschap komt veel voor. In meer dan de helft van de abortus is een chromosomale afwijking aanwezig. Paren die een abortus hebben gehad met een extra chromosoom 13, 18 of 21 lopen waarschijnlijk een verhoogd risico voor het krijgen van een kind met een extra chromosoom in de toekomst. Paren die een abortus hebben gehad met een structurele chromosoomafwijking zijn in veel gevallen zelf drager van een chromosomale afwijking en hebben een sterk verhoogd risico op een afwijkend kind in de toekomst.

Het is praktisch onmogelijk om chromo-soomonderzoek van alle abortus te verrichten. De waarde van micro- en macroscopisch onderzoek, de rol die cytomegalovirus heeft bij vroege abortus en de mogelijkheid fluorescentie in situ hybridisatie te gebruiken voor chromosoomonderzoek van opgeslagen abortusweefsel zijn onderzocht.

\section{Microscopie}

In hoofdstuk 3 wordt beschreven dat de intra-observer variatie bij de beoordeling van histologische kenmerken geassocieerd met chromosomale afwijkingen van abortusweefsel acceptabel is. Met andere woorden: een persoon beoordeelt eenzelfde preparaat consequent.

De variatie tussen personen bleek veel groter. De verschillende waarnemers beoordeelden alleen de grootte en vorm van de placentavlokken en het aantal pseudo-inclusies, 'insluitlichaampjes', op gelijke wijze.

Het tweede doel van de studie verticht voor dit proefschrift, was vast te stellen of een aantal histologische kenmerken bij sommige waarnemers een afwijkend chromosoompatroon van de abortus kon voorspellen met een hogere mate van zekerheid dan de, in de gebruikte populatie, à priori kans van $60 \%$ op aanwezigheid van een chromosomale afwijking (hoofdstuk 4). Tevens werd gebruik gemaakt van de in hoofdstuk 3 verkregen kennis over reproduceerbaarheid.

Lacunaire hydrops van het vlokstroma, uitgesproken trofoblast hyperplasie en de aanwezigheid van trofoblastaire lacunae bleken de enige bruikbare histologische parameters voor het herkennen van chromosomale afwijkingen. Hiermee werden echter voornamelijk triploïde abortus opgespoord. De voor de klinische praktijk meer relevante abortus met een extra chromosoom of een structurele afwijking waren niet van de chromosomaal normale abortus te onderscheiden. De meeste kenmerken bleken ongeschikt voor het opsporen van welke chromosomale afwijking dan ook.

In hoofdstuk 5 zijn grootte van de placentavlok en de mate van trofoblasthyperplasie gemeten met behulp van een punten tel-methode. Ook op deze manier onderscheidden de abortus met chromosomale afwijkingen, anders dan triploïdie, zich niet van de chromosomaal normale abortus.

In hoofstuk 6 is onderzocht of histologische kenmerken, waarvan gezegd wordt dat ze met het chromosoompatroon verband houden, in feite een gevolg zijn van degeneratie van het weefsel ten gevolge van sterven van het embryo.

Het bleek dat placenta"s van afbre- 
kingen verricht op sociale indicatie grotere en onregelmatiger placentavlokken, meer bloedvaten, minder vlokfibrose en een prominentere trofoblastlaag hadden dan placenta's wan spontane abortus. De lengte van het tijdsverschil tussen eerste bloedverlies van de vrouw en het uiteindelijk uitdrijven van de wrucht correleerde negatief met de mate van hydrops van het stroma en de integriteit van de trofoblastlaag.

\section{Macroscopie}

Tot nu is gebleken dat microscopisch onderzoek nauwelijks nut heeft voor het herkennen van chromosomale afwijkingen. In hoofdstuk 7 is de retrospectieve studie waarin de waarde van macroscopisch onderzoek van abortus voor het herkennen van chromosomale afwijkingen beschreven. Kenmerken als de aanwezigheid van een embryo met een heel vroeg in de zwangerschap gestopte ontwikkeling, een navelstrengstomp en placentavlokken met blaasvorming of een 'paraplu'-vormig vertakkingspatroon kwamen vaker of alleen bij chromosomaal afwijkende abortus voor. Daarentegen pasten bichoriale tweelingen vooral bij een normal chromosoompatroon. Deze bevindingen zullen in een prospectieve studie getoetst moeten worden.

\section{Cytomegalovirusinfectie}

In hoofdstuk 8 staat beschreven dat Cytomegalovirus (CMV) antigeen in ongeveer een derde van spontane en geînduceerde abortus gelijk verdeeld over de chrosomaal normale en abnormale abortus voorkomt. Ook buiten de zwangerschap wordt het antigeen in een derde van de baarmoederslijmvliesmonsters aangetroffen. Aanwezigheid van antigeen in decidua van de moeder bleek in hoge mate te correleren met aanwezigheid van antigeen bij het embryo. Histologisch was er geen verschil tussen monsters met en zonder CMV antigeen. De bevindingen passen bij de hypothese dat heel vroeg in de zwangerschap overdracht van het virus van moeder naar kind plaats vindt. Overdracht voordat het embryo het virus als lichaamsvreemd kan herkennen, waarschijnlijk voor de $14^{\text {e }}$ week van de zwangerschap, lijkt niet schadelijk voor de zwangerschap te zijn.

\section{Fluorescentie in situ hybridisatie}

In het laatste onderzoek is beschreven dat chromosomaal onderzoek van abortusweefsel opgeslagen in het archief ook na jaren nog mogelijk is. Fluorescentie in situ hybridisatie (FISH) levert in tegenstelling tot karyotypering beperkte informatie over het chromosoompatroon op, namelijk alleen over dat deel van het patroon waar de gebruikte probe voor kodeert. Verschillen tussen traditionele karyotypering, waarbij alleen het vlokstroma onderzocht wordt, en de in situ hybridisatie, waarbij ook de trofoblast cellen worden geanalyseerd, kunnen verklaard worden door placenta-mosaïcisme. 


\section{Dank U wel,}

'Experienced reseachers generally devote a considerable amount of time and energy to planning a study. A research question may be put forth first in a broad and ambitious fashion, unsuitable for a specific investigation. ...... The original statement is inevitably narrowed and made more precise as a study is designed to evaluate aspeets of one or more specific hypotheses. Issues such as the populations available for study, the possibilities of obtaining pertinent information on the exposures of interest, and other constraints such as time and cost, often lead to a modification of the original question, so that usually only a portion of the larger, more general question will be approached by any single investigation."

Citaat uit Schlesselman. JJ. Case-control studies: design. conduct and analysis. Oxford University Press, 1982, p69.

Dit proefschrift is een voorbeeld van de gang van zaken die in het bovenstaande citaat is weergegeven.

Vele mensen hebben meegedaan aan het 'abortus-projekt'. Dit projekt was breed opgezet: patienten van de polikliniek Infertiliteit werden enkele maanden vervolgd, waarbij bloedmonsters en menstruum verzameld werden, naast de vele echoscopische en semen-onderzoeken. Dit alles om te zien of heel vroege 'verborgen' miskramen, dit is voordat de menstruatie verwacht kon worden ( $=13^{\mathrm{e}}$ dag na de eisprong), bij deze mensen voorkwamen. Daarnaast werd gekeken of afwijkende uitslagen van het vruchtbaarheidsonderzoek met het krijgen van miskramen correleerden.

Het pathologisch onderzoek van de miskramen was slechts een onderdeel van het totale 'abortus-projekt'.

Het 'bleek dat 'verborgen' miskramen bij de 135 patiënten-paren met vruchtbaarheidsproblemen niet voorkwamen. Een belangrijke bevinding, doch voor de voortgang van het onderzoek niet zo gewenst.

Voor alle duidelijkheid, het PA-onderzoek betrof al gauw alle 'klinische' miskramen die zich in de kliniek voordeden en voor onderzoek aangeboden werden door assistenten en staf van de afdeling Obstetric \& Gynaecologie.

Het zal $U$ duidelijk zijn dat een zo omvangrijk project niet zonder hulp van anderen kon plaatsvinden:

De medewerkers van de polikliniek, de verloskamers, de operatie-kamers en de prikdienst waren onmisbaar om de patienten die aan het projekt deelnamen op te vangen, te voorzien van briefjes en potjes, bloed af te nemen en te zorgen dat opgevangen weefsel van menstruatie of miskraam bij mij terecht kwam.

De arts-assistenten en stafleden van Obstetrie \& Gynaecologie dank ik voor het insluizen van patiènten en aanbieden van de miskramen.

Alle medewetkers van de laboratoria vaor bloedtransfusie/immunologie en chemie 6 dank ik voor de enthousiaste en uitstekende zorg voor de vele bloedmonsters en uitslagen. 
Hetzelfde geldt voor de onderzoekers van het semen, in de oudbouw verricht door de analisten van het zaadlabje bij de afdeling Pathologie en in de nieuwbouw door de analisten van het IVF-laboratorium. Hiervan wil ik met name Angela Reynen-Beek noemen, die mij bovendien coupes leerde snijden.

De medewerkers wan Genetica, van wie ik leerde weefselkweken in te zetten en. chromosomen te knippen, hebben een essentieel steentje bijgedragen aan het onderzoek. Het verwersen, afwerken en analyseren van de kweken werd door hen verricht. Met name wil ik Ruud Aarts noemen, die speciaal voor het project werd aangesteld.

Van de medewerkers van de afdeling Pathologie leerde ik hoeveel er nodig is voordat weefsel zoals dat op PA-lab binnenkomt, tot enkele $\mu \mathrm{m}$ dunne gekleurde coupes voor histologische beoordeling geschikt is gemaakt. Ik wil jullie allemaal bedanken voor de ruimte en hulp die $\mathrm{ik}$, letterlijk en figuurlijk, kreeg om het onderzoek zoals beschreven in dit proefschrift uit te voeren.

Als je zolang ergens werkt kom je mensen tegen die er om wat voor een reden dan ook in positieve zin uitspringen en essentieel zijn voor het tot een goed einde brengen van het werk.

Leonie, je kwam op het goede moment, ik zag het niet meer zitten.

Prof.dr JW Arends raakte in een latere fase bij het onderzoek betrokken en zorgde dat het onderzoek 'vorm' kreeg.

Prof.dr JPM Geraedts, Joep, het is gelukt en ik ben er trots op dat je mijn promotor bent,

Ineke. 


\section{Curriculum vitae}

Gesina van Lijnschoten, roepnaam Ineke, is geboren op 4 augustus 1961 te Amsterdam als onverwachte tweede helft wan een tweeling. Volgens de overlevering is zij met de helm op geboren en zat zij aan een takje van de navelstreng van de eerstgeborene.

In 1979 behaalde zij het Atheneum-B diploma. Na eerst een jaar de opleiding tot operatie-assistente in het Onze Lieve Vrouwe Gasthuis te Amsterdam gevolgd te hebben werd zij geplaatst voor de studie Geneeskunde (Vrije Universiteit te Amsterdam). In 1987 studeerde zij af als arts. In 1988 werd zij aangesteld als assistent in opleiding tot onderzoeker bij de vakgroep Moleculaire Celbiologie \& Genetica (voorheen Genetica/Celbiologie) van de Rijksuniversiteit Limburg. Het in het voorliggende proefschrift beschreven onderzoek werd in nauw samenwerkingsverband met de vakgroepen Obstetrie \& Gynaecologie en Pathologie, binnen het programma 'Aanleg- en Ontwikkelingsstoornissen' van het thema 'Perinatalle Geneeskunde' verricht. 